MLM-3791

UC-700

\title{
Mound Facility \\ Physical Characterization
}

Prepared by William R. Tonne with contributors Barbara M. Alexander, Matthew R. Cage, Ernest H. Hase, Mark J. Schmidt, Jeanne E. Schneider, William Slusher, and James E. Todd

December 1, 1993

MOUND 


\section{TABLE OF CONTENTS}

GLOSSARY OF ACRONYMS AND ABBREVIATIONS $\ldots \ldots \ldots \ldots \ldots 2$

INTRODUCTION $\ldots \ldots \ldots \ldots \ldots \ldots \ldots \ldots \ldots \ldots \ldots \ldots \ldots \ldots$

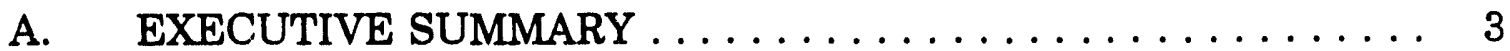

Functional Unit Material Condition .............. 4

Current Facility Status $\ldots \ldots \ldots \ldots \ldots \ldots \ldots \ldots \ldots \ldots \ldots \ldots \ldots \ldots$

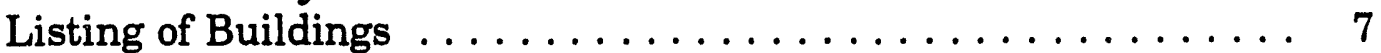

Space Plans ........................ 14

Summary of Maintenance Program and Repair Backlog . . . . . . 14

Environmental Restoration .................. 15

Decontamination and Decommissioning Programs ........ 17

B. $\quad$ SITE DESCRIPTION $\ldots \ldots \ldots \ldots \ldots \ldots \ldots \ldots \ldots \ldots \ldots$

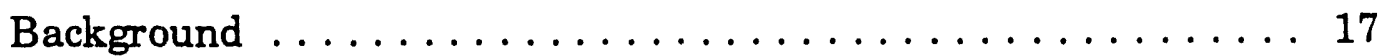

Utility Sources, Loads, and Distribution/Collection Systems . . . . 18

C. $\quad$ SITE ASSUMPTIONS $\ldots \ldots \ldots \ldots \ldots \ldots \ldots \ldots \ldots$

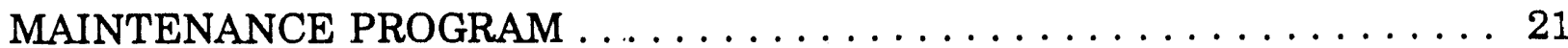

A. PROGRAM OVERVIEW $\ldots \ldots \ldots \ldots \ldots \ldots \ldots \ldots \ldots \ldots \ldots \ldots$

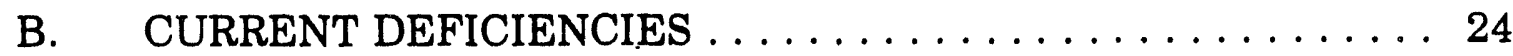

SECTION 1: ADMINISTRATIVE BUILDINGS $\ldots \ldots \ldots \ldots \ldots \ldots \ldots \ldots$

SECTION 2: STORAGE BUILDINGS $\ldots \ldots \ldots \ldots \ldots \ldots \ldots \ldots \ldots \ldots$

SECTION 3: PRODUCTION BUILDINGS $\ldots \ldots \ldots \ldots \ldots \ldots \ldots \ldots \ldots$

SECTION 4: SERVICE BUILDINGS $\ldots \ldots \ldots \ldots \ldots \ldots \ldots \ldots \ldots \ldots$ - 1

SECTION 5: LABORATORY BUILDINGS $\ldots \ldots \ldots \ldots \ldots \ldots \ldots \ldots$

SECTION 6: UTILITY PLANTS $\ldots \ldots \ldots \ldots \ldots \ldots \ldots \ldots \ldots \ldots \ldots$. 1

SECTION 7: SOUTH PROPERTY $\ldots \ldots \ldots \ldots \ldots \ldots \ldots \ldots \ldots \ldots$ 


\section{GLOSSARY OF ACRONYMS AND ABBREVIATIONS}

AES

APE

AWLPG

CAS

CAMP

$\mathrm{D} \& \mathrm{D}$

DFSC

ER

ES\&H

FCAP

FSAR

GPP

GPM

GSA

LSA

S\&S

SAR

TRU

WFO
Authorization of Engineering Services

Ammunition Peculiar Equipment

Albuquerque Workload Planning Guidance

Capital Assets Survey

Capital Assets Management Process

Decontamination and Decommissioning

Defense Fuel Supply Center

Environmental Restoration

Environment, Safety, and Health

Facilities Capability Assurance Program

Final Safety Analysis Report

General Plant Projects

General Plant Maintenance

General Services Administration

Low Specific Activity

Safeguards and Security

Safety Analysis Report

Transuranic

Work For Others 


\section{MOUND PLANT PHYSICAL CHARACTERIZATION}

\section{INTRODUCTION}

The purpose of this report is to provide a baseline physical characterization of Mound's facilities as of September 1993. The baseline characterizations are to be used in the development of long-term future use strategy development for the Mound site. This document describes the current missions and alternative future use scenarios for each building. Current mission descriptions cover facility capabilities, physical resources required to support operations, current safety enveiope and current status of facilities. Future use scenarios identify potential alternative future uses, facility modifications required for likely use, facility modifications of other uses, changes to safety envelope for the likely use, cleanup criteria for each future use scenario, and disposition of surplus equipment.

This Introductory Chapter includes an Executive Summary that contains narrative on the Functional Unit Material Condition, Current Facility Status, Listing of Buildings, Space Plans, Summary of Maintenance Program and Repair Backlog, Environmental Restoration, and Decontamination and Decommissioning Programs. Under Section B, Site Description, is a brief listing of the Site's Development, as well as Current Utility Sources. Section C contains Site Assumptions. A Maintenance Program Overview, as well as Current Deficiencies, is contained within the Maintenance Program Chapter.

\section{A. EXECUTIVE SUMMARY}

The physical characterization is the evaluation of Mound's capital assets as to their condition, present mission, and potential for future missions. While leaving the production era and entering into the era of reconfiguration, different operating philosophies with respect to building use must be addressed. This document is intended to be an assistance in making the transition.

Mound's planning for capital asset replacement, maintenance, upgrading, and modification has been significantly affected by the uncertainty surrounding future production, testing and component evaluation requirements, and the future configuration of the nuclear weapons complex.

Mound's employee headcount has focused on ES\&H driven needs, infrastructure maintenance, modernization, and consolidation projects. As a result, capital funding requests have been limited to the necessary monies to resolve facility and ES\&H deficiencies. No new capabilities are requested. 
As DOE's plans change, and as affected by reconfiguration, Mound's plans and requirements will change. Using the existing facilities, along with the following key projects, a fixed basis can be established for this changing operating philosophy. Thus, building utilization plans and budgetary plans can be developed from this basis.

The key projects that drive these funding requirements are:

1. Safety Driven Projects
a. T Building Life Safety Code Upgrades
b. Emergency Notification System
$\$ 2.9 \mathrm{M}$
c. Plant Life Safety Code Upgrades
$14.1 \mathrm{M}$
$2.3 \mathrm{M}$

2. Environmental Driven Projects
a. Hazardous Waste Storage Facility
$5.4 \mathrm{M}$
b. Site Drainage Control
$12.6 \mathrm{M}$
c. Off-Site Drainage
$5.0 \mathrm{M}$
d. Storm Water Treatment
$5.4 \mathrm{M}$

3. FCAP and Modernization Driven Projects
a. Roads and Parking Lot Replacements
$1.8 \mathrm{M}$
b. Effluent Recovery System
$6.5 \mathrm{M}$
c. SM/PP Roadway Replacement
$1.9 \mathrm{M}$
d. Mound Entry Control System
$4.0 \mathrm{M}$
e. Steam and Condensate System
$7.0 \mathrm{M}$
f. Cooling System Replacements
$13.6 \mathrm{M}$

Note: The above TECs do not include indirects that result from a late HQ-directed action. TECs will increase approximately $40 \%$ because of this new requirement.

\section{Functional Unit Material Condition}

The descriptive information for each functional unit having buildings contains a list of the included buildings and their associated square footage, condition, age, and remaining projected useful life.

The conditions being reported are determined by inspections, which have been performed on a three-year cycle. No inspections have been performed using the new CAS Inspection Deficiency Standards. These three-year inspections rate a building as to the condition of the physical building structure, the building systems, and the technological adequacy of the production equipment and production systems. The rating shown is a summation of the above elements. The remaining projected useful life is determined by considering the building age, 
condition, upgrades planned to be completed before FY 1995, and Mound's experience with similar buildings. For this report, the remaining projected useful life figures have been established by the inspectors using their professional judgement.

At this time, the only buildings that have received rigorous Natural Phenomenon Risk Assessment are those buildings, structures, and equipment involved with projects in Mound's Nuclear areas. These types of analyses will be used, on a graded basis, for Mound's more critical buildings and equipment in the second phase of the CAS inspections.

With the receipt of the FY 1993 funding earmarked for CAMP/CAS, EG\&G is staffing up to perform CAS inspections as required by DOE Order 4320.2. Preliminary inspections are slated to begin in April 1993.

In general, the condition of the Mound functional units is good with many of Mound's operations in modern, up-to-date facilities. The GSA Code Condition Rating for Mound averages to a moderate rating.

The modernization of Mound's facilities and operations has been a high priority effort since the late 1970's. From the late 1970's through today's currently funded projects, DOE will have invested over $\$ 400 \mathrm{M}$ in capital projects at Mound which has resulted in many modern facilities. These expenditures modernized Mound and used the latest technology. The plans were driven by aging equipment, by systems that were expensive to maintain and that lacked the capability to meet the product precision demanded by the design agencies, and by a commitment to reduce radioactive emissions.

\section{Current Facility Status}

The current status of modernization of Mound's primary operations is as follows:

- Nuclear Operations:

Production

Modernization complete.

Process Development

Modernization would have been accomplished by the now cancelled FY 1989 FCAP Project, Nuclear Facilities Modernization. 
- $\quad$ Stockpile Evaluation

Stockpile evaluation operations have been modernized in recent years by funding from weapons line items. All bell jars used for testing are now in gloveboxes connected to the effluent recovery system. Future workload requirements will determine further modernization needs.

- $\quad$ Radioactive Effluent Recovery Operations

Modernization was partially effected by the FY 1984 B61 and continues with the FY 1989 W89 SRAM II. The final increment is budgeted in FY 1997 with the FCAP Effluent Recovery System Replacement. The final increment is workload dependent and may not be required.

- Non-Nuclear Production Operations:

The Modernization Plan for Non-Nuclear Production Operations consists of five focused factories and commercially-supplied parts feeding final assembly operations.

- $\quad$ Focused Factories:

1. Parts Machining

Modernization complete

2. Tape Processing

Modernization is now completed.

3. Ceramics Header Production

Current facilities have adequate capability and

capacity. No additional modernization is required.

4. Powder Processing

The Class I operations for weapons system requirements are in modern facilities. No further significant modernization is planned.

5. Plastic Headers and Formulation

Current facilities have adequate capability and capacity. No additional modernization is required.

Final Assembly Operations:

Use commercially supplied parts feeding final assembly operations. 
- Production Support Operations:

- Analytical Support

Analytical Support equipment and systems have been modernized over the last ten years and today fully meet the analytical requirements of Mound's mission assignments.

- $\quad$ Component Testing (Non-Nuclear)

Modernization is complete.

$\therefore \quad$ Safeguards and Security

Significant modernization has been accomplished.

- $\quad$ Plant Utilities

Significant modernization has been accomplished in all areas. Infrastructure projects will complete the modernization during the 1990's.

- Metrology Operations

Significant modernization has been accomplished via equipment and system purchases on weapons line items.

- Plant Services

Significant modernization has been accomplished. The main maintenance shop, warehouse, and cafeteria are in relatively new and modern facilities.

- Plant Safety:

All buildings at Mound will be brought into compliance with the current Life Safety Codes by FY 1997.

Mound currently has the ability to satisfactorily accomplish its mission assignments. The spending plan proposed in this is driven by Environmental, Safety, and Health projects, and FCAP projects replacing existing poor facilities with modern ones providing significant increases in protection for workers and the environment. Should some or all of the spending plan be rejected, Mound's goals in the ES\&H and productivity arenas will not be met.

\section{Listing of Buildings}

Following is a listing of all Mound Buildings along with their gross square footage. 
EXISTING MOUND BUILDINGS

COMN GROSS

BLDG SQUARE

DSGN FEET

A

B

C

$\cos$

DS

E

G

$\mathrm{GH}$

GP44

GIS

GP1

GW

$\mathrm{H}$

$\mathrm{HH}$

I

M

OSE

OSW

PH
55,582

27,735

13,403

64,654

47,810

47,755

7,518

5,347

365

166

7,792

9,782

17,334

15,276

25,736

56,018

90,072

54,280

646
CURRENT USE

Administration/Quality

Inert Production

Record Storage

Development/Production

Development/Standards/Testing

Analytical Services/Production/ Analytical Laboratory

Garage

Visitor Control

Record Storage

Guard Island Entrance

Change Rooms/Firing Range

Bonded Stores/Receiving Inspection

Environmental Laboratories/

Laundry/Change Rooms

Isotope Separation

Explosives/Pyrotechnics

Production

Tooling Fabrication/Ceramics

Machining/Electro Plating/and

Electronics

Engineering/DOE/Cafeteria/

Auditorium/Computer Facility

Accounting/Management Information/ Drafting/Central Computer Facility

Storage
FY 1993

LANDLORD

Defense Programs

Defense Programs

Defense Programs

Defense Programs

Defense Programs

Defense Programs

Defense Programs

Defense Programs

Defense Programs

Defense Programs

Defense Programs

Defense Programs

Defense Programs

Defense Programs

Defense Programs

Defense Programs

Defense Programs

Defense Programs

Defense Programs 
EXISTING MOUND BUILDINGS

COMN GROSS

DSGN FEET

CURRENT USE

FY 1993

LANDLORD

$\mathrm{P}$

15,143 Powerhouse (Steam/Chilled

Water/Compressed

Air/Breathing Air)

PS

2,288 Paint Shop

Defense Programs

$\mathrm{R}$

$55,003 \quad$ Nuclear Laboratories/Offices/

Library/D\&D Program

SD

1,593 D\&D Program

SM

21,700 D\&D Program

590 Salt Storage for Road Treatment

SW

43,066

Tritium Development/ Surveillance

$\mathrm{T}$

172,963 Nuclear Operations/Tritium

Development/Laboratories/Heal

th Physics

W

32,484 Maintenance

Defense Programs

WD

16,216 Radioactive Waste Treatment

Defense Programs

WH1

374 Well House

Defense Programs

WH2

374

Well House

Defense Programs

WH3

128

Well House

986

Explosives Processing

Defense Programs

1

2

6,291 Test Fire

12,391 Test Fire

314 Magazine

90 Magazine

Defense Programs

Defense Programs

Defense Programs

Defense Programs

Defense Programs

$387 \quad$ Magazine

Defense Programs 
EXISTING MOUND BUHDINGS

\section{COMN GROSS \\ BLDG SQUARE \\ DSGN FEET}

8

10

11

13

14

16

17

19

20

21

22

23

24

25

26

27

28

29

30

31

33

34

4480

303

4069

9,090

3,422

840

430

800

5,285

11,329

6,601

740

8,740

1,344

1,110
66 Magazine

66 Magazine

372 Magazine

47 Firing Shed

53 Metal Melting

480 Production Storage

1120 Production Storage

Property Management/Surplus/ Property Disposal

\section{Magazine}

D\&D Program

Development/Warehousing

Waste Material Staging Area

Water Treatment (Potable)

Weather Station

Maintenance

Energetic Materials Production

Ceramics Production

Plastics Production

Health Physics

TRU Waste Staging

D\&D Operations
FY 1993

LANDLORD

Defense Programs

Defense Programs

Defense Programs

Defense Programs

Defense Programs

Defense Programs

Defense Programs

Defense Programs

Defense Programs

Environmental

Management

Defense Programs

Defense Programs

Defense Programs

Defense Programs

Defense Programs

Defense Programs

Defense Programs

Defense Programs

Defense Programs

Environmental

Management

Environmental

Management

Defense Programs 


\section{EXISTING MOUND BUILDINGS}

COMN GROSS

BLDG SQUARE

DSGN FEET

35

36

37

38

39

40

42

43

44

45

46

47

48

49

50

51

52

53

54

55

56

57

2,500
Non-Destructive Testing (NDT)

Laboratory

4,255 Support Functions for RTG

Assembly and Testing

Operations

2,463 Organic Materials Development

44,327 Nuclear Programs/D\&D

Program

3,515 Engineering

12,227 Print Shop/Technical Manuals/ Publications

2,892 Pyrotechnics Production

1,516 Development

2,480 Cafeteria

9,500 Health Physics

2,439 Welding Development

3,611 Security

7,950 Surveillance

14,929 Timer Fabrication

14,849 RTG Assembly and Testing

3,541 Development

78 Magazine

239 Magazine

331 Magazine

330 Waste Management

613 Fire Pump and Water Tank

510 Sanitary Sewage Treatment
FY 1993

LANDLORD

Defense Programs

Nuclear Energy

Defense Programs

Nuclear Energy

Defense Programs

Defense Programs

Defense Programs

Defense Programs

Defense Programs

Defense Programs

Defense Programs

Defense Programs

Defense Programs

Defense Programs

Nuclear Energy

Defense Programs

Defense Programs

Defense Programs

Defense Programs

Defense Programs

Defense Programs

Defense Programs 


\section{COMN \\ BLDG \\ DSGN \\ GROSS \\ SQUARE \\ FEET}

58

59

60

61

63

64

65

66

67

68

69

70

71

72

73

74

79

80

81

82

83

84

45,490

16,461

72

2,400

600

3,787

1,990

1,620

3,366

800

2,400

2,200

400

1,650

314

314

314

314

314
6,110 Filter Bank

668 Neutron Radiography

3,9E8 Ceramics

\section{CURRENT USE}

Warehousing/Procurement/

Contracting

Quality/Product Tester/Design/ Development

$$
\text { Magazine }
$$

Production

Development

Energetic Material Support

D\&D Staging Area

Production/Tritium Surveillance

Quality

Flammable Liquids Storage

Hazardous Waste Staging

Gas Cylinder Storage

Production Storage

Waste Management Support

Magazine

Magazine

Magazine

Magazine

Magazine
FY 1993

LANDLORD

Defense Programs

Defense Programs

Defense Programs

Defense Programs

Defense Programs

Defense Programs

Defense Programs

Defense Programs

Defense Programs

Environmental

Management

Defense Programs

Defense Programs

Defense Programs

Defense Programs

Defense Programs

Defense Programs

Defense Programs

Defense Programs

Defense Programs

Defense Programs

Defense Programs

Defense Programs 
EXISTING MOUND BUILDINGS

\begin{tabular}{|c|c|c|c|}
\hline $\begin{array}{l}\text { COMN } \\
\text { BLDG } \\
\text { DSGN }\end{array}$ & $\begin{array}{l}\text { GROSS } \\
\text { SQUARE } \\
\text { FEET }\end{array}$ & CURRENT USE & $\begin{array}{l}\text { FY } 1993 \\
\text { LANDLORD }\end{array}$ \\
\hline 85 & 3,160 & Powder Blending/Processing & Defense Programs \\
\hline 87 & 38,882 & Destructive Testing & Defense Programs \\
\hline 88 & 7,200 & $\begin{array}{l}\text { Support Functions for RTG } \\
\text { Assembly and Testing } \\
\text { Operations }\end{array}$ & Defense Programs \\
\hline 89 & 4,830 & $\begin{array}{l}\text { Detonator (Long Term Surveil- } \\
\text { lance) }\end{array}$ & Defense Programs \\
\hline 90 & 656 & Retort (Explosives Waste) & Defense Programs \\
\hline 91 & 8,065 & $\begin{array}{l}\text { Environmental, Safety and } \\
\text { Health/Training }\end{array}$ & Defense Programs \\
\hline 92 & 1,600 & Production Training & Defense Programs \\
\hline 93 & 2,936 & Standards & Defense Programs \\
\hline 94 & 1,240 & Materials Compatibility & Defense Programs \\
\hline 95 & 2,000 & Utilities Operations & Defense Programs \\
\hline 96 & 432 & Disintegrator/Storage & Defense Programs \\
\hline 98 & 8,517 & Fire Station & Defense Programs \\
\hline 99 & 11,412 & Security Operations & Defense Programs \\
\hline 100 & 6,292 & Security & Defense Programs \\
\hline 101 & 1,815 & Engineering & Defense Programs \\
\hline 102 & 10,982 & Engineering (D\&D) & $\begin{array}{l}\text { Environmental } \\
\text { Management }\end{array}$ \\
\hline 104 & 1,800 & Test Fire Maintenance & Defense Programs \\
\hline 105 & 38,027 & Production Machining & Defense Programs \\
\hline 106 & 180 & Production Storage & Defense Programs \\
\hline 112 & 785 & Sand Filters & Defense Programs \\
\hline 113 & 547 & Dewatering & Defense Programs \\
\hline 120 & 350 & Health Physics Storage & Defense Programs \\
\hline
\end{tabular}




\section{Space Plans}

Mound is positioned for economic development as a result of historical modernization progress and technical competence in current and emerging technologies, on-time delivery of quality products at optimum cost, plant areas modifiable for process and/or production, and an unequaled tritium handling facility. In order to enhance the opportunities for this selective growth, Mound is continuing the DOE's downsizing initiative through an extensive consolidation effort.

\section{Summary of Maintenance Program and Repair Backlog}

The Mound site is located on 305 acres of land and comprises more than 132 buildings having a total of nearly 1.4 million square feet of floor space. It has approximately 6.6 miles of paved roads, approximately 16.6 acres of parking lots, and approximately 15 miles of security fencing. Maintenance operations are responsible for the maintenance of these buildings, equipment, utilities, and grounds.

All steam and compressed air for the site is generated in the central powerhouse. A significant portion of all the site's comfort cooling and process cooling is achieved using an ethylene glycol recirculated system with the chillers located in the central powerhouse as well as one satellite plant. All potable, process, and fire protection waters are supplied by three wells located on the plant site. Electrical service is supplied by Dayton Power and Light Company and is distributed internally within the plant.

As the maintenance budget continues its annual decrease, the need for safety repairs and modifications will continue to increase. The biggest challenge facing the maintenance organization will be to satisfy this increasing need while providing a constant level of maintenance surport and engineering project support. This increasing "timely response required" workload is, and will be, especially demanding in key trade classifications. With attrition, retirements, and possible lay-offs anticipated in the near future, headcounts in these key trade areas are expected to decrease. Thus, the true effect of budgetary restrictions and increased safety repair ipport is already being experienced in the areas where Mound can least afford it. Much overtime has been required of these key trade classifications in past years to meet ongoing maintenance and repair, as well as in-house construction and modification projects. However, the overtime budget has been significantly reduced, further aggravating the problem of limited personnel.

Mound plans to place significant space in a standby condition as DOE needs allow, thus reducing operating costs. The assumption typically made in such times of curtailed production and development is that less maintenance will be required. In most cases, however, the need for maintenance increases during such times. For 
example, equipment that lubricates and generally maintains itself during its operation will require attention during slack or downtime periods. Also, increased D\&D and Environmental Restoration will need more maintenance craft personnel to remove equipment and prepare it for shipment or transfer. As stated recently by the DOE/AL Maintenance Program Manager, the maintenance budget might need to increase as the result of reconfiguration decisions that might close Mound.

The primary driver of Mound's current maintenance budget, however, are those DOE and federal regulatory changes that drive up the daily maintenance costs of the site. The intent of this new DOE Maintenance Order is to bring operations into compliance with all known DOE orders that refer to maintenance requirements.

Over the course of the past few years, Mound's maintenance and repair backlog has been growing significantly because of annual maintenance operating funding shortfalls. With the current budget projections, backlog management relies heavily on future operating, line item, and General Plant Project (GPP) funding. Without such funds, the backlog will grow exponentially for many capital asset items (for example, roofs or roads).

Mound has carefully developed a systematic maintenance and repair backlog reduction plan that will reduce the current backlog over the course of the next ten years, contingent on funding levels.

The details of Mound's Maintenance Program, its current initiatives and deficiencies, along with the maintenance and repair backlog reduction plan can be found in Sections B and C.

\section{Environmental Restoration}

The Environmental Restoration efforts at Mound are associated with the requirements of the Federal Facilities Compliance Agreement to achieve compliance with the Comprehensive Environmental Response, Compensation, and Liability Act and the Resource Conservation and Recovery Act (CERCLA/RCRA) Programs. Those projects are not defined in the Mound Capital Budget Submission or in the Production and Surveillance Budget. They are funded by a controlled budget set aside for the Environmental Restoration (ER) Project, DOE-wide.

The projects contained within the ER plan are budgeted with special funds. These projects are surrently in the assessment phase and will be deleted from the plan should such action be deemed necessary. 
The Environmental Restoration (ER) Program has currently identified nine operable units at Mound based on available data and historical information. These operable units are given below.

Operable unit is defined in the National Contingency Plan as "a discrete part of the entire response action that decreases a release, threat of release, or pathway of exposure" (40 CFR 300.6).

Operable Unit 1 Area $B /$ Groundwater is addressing volatile organic chemical contamination of the Buried Valley Aquifer at Mound Plant.

Operable Unit 2 Main Hill Seeps is addressing tritium and volatile organic chemical contamination of the indurated bedrock on the Main Hill at Mound Plant.

Operable Unit 3 Miscellaneous Sites is addressing possible hazardous constituents at potential release sites that are not currently operational, including sites covered by RCRA, and contain no known radioactive contamination. This operable unit is planned for closure and any potential release site requiring further action will be addressed in another operable unit.

Operable Unit 4 Miami-Erie Canal is addressing an off-site area that contains plutonium-contaminated sediments.

Operable Unit 5 Radioactively Contaminated Soil is addressing potential release sites at Mound Plant that have soils with known or suspected radioactive contamination as well as other potential release sites on the SM/PP hill and new property.

Operable Unit 6 Decontamination and Decommissioning (D\&D) Program Sites, Hazardous Constituents, is addressing potential release sites at Mound Plant that contain radioactive contamination. These sites are not included in the Radioactively Contaminated Soil Operable Unit because funding is provided by the D\&D Program.

What was formerly Operable Unit 7 has been realigned to be included into other operable units.

Operable Unit 8, Inactive Underground Storage Tanks, has been closed out with the approval of the Mound Plant Active UST Management Plan. All inactive USTs were evaluated and, where appropriate, moved to other operable units for investigation. 
Operable Unit 9 Site-Wide RF/FS is intended to serve two objectives: 1) provide a summary of the ER Program at Mound Plant, and 2) provide a detailed plan for site-wide sampling efforts.

\section{Decontamination and Decommissioning Programs}

Mound has had an aggressive Decontamination and Decommissioning (D\&D) program for a number of years. Over the past few years the funding for the D\&D programs has grown and the DOE emphasis on ES\&H matters has increased. The Mound D\&D program now includes the following major efforts:

- $\quad$ Plutonium Processing (PP) Building (90\% of Building)

- $\quad$ Special Metallurgical (SM) Building (Complete Removal)

- $\quad$ SW and WD Building Areas (15\% of Buildings)

R140 and Support Areas

- $\quad$ EW Soil Cleanup (Complete Removal)

- Underground Liquid Waste Lines (Complete Removal)

- $\quad$ Semi-Works (SW) Cave Areas (5\% of Building)

In recent years the D\&D efforts have been funded jointly by the Production and Surveillance budget and the Environmental Restoration/Waste Management (EM) budget. With the advent of the DOE Environmental Restoration Program, the EM Program has been picking up a larger share of the D\&D costs each year.

\section{B. SITE DESCRIPTION}

\section{Background}

Late in 1945, the Manhattan Engineering District determined that the research, development, and production organization in the Dayton area should become a permanent facility. A search for a suitable location in 1946 led to the selection of the 182-acre tract adjacent to Miamisburg, Ohio, about ten miles south-southwest of Dayton. An additional 124-acre tract was acquired in 1981 . Construction at the site began in 1947 and the initial phase was completed in 1949. 
The original 182-acre site is formed by two topographically high areas (hills) and a lower intermediate valley area. The newly acquired 124-acre tract is generally undulating toward the southwest. The southernmost portion of the valley is located over the buried valley aquifer. This aquifer has been designed as a "sole source aquifer" under the Federal EPA Safe Drinking Water Act.

Elevations at the site vary from 700 to 910 feet above sea level; most of the site, however, is above 800 feet above sea level. Hillside slopes of $20 \%$ are common. The original site construction and subsequent construction has placed the majority of the operating buildings on top of the two high areas and the lower intermediate valley. The 124-acre additional tract has not been developed.

There are now approximately 1,706 employees and more than 132 buildings comprising nearly 1.4 million square feet within buildings at Mound. These facilities are significant assets for the United States in conducting its national defense program. The buildings on the site vary in size from less than 100 square feet (a magazine) to over 150,000 square feet (a production building). Building construction is generally steel and masonry, with some being reinforced concrete.

The functions within these buildings vary from an office environment to the highly sophisticated and controlled environment for safely handling explosives or nuclear materials. Also, some facilities have been designed and constructed for use in explosives materials handling.

The buildings on site vary widely in their physical condition and technology status when the GSA Code Condition Rating Methodology is applied. The average condition of the buildings at the site is moderate.

An important part of the mission assigned to Mound is the management of, and planning for, the efficient use of these assets. To prepare for the future, an extensive set of site development planning documents have been compiled.

\section{Utility Sources, Loads, and Distribution/Collection Systems}

The Mound Plant has two primary energy needs: electricity and boiler fuel. Electricity is provided to the plant by the Dayton Power and Light (DP\&L) Company. Mound has two boilers, each with dual fuel capability: natural gas and No. 2 fuel oil. Fuel oil is used only as a backup during natural gas curtailment and is drawn from on-site storage tanks. Effective November 1, 1992, Mound participates in competitive procurement of natural gas through the Defense Fuel Supply Center (DFSC). DFSC competitively bids and establishes contracts with gas suppliers. The gas supplier furnishes the gas to the "city gate" where the Local Distribution Company, DP\&L, transports the gas to Mound. The Mound Plant is on an interruptible natural gas supply. 
The Mound Plant electrical needs are supplied by three 12,470-volt feeders from DP\&L. This source had been adequate until 1985, when the plant load exceeded the firm capacity supplied. A portion of the FY 1991 FCAP project, "Site Electrical Replacements," was to have upgraded DP\&L service to 69,000 volts, which would have provided firm electrical capacity to the plant. This portion of the project was cancelled in FY 199\%. The internal distribution system, which includes the primary 12,470-volt and secondary 480-volt systems is adequa e. An FY 1990 GPP project provided power factor correction to the plant which resulted in an increase in power factor from approximately $88 \%$ to greater than $95 \%$. Although this increased firm capacity by $1 \mathrm{MVA}$, at peak production Mound operates without adequate firm electrical capacity from April through September; however, longer term site electrical requirements will be dependent on site work load.

The buildings at Mound are predominantly heated by steam. There are two steam boilers located in the Powerhouse, one rated at 85,000 PPH and the other rated to $70,000 \mathrm{PPH}$. The boilers generate saturated steam at $125 \mathrm{psig}$, which is distributed through above-ground pipes on elevated stanchions to the various buildings and the pressure is reduced to $30 \mathrm{psig}$ for use in the buildings. The steam condensate is collected in the buildings in vented condensate receivers and is returned to the powerhouse for feed water to the boilers. The steam and condensate systems are very tight and approximately $90 \%$ of all steam generated is returned to the powerhouse by the condensate return system, resulting in significant savings in thermal energy as well as water for makeup and chemicals for treatment. The $10 \%$ that is not returned is associated with such effects as direct steam humidification and flash steam from condensate receivers.

Many of Mound's buildings are air conditioned by central chiller systems that chill and circulate an aqueous solution of $30 \%$, by volume, ethylene glycol to the buildings through pipes elevated on above-ground stanchions. There are two central chiller systems. One is in the Powerhouse and includes five electrically driven centrifugal chillers with a total installed capacity of 5,700 tons. This system serves 26 buildings and has a peak load of 3,500 tons. The other central chiller system is located in Building 95, on the SM/PP hill, and serves eight buildings in the SM/PP and the Test Fire areas. The Building 95 system has two chillers with a total installed capacity of 1,300 tons. The peak load for this system is less than 500 tons.

\section{SITE ASSUMPTIONS}

Weapon production work load at Mound has decreased significantly over the past several years. Mound will cease its Defense Program product and surveillance operations by the end of fiscal year 1995. Other indirect and nonweapons work load has remained substantially constant and in some cases has increased. A major shift in emphasis is occurring in $\mathrm{ES \& H}$, maintenance, quality assurance, 
and conduct of operations. Pending firm guidance from DOE following the Record of Decision and the ramifications of the Decision, it is incumbent upon Mound to effact its downsizing and consolidation activities in a manner that takes into consideration the following factors:

1. DOE's Reconfiguration plans as reflected in the Finding of No Significant Impact (FONSI) on September 8, 1993,

2. Potential to take advantage of under-used Mound capabilities and numerous Mound technologies for economic development and modernized facilities,

3. Mound's ability to attract new and expanded mission assignments in nonweapons areas,

4. Technology transfer of capabilities to commercial sector,

5. Privatization of the facilities and capabilities.

The uncertainty in programmatic need is also reflected in the uncertainty in the future population of the plant. The headcount to accommodate projected future work loads can decline from the existing headcount of about 1700 people to about 1200 by the year 2000 , in the case of additional work load; to as low as 800 people in the same time period in the case of declining work loads. Accordingly, consolidation plans must take into consideration this wide variation in headcount. In addition, there is, and probable will continue to be, a shift from "gray collar" workers such as those in manufacturing to "knowledge" and more high technologybased workers and environmental clean-up workers.

The following assumptions have been made for Mound's Site Development Plan and this CAMP report, subject to specific guidance from DOE as part of the recor.figuration efforts:

1. Present defense program mission assignments for production will continue but at significantly reduced levels through FY 1995,

2. Present mission assignments for surveillance of the stock pile will decrease in response to the level of weapons retirements ending in FY 1995 ,

3. Adequate funding will be provided to maintain facilities allowing their environmentally responsible operation,

4. Emphasis on environment, safety, and health programs will continue at present levels or increase, 
5. Funding for environmental restoration and waste management (EM) activities will increase from current levels and are not included in CAMP,

6. Weapons Line Item capital requirements are not included in CAMP.

\section{MAINTENANCE PROGRAM}

\section{A. PROGRAM OVERVIEW}

Numerous exercises are performed annually addressing the funding needed to support Mound's maintenance and repair requirements.

1. Preventive Maintenance (PM)/Equipment Management

The clearly defined objective of Mound's Preventive Maintenance Programs is to reduce downtime and extend the life of plant equipment. The Equipment Management Program supports this objective by providing a database that permits analysis of equipment repairs, trend development, replacement versus repair data, and budget data to support new acquisitions. The program issues preventive maintenance activities on a weekly basis for all of the site's equipment.

Also, the PM Program is structured to issue periodic operator- and craft-performed functional test activities, which are not necessarily maintenance in nature, but which are required to meet safety or regulatory requirements, together with the PM activities. The completion of these activities is recorded and maintained as a permanent record by equipment within the maintenance software system.

2. Maintenance Planning Organization

One of the primary objectives of the Maintenance Planning Organization is to plan all in-house construction, minor modifications, and repair projects using Universal Maintenance Standards. This task also entails ensuring timely material delivery for job execution. On minor modification projects (less than $\$ 4000$ ) the planning organization serves as the design group and the project management function for work execution. 
In conjunction with the area foreman, this organization schedules all work on a daily basis and ensures that work is completed per scope prior to work order closeout. For purposes of this exercise, only the organi ation's budget requirements for supporting the maintenance and repair workload is included.

\section{Maintenance Engineering}

The Maintenance Engineering function responsibilities include the following: design and execution of all non-HVAC Maintenance projects; daily technical support upon request of planners/foremen; technical support of the Preventive Maintenance Program; maintainability reviews of all the site's outside design criteria and construction prints, specifications, and appropriate submittals; and ongoing site condition appraisals of the plant's facilities and utilities.

4. HVAC Maintenance and Engineering

The HVAC Maintenance and Engineering Function is responsible for the design and maintenance of all new and existing HVAC-related - equipment for the site. Much support is provided to the Project Management and Facilities Engineering functions within Facilities Engineering on new building designs and production lab modifications. This level of support was not included as "maintenance related." The group is also responsible for the engineering of all centrally distributed process cooling applications.

5. Trades Maintenance

The trades maintenance force responsibilities include the execution of the following: all major in-house construction modification projects generated by the Facilities, HVAC, and Maintenance Engineering functions; all minor modification requests (less than \$4000) from any on-site organization; and all building equipment and process equipment repair requests. The maintenance of all other real property is also handled organizationally through this group (that is, yards and grounds, building and utilities repair and upkeep).

\section{Contract Maintenance and Repair}

All maintenance and repair projects that are of the types of work viewed as Davis Bacon covered by DOE are contracted (for example, major roof or road repairs). Many major central utility-producing pieces of equipment and specialized process equipment items have 
their preventive and repair maintenance work performed by outside vendors. The site's central computer mainframe equipment is also maintained by the vendor. Several software maintenance contracts are also in place.

\section{Electronics}

As discussed above, some of the site's electronics maintenance is contracted out to the equipment vendor on specialized pieces of equipment. The bulk of the site's electronics maintenance and repair activities, however, is performed internal to the site. This activity includes support of all utility, building, process, and personal computer equipment items. The organization also supports in-house major modifications and installation projects.

8. Custodial Services

Treated at Mound as a plant overhead function, this organization's services are production and office facilities relative to routine cleaning. Also included are any contracted window and carpet cleaning services.

\section{Laborer Services}

This organization is primarily responsible for the site's yards and grounds maintenance. Included in this function is external to building cleanup, grass mowings, and frequent support of trades performing yards and grounds repairs.

10. Vehicular Maintenance

This function maintains the site's mobile maintenance equipment, security vehicles, warehousing and transportation vehicles, and the various pieces of yards and grounds maintenance equipment.

\section{Maintenance Management}

The final element included in the maintenance program overview is that of the maintenance management staff. Included in the element is only that support level of maintenance foreman rendered to maintenance and repair activities. Their support of in-house engineered projects is excluded. The total overhead burden cost of the maintenance managers who supervise the organi-zation's planners, foremen, and engineers is also included in the maintenance plan. 


\section{B. CURRENT DEFICIENCIES}

The biggest challenge the maintenance organization will face in FY 1994 and beyond will be that of supporting the ever-increasing backlog of preventive maintenance items, corrective repairs, and repair maintenance. During the past reporting period there has been a substantial increase of backlogged hours. Most of these activities are in support of building-related activities.

This increase in workload is especially tremendous in the demand on key trade classifications. With attrition, retirements, and possible layoffs anticipated in the near future resulting from budgetary constraints, headcounts in these key trades will continue to decrease. Thus, the true effect of budgetary restrictions and increased repair support is already being experienced in the areas where Mound can least afford it. High levels of overtime have been required of these key trade classifications in past years to meet the ongoing maintenance and repair efforts, as well as in-house construction/modification projects. However, the overtime budget recent years has been significantly reduced, thus further aggravating the problem of limited key trade personnel. 


\section{MOUND FACHITY PHYSICAL CHARACTERIZATION}

\section{SECTION 1: ADMINISTRATIVE BLILDINGS}

A. Planning Basis: The administration buildings are a functional unit consisting of office, training, computer, and security headquarters buildings as well as a cafeteria.

Although the production workload at Mound is decreasing over the long term, demand for administrative space is not expected to decrease. Increasing demands for ES\&H-type activities will at least offset any reduction in administrative personnel because of production decreases.

Because of the current reduction in budget and workload, an effort is underway at Mound to consolidate facilities; that is, to shut down as much space as possible to the appropriate level of standby condition. Although a draft plan listing possible facilities and time frame of execution has been prepared for this effort, it is premature to detail its impact on this building functional unit.

For Mound's administrative space requirements, the standards prescribed in DOE $4300.1 \mathrm{~B}$ are observed. The goal of this criteria is to achieve an average workstation use rate of 135 occupiable square feet or less per person.

1. Present Mission: The present mission of this functional unit is to provide facilities for administrative support to the production and laboratnry activities conducted at Mound.

2. Material Condition and Expected Useful Life: The facilities grouped within this functional unit range in age from original plant construction (1948) to quite new (1988). Construction ranges from concrete block to wooden modulars. Overall condition of this functional unit is good. 


\section{ADMINISTRATIVE BUILDINGS}

\begin{tabular}{|c|c|c|c|c|c|c|}
\hline \multirow[b]{2}{*}{$\underline{B L D G}$} & \multirow{2}{*}{ DESCRIPTION } & \multicolumn{3}{|c|}{$\begin{array}{l}\text { SQUARE } \\
\text { FOOTAGE }\end{array}$} & \multicolumn{2}{|c|}{$\begin{array}{l}\text { REMAINING } \\
\text { PROJECTED }\end{array}$} \\
\hline & & CONDITION & (X 1000) & AGE (Yrs.) & & \\
\hline A & Administration & Good & 55.6 & 45 & & 35 \\
\hline GH & Employment & Good & 5.3 & 45 & & 25 \\
\hline GIS & Guard Island & Fair & 0.2 & 45 & & 25 \\
\hline OSE & Opns Supp (E) & Excellent & 90.1 & 7 & & 53 \\
\hline Osw & Opns Supp (W) & Good & 54.3 & 19 & & 51 \\
\hline 34 & Fire Training & Fair & 1.1 & 28 & & 32 \\
\hline 44 & Cafeteria & Fair & 2.5 & 24 & & 26 \\
\hline 47 & Security & Excellent & 3.6 & 24 & & 36 \\
\hline 69 & Production Supp & Fair & 1.6 & 12 (Wood & Mod) & 23 \\
\hline 70 & Quality Supp & Fair & 3.4 & 12 (Wood & Mod) & 23 \\
\hline 79 & Waste Mgmt Supp & Fair & 1.7 & 10 (Wood & Mod) & 25 \\
\hline 88 & RTG Admin Supp & Good & 7.2 & 10 (Wood & Mod) & 25 \\
\hline 91 & Admin/Training & Fair & 8.1 & 9 (Wood & Mod) & 26 \\
\hline 92 & Prod Training & Fair & 1.6 & 9 (Wood & Mod) & 26 \\
\hline 93 & Standards Supp & Good & 2.9 & 9 (Wood & Mod) & 26 \\
\hline 99 & Security Ops & Excellent & 11.4 & 6 & & 64 \\
\hline 100 & Security Precinct & Excellent & 6.3 & 5 & & 65 \\
\hline 101 & Engrg Supp & Excellent & 1.8 & 7 (Wood & Mod) & 28 \\
\hline 102 & D\&D Engrg Supp & Excellent & 11.0 & 6 & & 64 \\
\hline
\end{tabular}

3. Key Activities and Upgrades: The types of projects planned for this functional unit over the next twenty years are generally Facilities Capability Assurance Program (FCAP) type projects such as heating, ventilating, and air conditioning (HVAC) and General Plant Projects (GPP) such as roof replacement projects necessary to maintain its acceptable condition.

4. ES\&H and S\&S Upgrades Required: In FY 1995 an ES\&H project, Plant Life Safety Code Upgrades, is planned to upgrade some of these facilities to the latest life safety code.

5. Decommissioning and Decontamination Activities: None is planned for this functional unit.

B. Description of Events and Projects: The events and projects are briefly described in the following narratives, which are provided in chronological order.

1. In FY 1995, an ES\&H line item is planned to ensure the facilities in this functional unit meet the latest life safety codes. Buildings 
included are A, OSE, OSW, and 102. (\$2.3M - FY 1995 ES\&H Line Item)

2. Beginning in FY 1995, roofs will be replaced on several of the older facilities within this functional unit. It is planned that GPP funds will be provided for this effort. Over the past number of years, the maintenance budget has been unable to keep up with the necessary repairs required, thus necessitating capital funding. (\$300K - FY 1995 GPP)

3. In FY 1996, a number of HVAC replacements will be required. According to the American Society of Heating, Refrigerating, and Air Conditioning Engineers (ASHRAE), the normal expected life of HVAC equipment is approximately 25 years. Therefore, as the building equipment reaches that useful life, replacement equipment must be budgeted. (\$2.2M - FY 1996 FCAP Line Item)

4. In FY 2001, several more buildings will require roof replacements. (\$600K- FY 2001 GPP)

5. In FY 2003, additional HVAC replacements will be needed. (\$2.3M FY 2003 FCAP Line Item)

6. In FY 2005, several buildings will require domestic water line replacements. (\$1.3M - FY 2005 FCAP Line Item)

All of the above projects are essential to maintaining the Administrative Buildings at a minimal level of suitability for their mission.

C. Functional Unit Maintenance Activities:

Maintenance Planning: Facilities-planned maintenance activities have been automated. Routine inspections of roofs, filters, exit lights, HVAC equipment, lightning protection equipment, etc., are automatically scheduled. These routine preventive maintenance type activities generate small repair projects that are accomplished by in-house trades personnel.

Activities that are beyond the scope of in-house personnel are documented in routine surveys with participation of building management personnel as well as input from Engineering. These identified deficiencies are then appropriately grouped in manageable units and completed using Line Item, GPP, GPM, or expense funds as appropriate to the situation. On a yearly basis these needs are evaluated and prioritized for ccmpletion. 
Current Funding Status: Many of the administrative buildings are in need of repairs of a more substantial nature than can be accomplished with inhouse personnel. Funds for these types of activities (for example, new roofs, HVAC equipment, major concrete repairs) have been limited to less than 30 $40 \%$ of need.

Future Capital funding through the FCAP program and/or GPP funding is required to ensure the integrity of these buildings. Should such funding not materialize or be substantially delayed, maintenance fund requirements will increase exponentially over the life of the functional unit. 


\section{A-BUILDING PHYSICAL CHARACTERIZATION}

1) Current Mission Description

a) Facility Capabilities

A-Building is a $55,582-\mathrm{ft}^{2}$ building that has two stories plus a basement. The top floor holds executive offices, and the remainder of the space holds general offices.

b) Resources Required to Support Operations

Primary Physical Resources:

Electricity

Potable water

Sanitary drainage

Physical security

Telecommunication devices

Fire protection, sprinklers, fire department

HVAC

Services:

Human Resources

Finance and Accounting

Environmental, Safety, and Health

Maintenance

Custodial

Payroll

Supply

c) Current Safety Envelope

A-Building operations are classified as standard industrial hazard.

d) Current Status

1. No formal CAS review has been done.

2. No formal CAMP review has been done based on the latest Reconfiguration decision. 
2) Future Facility Use

a) Alternate Future Use Scenarios

1. WFO in the same discipline is likely under recent May 27, 1993, reconfiguration guidance.

2. WFO in a new discipline is unknown under recent May 27, 1993, reconfiguration guidance. Probably none.

3. Commercialization possibilities under a lease agreement: None.

4. Commercialization under a sale agreement is unlikely in the short term, although there is a long-term possibility.

5. Deactivation effort should be minimal for the building, as it is not contaminated with either radiological or energetic materials.

b) Facility Modifications Required for Likely Use

The roof has general leaks because of the building's age.

c) Facility Modifications Required for Other Uses

Unknown.

d) Changes to Safety Envelope

The facility use suggested above should be covered under standard industrial hazard category. Any new work conducted in A-Building may require that a safety assessment be performed to identify any new hazards involved in the process.

e) Cleanup Criteria for Each Future Use Scenario

A-Building is not contaminated with any radioactive or energetic materials.

f) Disposition of Surplus Equipment

Surplus equipment in A-Building may be readily disposed of, as required. 


\section{GH BUILDING PHYSICAL CHARACTERIZATION}

1) Current Mission Description

a) Facility Capabilities

GH is a 5,347- $\mathrm{ft}^{2}$ building that is used as office space for uncleared employees, part-time employees, and new employees. GH Building will be converted into a computer lab training center and a rad worker training facility in January 1994.

b) Resources Required to Support Operations

Primary Physical Resources:

Electricity

Potable water

Sanitary drainage

Physical security

Telecommunication devices

Fire protection, sprinklers, fire department

HVAC

Services:

Human Resources

Environmental, Safety, and Health

Maintenance

Custodial

Supply

c) Current Safety Envelope

GH Building operations are classified as standard industrial hazard.

d) Current Status

1. No formal CAS review has been done.

2. No formal CAMP review has been done based on the latest Reconfiguration decision. 
2) Future Facility Use

a) Alternate Future Use Scenarios

1. WFO in the same discipline is likely under recent May 27, 1993, reconfiguration guidance.

2. WFO in a new discipline is unknown under recent May 27, 1993, reconfiguration guidance. Probably none.

3. Commercialization possibilities under a lease agreement: None.

4. Commercialization under a sale agreement is unlikely in the short term, although there is a long-term possibility.

5. Deactivation effort should be minimal for the building, as it is not contaminated with either radiological or energetic materials.

b) Facility Modifications Required for Likely Use

Major work required on roof for leaks. HVAC needs updating along with building sewer systum.

c) Facility Modifications Required for Other Uses

Unknown.

d) Changes to Safety Envelope

The facility use suggested above should be covered under standard industrial hazard category. Any new work conducted in GH may require that a safety assessment be performed to identify any new hazards involved in the process.

e) Cleanup Criteria for Each Future Use Scenario

$\mathrm{GH}$ is not contaminated with any radioactive or energetic materials.

f) Disposition of Surplus Equipment

None. 


\section{BUILDING GIS PHYSICAL CHARACTERIZATION}

\section{1) Current Mission Description}

a) Facility Capabilities

Building GIS is a $166-\mathrm{ft}^{2}$ building that is used as a checkpoint when entering the main hill portion of the plant. It is currently not actively used for this purpose.

b) Resources Required to Support Operations

Primary Physical Resources:

Electricity

Physical security: padlocks

Telecommunication devices

Services:

Human Resources

Finance and Accounting

Environmental, Safety, and Health

Maintenance

Custodial

Payroll

Meal

Supply

c) Current Safety Envelope

Building GIS operations are classified as standard industrial hazard.

d) Current Status

1. No formal CAS review has been done. A quick condition assessment was done in July 1992.

2. No formal CAMP review has been done based on the latest Reconfiguration decision. A CAMP report was submitted on April 1, 1992, which focused on ES\&H needs, infrastructure maintenance, and consolidation projects. 
2) Future Facility Use

a) Alternate Future Use Scenarios

1. WFO in the same discipline is unknown under recent May 27, 1993, reconfiguration guidance. Probably none.

2. WFO in a new discipline is unknown under recent May 27, 1993, reconfiguration guidance. Probably none.

3. Commercialization possibilities under a lease agreement: Building GIS would be useful for any application requiring a main checkpoint or general plant directory assistance.

4. Commercialization under a sale agreement is unlikely in the short term, although there is a long-term possibility.

5. Deactivation effort should be minimal; the building is not contaminated with either radiological or energetic materials.

b) Facility Modifications Required for Likely Use

Probably no major building modification would be required for this use. The basic changes required would involve equipment.

c) Facility Modifications Required for Other Uses

Unknown.

d) Changes to Safety Envelope

The facility use suggested above should be covered under standard industrial hazard category unless hazardous materials are involved. Any new work conducted in Building GIS may require that a safety assessment be performed to identify any new hazards involved in the process.

e) Cleanup Criteria for Each Future Use Scenario

Building GIS is not contaminated with any radioactive or energetic materials.

f) Disposition of Surplus Equipment

There is no surplus equipment in Building GIS. 


\section{OSE BUILDING PHYSICAL CHARACTERIZATION}

1) Current Mission Description

a) Facility Capabilities

OSE Building is a $90,072-\mathrm{ft}^{2}$ building that houses engineering offices, the DOE offices, a cafeteria, an auditorium, and a computer facility.

b) Resources Required to Support Operations

Primary Physical Resources:

Electricity

Potable water

Sanitary drainage

Physical security

Telecommunication devices

Fire protection, sprinklers, fire department

HVAC

Services:

Human Resources

Environmental, Safety, and Health

Maintenance

Custodial

Supply

c) Current Safety Envelope

OSE Building operations are classified as standard industrial hazard.

d) Current Status

1. No formal CAS review has been done. A quick condition assessment was done in July 1992.

2. No formal CAMP review has been done based on the latest Reconfiguration decision. 


\section{a) Alternate Future Use Scenarios}

1. WFO in the same discipline is likely under recent May 27, 1993, reconfiguration guidance.

2. WFO in a new discipline is unknown under recent May 27, 1993, reconfiguration guidance. Probably none.

3. Commercialization under a lease agreement possibilities: None.

4. Commercialization under a sale agreement is unlikely in the short term, although there is a long-term possibility.

5. Deactivation effort should be minimal for the building, as it is not contaminated with either radiological or energetic materials.

\section{b) Facility Modifications Required for Likely Use}

None.

c) Facility Modifications Required for Other Uses

Unknown.

d) Changes to Safety Envelope

The facility use suggested above should be covered under standard industrial hazard category. Any new work conducted in OSE Building may require that a safety assessment be performed to identify any new hazards involved in the process.

e) Cleanup Criteria for Each Future Use Scenario

OSE Building is not contaminated with any radioactive or energetic materials.

\section{f) Disposition of Surplus Equipment}

Surplus equipment in OSE Building may be readily disposed of, as required. 


\section{OSW BUILDING PHYSICAL CHARACTERIZATION}

1) Current Mission Description

a) Facility Capabilities

OSW is a $54,280-\mathrm{ft}^{2}$ building that houses the plant-wide computer system and computer-aided design (CAD) products, processes, and facilities. Drawing Control program management and administrative offices are also in OSW Building, as well as environmentallycontrolled rooms for computer operations, vaulted areas for storage of sensitive documents, and drawing management equipment including computer output microfisch (COM), document scanning and drawing production.

b) Resources Required to Support Operations

Primary Physical Resources:

Electricity

Potable water

Sanitary drainage

Physical security

Telecommunication devices

Fire protection, sprinklers, fire department HVAC

Services:

Human Resources

Environmental, Safety, and Health

Maintenance

Custodial

Supply

c) Current Safety Envelope

OSW Building operations are classified as standard industrial hazard.

d) Current Status

1. No formal CAS review has been done.

2. No formal CAMP review has been done based on the latest Reconfiguration decision. 


\section{2) Future Facility Use}

a) Alternate Future Use Scenarios

1. WFO in the same discipline is likely under recent May 27, 1993 , reconfiguration guidance.

2. WFO in a new discipline is unknown under recent May 27, 1993, reconfiguration guidance. Probably none.

3. Commercialization possibilities under a lease agreement: None.

4. Commercialization under a sale agreement is unlikely in the short term, although there is a long-term possibility.

5. Deactivation effort should be minimal for the building, as it is not contaminated with either radiological or energetic materials.

b) Facility Modifications Required for Likely Use

Probably no major building modification would be required for this use. The basic changes required would involve equipment.

c) Facility Modifications Required for Other Uses

Unknown.

d) Changes to Safety Envelope

The facility use suggested above should be covered under standard industrial hazard category. Any new work conducted in OSW may require that a safety assessment be performed to identify any new hazards involved in the process.

e) Cleanup Criteria for Each Future Use Scenario

OSW is not contaminated with any radioactive or energetic materials.

f) Disposition of Surplus Equipment

None. 


\section{BUILDING 34 PHYSICAL CHARACTERIZATION}

1) Current Mission Description

a) Facility Capabilities

Building 34 is a $1110-\mathrm{ft}^{2}$ building complex used for emergency brigade training. Section 1 is a block concrete facility used for live fire training. Section 2 is used as office space or a class-room. Section 3 is used as a storage area.

b) Resources Required to Support Operations

Primary Physical Resources:

Electricity - Sections 2 and 3

Potable water - Section 1

Sanitary drainage - Section 1

Physical security - Sections 1, 2, and 3

Telecommunication devices - Section 2

Sprinklers - Section 1

Fire department - Sections 1, 2, and 3

HVAC - Sections 1, 2, and 3

Air compressor - Section 2

Services (All Buildings):

Human Resources

Finance and Accounting

Environmental, Safety, and Health

Maintenance

Custodial

Payroll

Meal

Supply

c) Current Safety Envelope

Building 34 operations are classified as standard industrial hazard.

d) Current Status

1. No formal CAS review has been done. A quick condition assessment was done in July 1992.

2. No formal CAMP review has been done based on the latest Reconfiguration decision. A CAMP report was submitted on April 1, 1992, which focused on ES\&H needs, infrastructure maintenance, and consolidation projects. 
2) Future Facility Use

a) Alternate Future Use Scenarios

1. WFO in the same discipline is unknown under recent May 27, 1993, reconfiguration guidance. Probably none.

2. WFO in a new discipline is unknown under recent May 27, 1993, reconfiguration guidance. Probably none.

3. Commercialization possibility under a lease agreement:

Building 34, particularly Section 1, would be useful for local fire departments to conduct live fire training.

4. Commercialization under a sale agreement is unlikely in the short term, although there is a long-term possibility.

5. D\&D is currently removing depleted uranium from the building complex and should be finished by early 1994 .

b) Facility Modifications Required for Likely Use

Major building modification would probably not be required.

c) Facility Modifications Required for Other Uses

Unknown.

d) Changes to Safety Envelope

The facility use suggested above should be covered under standard industrial hazard category unless hazardous materials are involved. Any new work conducted in Building 34 may require that a safety assessment be performed to identify any new hazards involved in the process.

e) Cleanup Criteria for Each Future Use Scenario

D\&D is currently removing depleted uranium from the building complex and should be finished by early 1994 .

f) Disposition of Surplus Equipment

Not applicable. 


\section{BUILDING 44 PHYSICAL CHARACTERIZATION}

1) Current Mission Description

a) Facility Capabilities

Building 44 is a $2,480-\mathrm{ft}^{2}$ building that was the SM/PP cafeteria. The building currently has vending machines in it and is used as a lunch and break area. Meetings and training classes are also sometimes held there.

b) Resources Required to Support Operations

Primary Physical Resources:

Electricity

Potable water

Sanitary drainage

Physical security

Fire protection, sprinklers, fire department

HVAC

Services:

Human Resources

Environmental, Safety, and Health

Maintenance

Custodial

Supply

c) Current Safety Envelope

None.

d) Current Status

1. No formal CAS review has been done.

2. No formal CAMP review has been done based on the latest Reconfiguration decision.

2) Future Facility Use

a) Alternate Future Use Scenarios

1. WFO in the same discipline is likely under recent May 27, 1993, reconfiguration guidance. 
2. WFO in a new discipline is unknown under recent May 27, 1993, reconfiguration guidance. Probably none.

3. Commercialization possibilities under a lease agreement: None.

4. Commercialization under a sale agreement is unlikely in the short term, although there is a long-term possibility.

5. Deactivation effort should be minimal for the building, as it is not contaminated with either radiological or energetic materials.

b) Facility Modifications Required for Likely Use

Probably no major building modification would be required for this use. The basic changes required would involve equipment.

c) Facility Modifications Required for Other Uses

Unknown.

d) Changes to Safety Envelope

The facility use suggested above should be covered under standard industrial hazard category.

Any new work conducted in Building 44 may require that a safety assessment be performed to identify any new hazards involved in the process.

e) Cleanup Criteria for Each Future Use Scenario

Building 44 is not contaminated with any radioactive or energetic materials.

f) Disposition of Surplus Equipment

None. 


\section{BUILDING 47 PHYSICAL CHARACTERIZATION}

1) Current Mission Description

a) Facility Capabilities

Building 47 is a $3,611-\mathrm{ft}^{2}$ building that is used for the protective force administrative functions, weapons storage, and classified waste storage. Shift formations are conducted three times a day and supervision of protective force activities is coordinated here. Building 47 is operational 24 hours a day.

b) Resources Required to Support Operations

Primary Physical Resources:

Electricity

Potable water

Sanitary drainage

Physical security

Telecommunication devices

Fire protection, sprinklers, fire department

HVAC

Services:

Environmental, Safety, and Health

Maintenance

Custodial

Supply

c) Current Safety Envelope

Building 47 operations are classified as standard industrial hazard.

d) Current Status

1. No formal CAS review has been done.

2. No formal CAMP review has been done based on the latest Reconfiguration decision. 
2) Future Facility Use

a) Alternate Future Use Scenarios

1. WFO in the same discipline is likely under recent May 27, 1993, reconfiguration guidance.

2. WFO in a new discipline is unknown under recent May 27, 1993, reconfiguration guidance. Probably none.

3. Commercialization possibilities under a lease agreement: None.

4. Commercialization under a sale agreement is unlikely in the short term, although there is a long-term possibility.

5. Deactivation effort should be minimal for the building, as it is not contaminated with either radiological or energetic materials.

b) Facility Modifications Required for Likely Use

Probably no major building modification would be required for this use. The basic changes required would involve equipment.

c) Facility Modifications Required for Other Uses

Unknown.

d) Changes to Safety Envelope

The facility use suggested above should be covered under standard industrial hazard category. Any new work conducted in Building 47 may require that a safety assessment be performed to identify any new hazards involved in the process.

e) Cleanup Criteria for Each Future Use Scenario

Building 47 is not contaminated with any radioactive or energetic materials.

f) Disposition of Surplus Equipment

None. 


\section{BUILDING 69 PHYSICAL CHARACTERIZATION}

1) Current Mission Description

a) Facility Capabilities

Building 69 is a $1620-\mathrm{ft}^{2}$, single story, modular-constructed, wooden building that is used for offices in support of production operations. It is currently in active use for this purpose.

b) Resources Required to Support Operations

Primary Physical Resources:

Electricity

Physical security

Telecommunication devices

Fire protection, sprinklers, fire department

HVAC

Services:

Human Resources

Finance and Accounting

Environmental, Safety, and Health

Maintenance

Custodial

Payroll

Meal

Supply

c) Current Safety Envelope

Building 69 operations are classified as standard industrial hazard.

d) Current Status

1. No formal CAS review has been done. A quick condition assessment was done in July 1992.

2. No formal CAMP review has been done based on the latest Reconfiguration decision. A CAMP report was submitted on April 1, 1992, which focused on ES\&H needs, infrastructure maintenance, and consolidation projects. 
a) Alternate Future Use Scenarios

1. WFO in the same discipline is unknown under recent May 27, 1993, reconfiguration guidance. Probably none.

2. WFO in a new discipline is unknown under recent May 27, 1993, reconfiguration guidance. Probably none.

3. Commercialization possibilities under a lease agreement: Building 69 would be useful for offices.

4. Commercialization under a sale agreement is unlikely in the short term, although there is a long-term possibility.

5. Deactivation effort should be minimal; the building is not contaminated with radiological or energetic materials.

b) Facility Modifications Required for Likely Use

Probably no major building modification would be required for this use. The basic changes required would involve equipment.

c) Facility Modifications Required for Other Uses

Unknown.

d) Changes to Safety Envelope

The facility use suggested above should be covered under standard industrial hazard category. Any new work conducted in Building 69 may require that a safety assessment be performed to identify any new hazards involved in the process.

e) Cleanup Criteria for Each Future Use Scenario

Building 69 is not contaminated with any radioactive or energetic materials.

f) Disposition of Surplus Equipment

The cost for disposition of equipment would be minimal since it is mostly office furniture. 


\section{BUILDING 70 PHYSICAL CHARACTERIZATION}

1) Current Mission Description

a) Facility Capabilities

Building 70 is a $3,366-\mathrm{ft}^{2}$ building that houses general offices.

b) Resources Required to Support Operations

Primary Physical Resources:

Electricity

Potable water

Sanitary drainage

Physical security

Telecommunication devices

Fire protection, sprinklers, fire department

HVAC

Services:

Human Resources

Environmental, Safety, and Health

Maintenance

Custodial

c) Current Safety Envelope

Building 70 operations are classified as standard industrial hazard.

d) Current Status

1. No formal CAS review has been done.

2. No formal CAMP review has been done based on the latest Reconfiguration decision.

2) Future Facility Use

a) Alternate Future Use Scenarios

1. WFO in the same discipline is possible under recent May 27, 1993 , reconfiguration guidance.

2. WFO in a new discipline is unknown under recent May 27, 1993, reconfiguration guidance. Probably none. 
3. Commercialization possibilities under a lease agreement: None.

4. Commercialization under a sale agreement is unlikely in the short term, although there is a long-term possibility.

5. Deactivation effort should be minimal for the building, as it is not contaminated with either radiological or energetic materials.

b) Facility Modifications Required for Likely Use

Probably no major building modification would be required for this use. The basic changes required would involve equipment.

c) Facility Modifications Required for Other Uses

Unknown.

d) Changes to Safety Envelope

The facility use suggested above should be covered under standard industrial hazard category.

Any new work conducted in Building 70 may require that a safety assessment be performed to identify any new hazards involved in the process.

e) Cleanup Criteria for Each Future Use Scenario

Building 70 is not contaminated with any radioactive or energetic materials.

f) Disposition of Surplus Equipment

None. 


\section{BUILDING 79 PHYSICAL CHARACTERIZATION}

1) Current Mission Description

a) Facility Capabilities

Building 79 is a $1,650-\mathrm{ft}^{2}$ single story, modular, constructed, wooden building that houses offices for waste management support. It is currently in active use for this purpose. All of Building 79 is used for offices.

b) Resources Required to Support Operations

Primary Physical Resources:

Electricity

Physical security

Telecommunication devices

Fire protection, sprinklers, fire department

HVAC

Services:

Human Resources

Finance and Accounting

Environmental, Safety, and Health

Maintenance

Custodial

Payroll

Meal

Supply

c) Current Safety Envelope

Building 79 operations are classified as standard industrial hazard.

d) Current Status

1. No formal CAS review has been done. A quick condition assessment was done in July 1992.

2. No formal CAMP review has been done based on the latest Reconfiguration decision. A CAMP report was submitted on April 1, 1992, which focused on ES\&H needs, infrastructure maintenance, and consolidation projects. 
2) Future Facility Use

a) Alternate Future Use Scenarios

1. WFO in the same discipline is unknown under recent May 27, 1993, reconfiguration guidance. Probably none.

2. WFO in a new discipline is unknown under recent May 27, 1993, reconfiguration guidance. Probably none.

3. Commercialization possibilities under a lease agreement: Building 79 would be useful for any application requiring office facilities.

4. Commercialization under a sale agreement is unlikely in the short term, although there is a long-term possibility.

5. Deactivation effort should be minimal; the building is not contaminated with radiological or energetic materials.

b) Facility Modifications Required for Likely Use

Probably no major bu'lding modification would be required for this use. Exterior painting will be required.

c) Facility Modifications Required for Other Uses

Unknown.

d) Changes to Safety Envelope

The facility use suggested above should be covered under standard industrial hazard category. Any new work conducted in Building 79 may require that a safety assessment be performed to identify any new hazards involved in the process.

e) Cleanup Criteria for Each Future Use Scenario

Building 79 is not contaminated with any radioactive or energetic materials.

f) Disposition of Surplus Equipment

The cost of any equipment removal would be minimal since only office furniture is involved. 


\section{BUILDING 88 PHYSICAL CHARACTERIZATION}

1) Current Mission Description

a) Facility Capabilities

Building 88 is a $7200-\mathrm{ft}^{2}$ office building which is used to support the RTG operations. The building was built in 1983.

b) Resources Required to Support Operations

Primary Physical Resources:

Electricity

Physical security

Fire protection, sprinklers, fire department

Potable water

Sanitary drains

HVAC

Services:

Human Resources

Finance and Accounting

Environmental, Safety, and Health

Maintenance

Custodial

Payroll

Meal

Supply

c) Current Safety Envelope

Building 88 operations are classified as standard industrial hazard.

d) Current Status

1. No formal CAS review has been done. A quick condition assessment was done in July 1992.

2. No formal CAMP review has been done based on the latest Reconfiguration decision. A CAMP report was submitted on April 1, 1992, which focused on ES\&H needs, infrastructure maintenance, and consolidation projects. 
2) Future Facility Use

a) Alternate Future Use Scenarios

1. WFO in the same discipline is likely under recent May 27, 1993, reconfiguration guidance.

2. WFO in a new discipline unknown under recent May 27, 1993, reconfiguration guidance. Probably none.

3. Commercialization possibilities under a lease agreement: Probably none.

4. Commercialization possibilities under a sale agreement: Probably none.

5. Deactivation effort should be minimal for the building as it is not contaminated with either radiological or energetic materials.

There are no near future plans to deactivate this building since it supports the RTG program.

b) Facility Modifications Required for Likely Use

None. This building is currently supporting the RTG program. Future use of the building would likely be the same.

c) Facility Modifications Required for Other Uses

None. Additional space in this building could be used to support other programs.

d) Changes to Safety Envelope

Not applicable.

e) Cleanup Criteria for Each Future Use Scenario

Not applicable.

f) Disposition of Surplus Equipment

Not applicable. 


\section{BUILDING 91 PHYSICAL CHARACTERIZATION}

1) Current Mission Description

a) Facility Capabilities

Building 91 is a $8,065-\mathrm{ft}^{2}$ building that is used for computer training and general office operations. Building 91 has conference rooms.

b) Resources Required to Support Operations

Primary Physical Resources:

Electricity

Potable water

Sanitary drainage

Physical security

Telecommunication devices

Fire protection, sprinklers, fire department

HVAC (marginal)

Services:

Human Resources

Finance and Accounting

Environmental, Safety, and Health

Maintenance

Custodial

Payroll

Meal

Supply

c) Current Safety Envelope

Building 91 operations are classified as standard industrial hazard.

d) Current Status

1. No formal CAS review has been done.

2. No formal CAMP review has been done based on the latest Reconfiguration decision. 


\section{2) Future Facility Use}

a) Alternate Future Use Scenarios

1. WFO in the same discipline is possible under recent May 27, 1993, reconfiguration guidance.

2. WFO in a new discipline is unknown under recent May 27, 1993, reconfiguration guidance. Probably none.

3. Commercialization possibilities under a lease agreement: None.

4. Commercialization under a sale agreement is unlikely in the short term, although there is a long-term possibility.

5. Deactivation effort should be minimal for the building, as it is not contaminated with either radiological or energetic materials.

\section{b) Facility Modifications Required for Likely Use}

HVAC operation is marginal and some updating is required. The roof needs work to fix leaks.

c) Facility Modifications Required for Other Uses

Unknown.

d) Changes to Safety Envelope

The facility use suggested above should be covered under standard industrial hazard category. Any new work conducted in Building 91 may require that a safety assessment be performed to identify any new hazards involved in the process.

e) Cleanup Criteria for Each Future Use Scenario

Building 91 is not contaminated with any radioactive or energetic materials.

f) Disposition of Surplus Equipment

None. 


\section{BUILDING 92 PHYSICAL CHARACTERIZATION}

1) Current Mission Description

a) Facility Capabilities

Building 92 is a $1,600-\mathrm{ft}^{2}$, wooden, modular-constructed building that is vacant. Building 92 had been used for offices.

b) Resources Required to Support Operations

Primary Physical Resources:

Electricity

Physical security

Fire protection, sprinklers, fire department

HVAC

Services:

Human Resources

Finance and Accounting

Environmental, Safety, and Health

Maintenance

Custodial

Payroll

Meal

Supply

c) Current Safety Envelope

Building 92 operations are classified as standard industrial hazard.

d) Current Status

1. No formal CAS review has been done. A quick condition assessment was cione in July 1992.

2. No formal CAMP review has been done based on the latest Reconfiguration decision. A CAMP report was submitted on April 1, 1992, which focused on ES\&H needs, infrastructure maintenance, and consolidation projects. 
2) Future Facility Use

a) Alternate Future Use Scenarios

1. WFO in the same discipline is unknown under recent May 27, 1993, reconfiguration guidance. Probably none.

2. WFO in a new discipline is unknown under recent May 27, 1993, reconfiguration guidance. Probably none.

3. Commercialization possibilities under a lease agreement: Building 92 would be useful for any general office use.

4. Commercialization under a sale agreement is unlikely in the short term, although there is a long-term possibility.

5. Deactivation effort should be minimal; the building is not contaminated with radiological or energetic materials.

b) Facility Modifications Required for Likely Use

Probably no major building modification would be required. The exterior needs to be painted. Some miror interior painting and some ceiling panel replacement may also be required.

c) Facility Modifications Required for Other Uses

Unknown.

d) Changes to Safety Envelope

The facility use suggested above should be covered under standard industrial hazard category. Any new work conducted in Building 92 may require that a safety assessment be performed to identify any new hazards involved in the process.

e) Cleanup Criteria for Each Future Use Scenario

Building 92 is not contaminated with any radioactive or energetic materials.

f) Disposition of Surplus Equipment

None: Building 92 is vacant. 


\section{BUILDING 93 PHYSICAL CHARACTERIZATION}

\section{1) Current Mission Description}

a) Facility Capabilities

Building 93 is a 2,936- $\mathrm{ft}^{2}$, two story, wooden, modular- constructed building that houses offices used for Standards functions in support of defense programs. It is currently in active use for this purpose.

Building 93 is entirely taken up by offices .

b) Resources Required to Support Operations

Primary Physical Resources:

Electricity

Physical security

Telecommunication devices

Fire protection, sprinklers, fire department

HVAC

Services:

Human Resources

Finance and Accounting

Environmental, Safety, and Health

Maintenance

Custodial

Payroll

Meal

Supply

c) Current Safety Envelope

Building 93 operations are classified as standard industrial hazard.

d) Current Status

1. No formal CAS review has been done. A quick condition assessment was done in July 1992.

2. No formal CAMP review has been done based on the latest Reconfiguration decision. A CAMP report was submitted on April 1, 1992, which focused on ES\&H needs, infrastructure maintenance, and consolidation projects. 
2) Future Facility Use

a) Alternate Future Use Scenarios

1. WFO in the same discipline is unknown under recent May 27, 1993, reconfiguration guidance. Probably none.

2. WFO in a new discipline is unknown under recent May 27, 1993, reconfiguration guidance. Probably none.

3. Commercialization possibilities under a lease agreement:

Building 93 would be useful for any general office space.

4. Commercialization under a sale agreement is unlikely in the short term, although there is a long-term possibility.

5. Deactivation effort should be minimal for the building, as it is not contaminated with either radiological or energetic materials.

b) Facility Modifications Required for Likely Use

Probably no major building modification would be required. Exterior painting and some interior painting may be required.

c) Facility Modifications Required for Other Uses

Unknown.

d) Changes to Safety Envelope

The facility use suggested above should be covered under standard industrial hazard category. Any new work conducted in Building 93 may require that a safety assessment be performed to identify any new hazards involved in the process.

e) Cleanup Criteria for Each Future Use Scenario

Building 93 is not contaminated with any radioactive or energetic materials.

f) Disposition of Surplus Equipment

The cost for disposition of equipment would be minimal since it is primarily office furniture. 


\section{BUILDING 99 PHYSICAL CHARACTERIZATION}

1) Current Mission Description

a) Facility Capabilities

Building 99 is an $11,412-\mathrm{ft}^{2}$ building that is the security operations facility. It serves as the central location for the security program. The primary communications center (alarm system), radio console, badge reader, and lock shop are housed on the first floor. The second floor holds offices for security management. The third floor houses the emergency operations center for the site. Building 99 is hardened to meet DOE standards.

b) Resources Required to Support Operations

Primary Physical Resources:

Electricity

Potable water

Sanitary drainage

Physical security

Telecommunication devices

Fire protection, sprinklers, fire department

HVAC

Services:

Human Resources

Environmental, Safety, and Health

Maintenance

Custodial

Supply

c) Current Safety Envelope

Building 99 operations are classified as standard industrial hazard.

d) Current Status

1. No formal CAS review has been done.

2. No formal CAMP review has been done based on the latest Reconfiguration decision. 
2) Future Facility Use

a) Alternate Future Use Scenarios

1. WFO in the same discipline is likely under recent May 27, 1993, reconfiguration guidance.

2. WFO in a new discipline is unknown under recent May 27, 1993, reconfiguration guidance. Probably none.

3. Commercialization possibilities under a lease agreement: None.

4. Commercialization under a sale agreement is unlikely in the short term, although there is a long-term possibility.

5. Deactivation effort should be minimal for the building, as it is not contaminated with either radiological or energetic materials.

b) Facility Modifications Required for Likely Use

Probably no major building modification would be required for this use. The basic changes required would involve equipment.

c) Facility Modifications Required for Other Uses

Unknown.

d) Changes to Safety Envelope

The facility use suggested above should be covered under standard industrial hazard category. Any new work conducted in Building 99 may require that a safety assessment be performed to identify any new hazards involved in the process.

e) Cleanup Criteria for Each Future Use Scenario

Building 99 is not contaminated with any radioactive or energetic materials.

f) Disposition of Surplus Equipment

None. 


\section{BUILDING 100 PHYSICAL CHARACTERIZATION}

1) Current Mission Description

a) Facility Capabilities

Building 100 is a $6,292-\mathrm{ft}^{2}$ building that is used to house the protective force training section, weapons storage, physical fitness assessment area change rooms, interactive video training room, and administrative offices.

b) Resources Required to Support Operations

Primary Physical Resources:

Electricity

Potable water

Sanitary drainage

Physical security

Telecommunication devices

Fire protection, sprinklers, fire department

HVAC and emergency generator

Services:

Human Resources

Environmental, Safety, and Health

Maintenance

Custodial

Supply

c) Current Safety Envelope

Building 100 operations are classified as standard industrial hazard.

d) Current Status

1. No formal CAS review has been done.

2. No formal CAMP review has been done based on the latest Reconfiguration decision. 
a) Alternate Future Use Scenarios

1. WFO in the same discipline is possible under recent May 27, 1993, reconfiguration guidance.

2. WFO in a new discipline is unknown under recent May 27, 1993, reconfiguration guidance. Probably none.

3. Commercialization possibilities under a lease agreement: None.

4. Commercialization under a sale agreement is unlikely in the short term, although there is a long-term possibility.

5. Deactivation effort should be minimal for the building, as it is not contaminated with either radiological or energetic materials.

b) Facility Modifications Required for Likely Use

Probably no major building modification would be required for this use. The basic changes required would involve equipment.

c) Facility Modifications Required for Other Uses

Unknown.

d) Changes to Safety Envelope

The facility use suggested above should be covered under standard industrial hazard category, unless hazardous materials are involved. Any new work conducted in Building 100 may require that a safety assessment be performed to identify any new hazards involved in the process.

e) Cleanup Criteria for Each Future Use Scenario

Building 100 is not contaminated with any radioactive or energetic materials.

f) Disposition of Surplus Equipment

None. 


\section{BUILDING 101 PHYSICAL CHARACTERIZATION}

1) Current Mission Description

a) Facility Capabilities

Building 101 is an $1815-\mathrm{ft}^{2}$ modular building that is used for offices and storage. It is currently in active use for this purpose.

b) Resources Required to Support Operations

Primary Physical Resources:

Electricity

Potable water

Sanitary drainage

Physical security

Telecommunication devices

Fire protection, sprinklers, fire department

HVAC

Services:

Human Resources

Finance and Accounting

Environmental, Safety, and Health

Maintenance

Custodial

Payroll

Meal

Supply

c) Current Safety Envelope

Building 101 operations are classified as standard industrial hazard.

d) Current Status

1. No formal CAS review has been done. A quick condition assessment was done in July 1992.

2. No formal CAMP review has been done based on the latest Reconfiguration decision. A CAMP report was submitted on April 1, 1992, which focused on ES\&H needs, infrastructure maintenance, and consolidation projects. 
2) Future Facility Use

a) Alternate Future Use Scenarios

1. WFO in the same discipline is possible under recent May 27, 1993, reconfiguration guidance. The building could continue to provide office and storage space.

2. WFO in a new discipline is unknown under recent May 27, 1993, reconfiguration guidance. Probably none.

3. Commercialization under a lease agreement is unlikely.

4. Commercialization under a sale agreement is unlikely.

5. Deactivation effort should be minimal for the building, as it is not contaminated with either radiological or energetic materials.

b) Facility Modifications Required for Likely Use

Probably no major building modification would be required for this use.

c) Facility Modifications Required for Other Uses

Unknown.

d) Changes to Safety Envelope

The facility use suggested above should be classified as standard industrial hazard.

e) Cleanup Criteria for Each Future Use Scenario

Building 101 is not contaminated with any radioactive or energetic materials.

f) Disposition of Surplus Equipment

None. 


\section{BUILDING 102 PHYSICAL CHARACTERIZATION}

\section{1) Current Mission Description}

a) Facility Capabilities

Building 102 is a $10,982-\mathrm{ft}^{2}$ office building that is used to support the D\&D operations. It was built in 1987.

b) Resources Required to Support Operations

Primary Physical Resources:

Electricity

Physical security

Fire protection, sprinklers, fire department

Potable water

Sanitary drains

HVAC

Services:

Human Resources

Finance and Accounting

Environmental, Safety, and Health

Maintenance

Custodial

Payroll

Meal

Supply

c) Current Safety Envelope

Building 102 operations are classified as standard industrial hazard.

d) Current Status

1. No formal CAS review has been done. A quick condition assessment was done in July 1992.

2. No formal CAMP review has been done based on the latest Reconfiguration decision. A CAMP report was submitted on April 1, 1992, which focused on ES\&H needs, infrastructure maintenance, and consolidation projects. 
2) Future Facility Use

a) Alternate Future Use Scenarios

1. WFO in the same discipline is likely under recent May 27, 1993, reconfiguration guidance.

2. WFO in a new discipline is unknown under recent May 27, 1993, reconfiguration guidance. Probably none.

3. Commercialization possibilities under a lease agreement are unknown under recent May 27, 1993, reconfiguration guidance. Probably none.

4. Commercialization possibilities under a sale agreement are unkno:- a under recent May 27, 1993, reconfiguration guidance. Probably none.

5. Deactivation effort should be minimal for the building, as it is not contaminated with either radiological or energetic materials.

There are no near future plans to deactivate this building, since it supports the D\&D program.

b) Facility Modifications Required for Likely Use

None. This building is currently supporting the D\&D program. Future use of the building would likely be the same.

c) Facility Modifications Required for Other Uses

None. Additional space in the building could be used to support other programs or commercial ventures.

d) Changes to Safety Envelope

Not applicable.

e) Cleanup Criteria for Each Future Use Scenario

Not applicable.

f) Disposition of Surplus Equipment

Not applicable. 


\section{SECTION 2: STORAGE BUILDINGS}

A. Planning Basis: The storage buildings are a functional unit consisting of all facilities at Mound predominantly used for storage. Several storage magazines were added to the Mound's capacity during the 1980's. A few more are planned and already funded through the ES\&H program. No future storage capacity is planned at this time.

Because of the current reduction in budget and workload, an effort is under way at Mound to consolidate facilities; that is, to shut down as much space as possible to the appropriate level of standby condition. Although a draft plan listing possible facilities and time frame of execution has been prepared for this effort, it is premature to detail its impact on this building functional unit.

1. Present Mission: The present mission of this functional unit is to provide facilities to meet the storage requirements of Mound. The various types of storage and their associated buildings identified by their respective building number or letter follows. Further identification is provided in paragraph A.2.

Production, development, and bonded storage (eight buildings): GW, 16, 17, 22, 66, 74, 89, and 106.

Magazines for staging and storing explosives (16 buildings): 5 , $6,7,8,10,11,20,52,53,54,64,80,81,82,83$, and 84 .

General warehousing and storage (four buildings): C, 19, 61, and 71 .

Radioactive materials or contaminated storage (five buildings): $21,23,31,68$, and 72 .

The total floor space for these 36 buildings is approximately 115,000 $\mathrm{ft}^{2}$. The expected duration of this mission extends throughout the entire planning period, with new capabilities required for specialized magazine storage and for the storage of system test items and their shipping containers.

2. Material Condition and Expected Useful Life: The material condition of the capital assets in this functional unit is generally good. With some upgrade replacement of roofs and equipment, the buildings are expected to retain their remaining projected useful life throughout the entire planning period. 
STORAGE BUILDINGS

\begin{tabular}{|c|c|c|c|c|c|}
\hline$\underline{B L D G}$ & DESCRIPTION & CONDITION & $\begin{array}{c}\text { SQUARE } \\
\text { FOOTAGE } \\
(\mathrm{X} 1000) \\
\end{array}$ & $\underline{A G E}$ (Yrs.) & $\begin{array}{l}\text { REMAINING } \\
\text { PROJECTED } \\
\text { USEFUL LIFE } \\
\end{array}$ \\
\hline C & Records Storage & Fair & 13.4 & 45 & 15 \\
\hline GW & Bonded Stores & Fair & 9.8 & 25 & 25 \\
\hline $\mathrm{PH}$ & Power House Storage & Adequate & 15.1 & 45 & 15 \\
\hline SST & Salt Storage & Adequate & .6 & 20 & 40 \\
\hline 5 & Magazine & Fair & 0.3 & 45 & 25 \\
\hline 6 & Magazine & Adequate & .09 & 45 & 15 \\
\hline 7 & Magazine & Fair & 0.4 & 37 & 23 \\
\hline 8 & Magazine & & .07 & & \\
\hline 10 & Magazine & Adequate & .07 & 7 & 53 \\
\hline 11 & Magazine & Fair & 0.4 & 37 & 23 \\
\hline 16 & Storage & Inadequate & 0.5 & 32 & 18 \\
\hline 17 & Warehouse & Fair & 1.1 & 32 & 18 \\
\hline 19 & Salvage and Sales & Good & 4.5 & 30 & 20 \\
\hline 20 & Magazine & Poor & 0.3 & 30 & 30 \\
\hline 21 & Raw Material Storage & Poor & 4.1 & 27 & 13 \\
\hline 22 & Warehouse & Good & 9.1 & 28 & 22 \\
\hline 23 & Waste Mat'l Staging & Fair & 3.4 & 27 & 13 \\
\hline 31 & Contaminated Waste Stor & Fair & 8.7 & 27 & 13 \\
\hline 52 & Magazine & Adequate & .08 & 7 & 53 \\
\hline 53 & Magazine & Adequate & .2 & 7 & 53 \\
\hline 54 & Magazine & Poor & 0.3 & 23 & 17 \\
\hline 61 & Warehouse & Good & 45.5 & 13 & 27 \\
\hline 64 & Magazine & Excellent & .07 & 20 & 40 \\
\hline 66 & Warehouse Support & Excellent & 0.6 & 14(Wood Mod) & 21 \\
\hline 68 & D\&D Staging Area & Good & 2.0 & 14 & 26 \\
\hline 71 & Flammable Liq. Stor. & Good & 0.8 & 10 & 30 \\
\hline 72 & Hazardous Waste Stor. & Poor & 2.4 & 10 & 20 \\
\hline 73 & Gas Cylinder Storage & Good & 2.2 & 10 & 50 \\
\hline 74 & Storage & Fair & 0.4 & 11 & 19 \\
\hline 80 & Magazine & Excellent & 0.3 & 7 & 53 \\
\hline 81 & Magazine & Excellent & 0.3 & 7 & 53 \\
\hline 82 & Magazine & Excellent & 0.3 & 7 & 53 \\
\hline 83 & Magazine & Excellent & 0.3 & 7 & 53 \\
\hline 84 & Magazine & Excellent & 0.3 & 7 & 53 \\
\hline 89 & Detonator Storage & Good & 4.8 & 8 & 31 \\
\hline 106 & Production Storage & Excellent & .2 & 9 & 51 \\
\hline 110 & Fuel Storage & $\cdots$ & $\cdots$ & -- & -- \\
\hline 120 & Health Physics Storage & Excellent & 0.0350 & -.. & -- \\
\hline
\end{tabular}


3. Key Activities and Upgrades: Key activities essential to maintain the acceptable condition of this functional unit include the upgrade of roofs, heating, ventilation and cooling systems, and mechanical and control systems as they reach the end of their normal life expectancy. Also, a new Hazardous Waste Storage Facility is planned for FY 1995 to meet RCRA and Ohio EPA requirements.

4. ES\&H and S\&S Upgrades Required: None

5. Decommissioning and Decontamination Activities: Standby and Decontamination and Decommissioning (D\&D) activities for this functional unit include:

Building $C$ will continue to be used as general storage until such time as it is demolished for other construction on the same building site or renovated to house a new mission assignment.

Building 21 is expected to remain on standby for future decontamination and decommissioning.

Several other facilities within this functional unit such as Buildings $16,17,23$, and 31 are being analyzed for their longrange need. This analysis will be completed prior to the next CAMP submission.

B. Description of Events and Projects:

1. In FY 1995, an Environmental Restoration/Waste Management (EM) funded project, Hazardous Storage Facility, is planned. This $21,000-\mathrm{ft}^{2}$ facility is required to properly store hazardous and reactive wastes to meet RCRA and Ohio EPA requirements. (\$5.4M - FY 1995 EM Line Item)

2. In FY 1996, the HVAC systems will need to be replaced in Buildings GW, 19, 22, 61, 66, and 89. (\$1.5M - FY 1996 FCAP Line Item)

3. In FY 1999, sanitary sewer lines will need to be replaced in Building GW. (\$1.OM - FY 1999 FCAP Line Item)

4. In FY 2001-2005, roofs will need to be replaced on various Storage Buildings. A study will be performed in 1999 to deiermine which roofs are the most deteriorated. ( $\$ 200 \mathrm{~K}$ - FY 2001 GPP, $\$ 200 \mathrm{~K}$ - FY 2003 GPP, \$200K - FY 2005 GPP) 
5. In FY 2003, the refrigeration system will need to be replaced in Building 80. ( $\$ 200 \mathrm{~K}$ - FY 2003 FCAP Line Item)

6. In FY 2005-2010, domestic water lines will need to be replaced in Building GW. (\$200K - FY 2005 FCAP Line Item)

C. Functional Unit Maintenance Activities:

Current Funding Status: Many of the storage buildings are in need of repairs of a more substantial nature than can be accomplished with inhouse personnel. Funds for these types of activities (that is, new roofs, HVAC equipment, major concrete repairs) have been limited to less than 30 $40 \%$ of requests. 


\section{BULLING PHYSICAL CHARACTERIZATION}

1) Current Mission Description

a) Facility Capabilities

C Building is a $13,403-\mathrm{ft}^{2}$ building that is used for radiological records storage and material storage for AES projects. Offices for supervisors, procedure writers, and maintenance planners are also in C Building.

b) Resources Required to Support Operations

Primary Physical Resources:

Electricity

Potable water

Sanitary drainage

Physical security

Telecommunication devices

Fire protection, sprinklers, fire department

HVAC (not reliable)

Services:

Human Resources

Environmental, Safety, and Health

Maintenance

Custodial

Supply

c) Current Safety Envelope

C Building operations are classified as standard industrial hazard.

d) Current Status

1. No formal CAS review has been done.

2. No formal CAMP review has been done based on the latest Reconfiguration decision.

2) Future Facility Use

a) Alternate Future Use Scenarios

1. WFO in the same discipline is possible under recent May 27, 1993, reconfiguration guidance. Probably none. 
2. WFO in a new discipline is unknown under recent May 27, 1993, reconfiguration guidance. Probably none.

3. Commercialization possibilities under a lease agreement: None.

4. Commercialization under a sale agreement is unlikely in the short term, although there is a long-term possibility.

5. Deactivation effort should be minimal for the building, as it is not contaminated with either radiological or energetic materials.

b) Facility Modifications Required for Likely Use

The basic changes required would involve equipment. Major HVAC rework is necessary, as existing equipment is nonfunctional or very unreliable.

c) Facility Modifications Required for Other Uses

Unknown.

d) Changes to Safety Envelope

The facility use suggested above should be covered under standard industrial hazard category unless hazardous materials are involved.

Any new work conducted in $\mathrm{C}$ Building may require that a safety assessment be performed to identify any new hazards involved in the process.

e) Cleanup Criteria for Each Future Use Scenario

$\mathrm{C}$ Building is not contaminated with any radioactive or energetic materials.

f) Disposition of Surplus Equipment

None. 


\section{GW BUILDING PHYSICAL CHARACTERIZATION}

\section{1) Current Mission Description}

a) Facility Capabilities

GW Building is a $9782-\mathrm{ft}^{2}$ building used for bonded stores and receiving inspection for the weapons program. Two-thirds of the second floor is office space; one-third is bonded stores having a small amount of chemicals. The first floor is the receiving inspection area where incoming material is inspected using high precision instruments.

b) Resources Required to Support Operations

Primary Physical Resources:

Electricity

Potable water

Sanitary drainage

Physical security

Telecommunication devices

Fire protection, sprinklers, fire department

HVAC (Precise temperature and humidity control on first floor)

Compressed air

Services:

Human Resources

Finance and Accounting

Environmental, Safety, and Health

Maintenance

Custodial

Payroll

Meal

Supply

c) Current Safety Envelope

GW Building operations are classified as standard industrial hazard.

d) Current Status

1. No formal CAS review has been done. A quick condition assessment was done in July 1992.

2. No formal CAMP review has been done based on the latest Reconfiguration decision. A CAMP report was submitted on April 1, 1992, which focused on ES\&H needs, infrastructure maintenance, and consolidation projects. 
3. GW Building supports all WR and reimbursable material requirements at Mound.

2) Future Facility Use

a) Alternate Future Use Scenarios

1. WFO in the same discipline is unknown under recent May 27, 1993, reconfiguration guidance. Probably none.

2. WFO in a new discipline is unknown under recent May 27, 1993, reconfiguration guidance. Probably none.

3. Commercialization under a lease agreement possibility: The inspection facility in GW Building would be useful for any application requiring precise physical inspection of materials.

4. Commercialization under a sale agreement is unlikely in the short term, although there is a long-term possibility.

5. Deactivation effort should be minimal; the building is not contaminated with either radiological or energetic materials.

(b) Facility Modifications Required for Likely Use

Probably no major building modification would be required for this use. The basic changes required would involve equipment.

c) Facility Modifications Required for Other Uses

Unknown.

d) Changes to Safety Envelope

The facility use suggested above should be covered under standard industrial hazard category unless hazardous materials are involved. Any new work conducted may require that a safety assessment be performed to identify any new hazards involved in the process.

e) Cleanup Criteria for Each Future Use Scenario

$\mathrm{GW}$ is not contaminated with radioactive or energetic materials.

f) Disposition of Surplus Equipment

Surplus equipment in GW Building may be readily disposed as required. 


\section{PH BUILDING PHYSICAL CHARACTERIZATION}

1) Current Mission Description

a) Facility Capabilities

PH Building is a $646-\mathrm{ft}^{2}$ building that is used for parts storage. It is currently in active use for this purpose.

b) Resources Required to Support Operations

Primary Physical Resources:

Electricity

Physical security

Fire protection, fire department

Services:

Human Resources

Finance and Accounting

Environmental, Safety, and Health

Maintenance

Custodial

Payroll

Meal

Supply

c) Current Safety Envelope

PH Building operations are classified as standard industrial hazard.

d) Current Status

1. No formal CAS review has been done. A quick condition assessment was done in July 1992.

2. No formal CAMP review has been done based on the latest Reconfiguration decision. A CAMP report was submitted on April 1, 1992, which focused on ES\&H needs, infrastructure maintenance, and consolidation projects. 
a) Alternate Future Use Scenarios

1. WFO in the same discipline is probable under recent May 27, 1993 , reconfiguration guidance. The building could continue as a storage facility.

2. WFO in a new discipline is unknown under recent May 27, 1993, reconfiguration guidance. Probably none.

3. Commercialization possibilities under a lease agreement: The building could continue as a storage facility.

4. Commercialization under a sale agreement is unlikely in the short term, although there is a long-term possibility.

5. Deactivation effort should be minimal for this building, as it is not known to be contaminated with any radioactive or energetic materials. However, it was formerly used for the pumping of \#6 fuel oil, and it is possible that traces of oil remain.

b) Facility Modifications Required for Likely Use

No major building modification would be required for this use.

c) Facility Modifications Required for Other Uses

Unknown.

d) Changes to Safety Envelope

The facility use suggested above should be covered under standard industrial hazard category. Any new work conducted in PH Building may require that a safety assessment be performed to identify any new hazards involved in the process.

e) Cleanup Criteria for Each uture Use Scenario

PH Building is not contaminated with any radioactive or energetic materials. The building should be surveyed for chemical contamination before unrestricted commercial use.

f) Disposition of Surplus Equipment

None. 


\section{SST BULDING PHYSICAL CHARACTERIZATION}

1) Current Mission Description

a) Facility Capabilities

SST Building is a 590- $\mathrm{ft}^{2}$ building that stores salt used for snow control on plant roads and sidewalks.

b) Resources Required to Support Operations

Primary Physical Resources:

Electricity

Physical security

Services:

Human Resources

Finance and Accounting

Environmental, Safety, and Health

Maintenance

Custodial

Payroll

Meal

Supply

c) Current Safety Envelope

SST Building operations are classified as standard industrial hazard.

d) Current Status

1. No formal CAS review has been done. A quick condition assessment was done in July 1992.

2. No formal CAMP review has been done based on the latest Reconfiguration decision. A CAMP report was submitted on April 1, 1992, which focused on ES\&H needs, infrastructure maintenance, and consolidation projects. 


\section{2) Future Facility Use}

\section{a) Alternate Future Use Scenarios}

1. WFO in the same discipline is unknown under recent May 27, 1993, reconfiguration guidance. Probably none.

2. WFO in a new discipline is unknown under recent May 27, 1993, reconfiguration guidance. Probably none.

3. Commercialization under a lease agreement possibility: SST Building would be useful for storing salt for snow control on plant roads and sidewalks.

4. Commercialization under a sale agreement is unlikely in the short term, although there is a long-term possibility.

5. Deactivation effort should be minimal for the building, as it is not contaminated with either radiological or energetic materials.

b) Facility Modifications Required for Likely Use

Probably no major building modification would be required for this use. The basic changes required would involve equipment.

c) Facility Modifications Required for Other Uses

Unknown.

d) Changes to Safety Envelope

The facility use suggested above should be covered under standard industrial hazard category unless hazardous materials are involved. Any new work conducted in SST Building may require that a safety assessment be performed to identify any new hazards involved in the process.

e) Cleanup Criteria for Each Future Use Scenario

SST Building is not contaminated with any radioactive or energetic materials.

f) Disposition of Surplus Equipment

Not applicable. 


\section{BUILDING 5 PHYSICAL CHARACTERIZATION}

1) Current Mission Description

a) Facility Capabilities

Building 5 is a $314-\mathrm{ft}^{2}$ magazine that is used for the storage of energetic materials. It is currently in active use for this purpose.

b) $\quad$ Resources Required to Support Operations

Primary Physical Resources:

Physical security: classified locks

Services:

Human Resources

Finance and Accounting

Environmental, Safety, and Health

Maintenance

Custodial

Payroll

Meal

Supply

c) Current Safety Envelope

Building 5 operations are classified as standard industrial hazard.

d) Current Status

1. No formal CAS review has been done. A quick condition assessment was done in July 1992.

2. No formal CAMP review has been done based on the latest Reconfiguration decision. A CAMF' report was submitted on April 1, 1992, which focused on ES\&H needs, infrastructure maintenance, and consolidation projects. 
2) Future Facility Use

a) Alternative Future Use Scenarios

1. WFO in the same discipline is unknown under the recent May 27, 1993, reconfiguration guidance. Probably none.

2. WFO in a new discipline is unknown under the recent May 27, 1993, reconfiguration guidance. Probably none.

3. Commercialization possibilities under a lease agreement: Building 5 would be useful for any application requiring storage of energetic materials or general storage.

4. Commercialization under a sale agreement is unlikely in the short term, although there is a long-term possibility.

5. Deactivation effort should be moderate for the building, as it is contaminated with energetic materials. There is no radiological contamination associated with this building.

b) Facility Modifications Required for Likely Use

Probably no building modifications would be required for this use.

c) Facility Modifications Required for Other Uses

Unknown.

d) Changes to Safety Envelope

The facility use suggested above should be covered under standard industrial hazard category. Any new work conducted in Building 5 may require that a safety assessment be performed to identify any new hazards involved in the process.

e) Cleanup Criteria for Each Future Use Scenario

Building 5 is contaminated with energetic materials, so some deactivation efforts will be required if the building is not to be used for storage of energetic materials.

f) Disposition of Surplus Equipment

There is no surplus equipment in Building 5. 


\section{BUILDING 6 PHYSICAL CHARACTERIZATION}

1) Current Mission Description

a) Facility Capabilities

Building 6 is a $90-\mathrm{ft}^{2}$ building that is used for ammunition storage for the security department. It is currently in active use for this purpose.

b) Resources Required to Support Operations

Primary Physical Resources:

Physical security: locks

Services:

Human Resources

Finance and Accounting

Environmental, Safety, and Health

Maintenance

Custodial

Payroll

Meal

Supply

c) Current Safety Envelope

Building 6 operations are classified as standard industrial hazard.

d) Current Status

1. No formai CAS review has been done. A quick condition assessment was done in July 1992.

2. No formal CAMP review has been done based on the latest Reconfiguration decision. A CAMP report was submitted on April 1, 1992, which focused on ES\&H needs, infrastructure maintenance, and consolidation projects.

2) Future Facility Use

a) Alternate Future Use Scenarios

1. WFO in the same discipline is unknown under recent May 27, 1993, reconfiguration guidance. Probably none. 
2. WFO in a new discipline is unknown under recent May 27, 1993, reconfiguration guidance. Probably none.

3. Commercialization possibilities under a lease agreement: Building 6 would be useful for any application requiring storage for energetic materials or general materials.

4. Commercialization under a sale agreement is unlikely in the short term, although there is a long-term possibility.

5. Deactivation effort should be moderate for the building as it is contaminated with energetic materials but no radiological materials are present.

b) Facility Modifications Required for Likely Use

Probably no major building modification would be required for this use.

c) Facility Modifications Required for Other Uses

Unknown.

d) Changes to Safety En

The facility use suggested above should be covered under standard industrial hazard category. Any new work conducted in Building 6 may require that a safety assessment be performed to identify any new hazards involved in the process.

e) Cleanup Criteria for Each Future Use Scenario

Building 6 is contaminated with energetic materials, so some deactivation will be necessary if the magazine is to be used for a different purpose.

f) Disposition of Surplus Equipmenit

There is no surplus equipment in Building 6 . 


\section{BUILDING 7 PHYSICAL CHARACTERIZATION}

1) Current Mission Description

a) Facility Capabilities

Building 7 is a $387-\mathrm{ft}^{2}$ magazine that is used for inert storage. It is currently in active use for this purpose.

b) Resources Required to Support Operations

Primary Physical Resources:

Physical security: locks

Electricity

Argon gas lines (never activated)

Services:

Human Resources

Finance and Accounting

Environmental, Safety, and Health

Maintenance

Custodial

Payroll

Meal

Supply

c) Current Safety Envelope

Building 7 operations are classified as standard industrial hazard.

d) Current Status

1. No formal CAS review has been done. A quick condition assessment was done in July 1992.

2. No formal CAMP review has been done based on the latest Reconfiguration decision. A CAMP report was submitted on April 1, 1992, which focused on ES\&H needs, infrastructure maintenance, and consolidation projects.

2) Future Facility Use

a) Alternate Future Use Scenarios

1. WFO in the same discipline is unknown under recent May 27, 1993, reconfiguration guidance. Probably none. 
2. WFO in a new discipline is unknown under recent May 27, 1993, reconfiguration guidance. Probably none.

3. Commercialization possibilities under a lease agreement: Building 7 would be useful for any application requiring storage for energetic materials or general materials.

4. Commercialization under a sale agreement is unlikely in the short term, although there is a long-term possibility.

5. Deactivation effort should be minimal for the building since it is not contaminated with either radiological or energetic materials.

b) Facility Modifications Required for Likely Use

Probably no major building modification would be required for this use.

c) Facility Modifications Required for Other Uses

Unknown.

d) Changes to Safety Envelope

The facility use suggested above should be covered under standard industrial hazard category.

Any new work conducted in Building 7 may require that a safety assessment be performed to identify any new hazards involved in the process.

e) Cleanup Criteria for Each Future Use Scenario

Building 7 is not contaminated with radiological or energetic materials.

f) Disposition of Surplus Equipment

There is no surplus equipment in Building 7. 


\section{BUILDING 8 PHYSICAL CHARACTERIZATION}

1) Current Mission Description

a) Facility Capabilities

Building 8 is a $66-\mathrm{ft}^{2}$ building that is used for ammunition storage for the security department. It is currently in active use for this purpose.

b) Resources Required to Support Operations

Primary Physical Resources:

Physical security: locks

Services:

Human Resources

Finance and Accounting

Environmental, Safety, and Health

Maintenance

Custodial

Payroll.

Meal

Supply

c) Current Safety Envelope

Building 8 operations are classified as standard industrial hazard.

d) Current Status

1. No formal CAS review has been done. A quick condition assessment was done in July 1992.

2. No formal CAMP review has been done based on the latest Reconfiguration decision. A CAMP report was submitted on April 1, 1992, which focused on ES\&H needs, infrastructure maintenance, and consolidation projects.

2) Future Facility Use

a) Alternate Future Use Scenarios

1. WFO in the same discipline is unknown under recent May 27, 1993, reconfiguration guidance. Probably none. 
2. WFO in a new discipline is unknown under recent May 27, 1993, reconfiguration guidance. Probably none.

3. Commercialization possibilities under a lease agreement: Building 8 would be useful for any application requiring storage for energetic materials or general materials.

4. Commercialization under a sale agreement is unlikely in the short term, although there is a long-term possibility.

5. Deactivation effort should be moderate for the building as it is contaminated with energetic materials but no radiological materials are present.

b) Facility Modifications Required for Likely Use

Probably no major building modification would be required for this use.

c) Facility Modifications Required for Other Uses

Unknown.

d) Changes to Safety Envelope

The facility use suggested above should be covered under standard industrial hazard category.

Any new work conducted in Building 8 may require that a safety assessment be performed to identify any new hazards involved in the process.

e) Cleanup Criteria for Each Future Use Scenario

Building 8 is contaminated with energetic materials so some deactivation will be necessary if the magazine is to be used for a different purpose.

f) Disposition of Surplus Equipment

There is no surplus equipment in Building 8. 


\section{BUILDING 1.0 PHYSICAL CHARACTERIZATION}

1) Current Mission Desicription

a) Facility Capaobilities

Building 10 is a $66-\mathrm{ft}^{2}$ magazine that is used for the storage of energetic materials. It is currently in active use for this purpose.

b) Resources Required to Support Operations

Primary Physical Resources:

Physical security: classified locks

Services:

Human Resources

Finance and Accounting

Environmental, Safety, and Health

Maintenance

Custodial

Payroll

Meal

Supply

c) Current Safety Envelope

Building 10 operations are classified as standard industrial hazard.

d) Current Status

1. No formal CAS review has been done. A quick condition assessment was done in July 1992.

2. No formal CAMP review has been done based on the latest Reconfiguration decision. A CAMP report was submitted on April 1, 1992, which focused on ES\&H needs, infrastructure maintenance, and consolidation projects. 
2) Future Facility Use

a) Alternate Future Use Scenarios

1. WFO in the same discipline is unknown under recent May 27, 1993, reconfiguration guidance. Probably none.

2. WFO in a new discipline is unknown under recent May 27, 1993, reconfiguration guidance. Probably none.

3. Commercialization possibilities under a lease agreement: Building 10 would be useful for any application requiring storage of energetic materials or general storage.

4. Commercialization under a sale agreement is unlikely in the short term, although there is a long-term possibility.

5. Deactivation effort should be moderate; the building is contaminated with energetic materials. There is no radiological contamination associated with this building.

b) Facility Modifications Required for Likely Use

Probably no major building modification would be required.

c) Facility Modifications Required for Other Uses

Unknown.

d) Changes to Safety Envelope

The facility use suggested above should be covered under standard industrial hazard category. Any new work conducted in Building 10 may require that a safety assessment be performed to identify any new hazards involved in the process.

e) Cleanup Criteria for Each Future Use Scenario

Building 10 is contaminated with energetic materials, so some deactivation efforts will be required if the building is not to be used for storage of energetic materials.

f) Disposition of Surplus Equipment

There is no surplus equipment in Building 10. 


\section{BUILDING 11 PHYSICAL CHARACTERIZATION}

1) Current Mission Description

a) Facility Capabilities

Building 11 is a $372-\mathrm{ft}^{2}$ magazine that is used for long-term storage for I Building explosives. It is currently inactive and nothing is stored there.

b) Resources Required to Support Operations

Primary Physical Resources:

Electricity

Steam heat

Services:

Human Resources

Finance and Accounting

Environmental, Safety, and Health

Maintenance

Custodial

Meal

Supply

c) Current Safety Envelope

Building 11 operations are classified as standard industrial hazard.

d) Current Status

1. No formal CAS review has been done. A quick condition assessment was done in July 1992.

2. No formal CAMP review has been done based on the latest Reconfiguration decision. A CAMP report was submitted on April 1, 1992, which focused on ES\&H needs, infrastructure maintenance, and consolidation projects. 
2) Future Facility Use

a) Alternate Future Use Scenarios

1. WFO in the same discipline is unknown under recent May 27, 1993 , reconfiguration guidance. Probably none.

2. WFO in a new discipline is unknown under recent May 27, 1993, reconfiguration guidance. Probably none.

3. Commercialization possibilities under a lease agreement: Building 11 would be useful for any application requiring explosives storage or any general storage needs.

4. Commercialization under a sale agreement is unlikely in the short term, although there is a long-term possibility.

5. Deactivation effort should be minimal for the building, as it is not contaminated with either radiological or energetic materials.

b) Facility Modifications Required for Likely Use

Probably no major building modification would be required for this use.

c) Facility Modifications Required for Other Uses

Unknown.

d) Changes to Safety Envelope

The facility use suggested above should be covered under standard industrial hazard category. Any new work conducted in Building 11 may require that a safety assessment be performed to identify any new hazards involved in the process.

e) Cleanup Criteria for Each Future Use Scenario

Building 11 is not contaminated with any radioactive or energetic materials.

f) Disposition of Surplus Equipment

There is no surplus equipment in Building 11. 


\section{BUILDING 16 PHYSICAL CHARACTERIZATION}

1) Current Mission Description

a) Facility Capabilities

Building 16 is a $480-\mathrm{ft}^{2}$ building used for production storage for I Building.

b) Resources Required to Support Operations

Primary Physical Resources:

Electricity

Sanitary drainage

Physical security

Fire protection, sprinklers, fire department

Heat

Services:

Human Resources

Finance and Accouncing

Environmental, Safety, and Health

Maintenance

Custodial

Payroll

Meal

Supply

c) Current Safety Envelope

Building 16 operations are classified as standard industrial hazard.

d) Current Status

1. No formal CAS review has been done. A quick condition assessment was done in July 1992.

2. No formal CAMP review has been done based on the latest Reconfiguration decision. A CAMP report was submitted on April 1, 1992, which focused on ES\&H needs, infrastructure maintenance, and consolidation projects. 
a) Alternate Future Use Scenarios

1. WFO in the same discipline is unknown under recent May 27, 1993, reconfiguration guidance. Probably none.

2. WFO in a new discipline is unknown under recent May 27, 1993, reconfiguration guidance. Probably none.

3. Commercialization under a lease agreement possibility: Building 16 would be useful for storage of items used in the potential commercialization of I Building.

4. Commercialization under a sale agreement is unlikely in the short term, although there is a long-term possibility.

5. Deactivation effort should be minimal for the building, as it is not contaminated with either radiological or energetic materials.

b) Facility Modifications Required for Likely Use

No major building modification would be required for this use.

c) Facility Modifications Required for Other Uses

Unknown.

d) Changes to Safety Envelope

The facility use suggested above should be covered under standard industrial hazard category unless hazardous materials are involved.

Any new work conducted in Building 16 may require that a safety assessment be performed to identify any new hazards involved in the process.

e) Cleanup Criteria for Each Future Use Scenario

Building 16 is not contaminated with any radioactive or energetic materials.

f) Disposition of Surplus Equipment

Not applicable. 


\section{BUILDING 17 PHYSICAL CHARACTERIZATION}

\section{1) Current Mission Description}

a) Facility Capabilities

Building 17 is a $1120-\mathrm{ft}^{2}$ building used for chemical storage for production areas.

b) Resources Required to Support Operations

Primary Physical Resources:

Electricity

Sanitary drainage

Physical security

Telerommunication devices

Fire protection, sprinklers, fire department

Heat

Services:

Human Resources

Finance and Accounting

Environmental, Safety, and Health

Maintenance

Custodial

Payroll

Meal

Supply

c) Current Safety Envelope

Building 17 operations are classified as standard industrial hazard.

d) Current Status

1. No formal CAS review has been done. A quick condition assessment was done in July 1992.

2. No formal CAMP review has been done based on the latest Reconfiguration decision. A CAMP report was submitted on April 1, 1992, which focused on ES\&H needs, infrastructure maintenance, and consolidation projects.

3. Building 17 supplies bonded chemicals for weapon production areas. 


\section{2) Future Facility Use}

a) Alternate Future Use Scenarios

1. WFO in the same discipline is unknown under recent May 27, 1993, recunfiguration guidance. Probably none.

2. WFO in a new discipline is unknown under recent May 27, 1993, reconfiguration guidance. Probably none.

3. Commercialization possibility under a lease agreement: Building 17 would be useful for any application requiring a storage facility.

4. Commercialization under a sale agreement is unlikely in the short term, although there is a long-term possibility

5. Deactivation effort should be minimal for the building as it is not contaminated with either radiological or energetic materials. The stored chemicals will be removed when the weapons program is discontinued in September 1995.

b) Facility Modifications Required for Likely Use

No major building modification would be required for this use.

c) Facility Modifications Required for Other Uses

Unknown.

d) Changes to Safety Envelope

The facility use suggested above should be covered under standard industrial hazard category unless hazardous materials are involved. Any new work conducted in Building 17 may require that a safety assessment be performed to identify any new hazards involved in the process.

e) Cleanup Criteria for Each Future Use Scenario

Building 17 is not contaminated with any radioactive or energetic materials.

i) Disposition of Surplus Equipment

Not applicable. 


\section{BUILDING 19 PHYSICAL CHARACTERIZATION}

1) Current Mission Description

a) Facility Capabilities

Building 19 is a $4480-\mathrm{ft}^{2}$ building used as a warehouse. The warehouse is currently $95 \%$ empty. Also, one office is housed in the building.

b) Resources Required to Support Operations

Primary Physical Resources:

Electricity

Sanitary drainage

Physical security

Telecommunication devices

Fire protection, sprinklers, fice department

HVAC

Services:

Human Resources

Finance and Accounting

Environmental, Safety, and Health

Maintenance

Custodial

Payroll

Meal

Supply

c) Current Safety Envelope

Building 19 operations are classified as standard industrial hazard.

d) Current Status

1. No formal CAS review has been done. A quick condition assessment was done in July 1992.

2. No formal CAMP review has been done based on the latest Reconfiguration decision. A CAMP report was submitted on April 1, 1992, which focused on ES\&H needs, infrastructure maintenance, and consolidation projects. 
2) Future Facility Use

a) Alternate Future Use Scenarios

1. WFO in the same discipline is unknown under recent May 27, 1993, reconfiguration guidance. Probably none.

2. WFO in a new discipline is unknown under recent May 27, 1993, reconfiguration guidance. Probably none.

3. Commercialization possibility under a lease agreement:

Building 19 would be useful for any application requiring a storage facility.

4. Commercialization under a sale agreement is unlikely in the short term, although there is a long-term possibility.

5. Deactivation effort should be minimal for the building, as it is not contaminated with either radiological or energetic materials.

b) Facility Modifications Required for Likely Use

Probably no major building modification would be required for this use.

c) Facility Modifications Required for Other Uses

Unknown.

d) Changes to Safety Envelope

The facility use suggested above should be covered under standard industrial hazard category unless hazardous materials are involved. Any new work conducted in Building 19 may require that a safety assessment be performed to identify any new hazards involved in the process.

e) Cleanup Criteria for Each Future Use Scenario

Building 19 is not contaminated with any radioactive or energetic materials.

f) Disposition of Surplus Equipment

Surplus equipment may be readily disposed as required. 


\section{BUILDING 20 PHYSICAL CHARACTERIZATION}

1) Current Mission Description

a) Facility Capabilities

Building 20 is a $303-\mathrm{ft}^{2}$ magazine that is used for the storage of energetic materials. It is currently in active use for this purpose.

b) Resources Required to Support Operations

Primary Physical Resources:

Physical security:

classified locks

Services:

Human Resources

Finance and Accounting

Environmental, Safety, and Health

Maintenance

Custodial

Payroll

Meal

Supply

c) Current Safety Envelope

Building 20 operations are classified as standard industrial hazard.

d) Current Status

1. No formal CAS review has been done. A quick condition assessment was done in July 1992.

2. No formal CAMP review has been done based on the latest Reconfiguration decision. A CAMP report was submitted on April 1, 1992, which focused on ES\&H needs, infrastructure maintenance, and consolidation projects.

2) Future Facility Use

a) Alternate Future Use Scenarios

1. WFO in the same discipline is unknown under recent May 27, 1993, reconfiguration guidance. Probably none. 
2. WFO in a new discipline is unknown under recent May 27, 1993, reconfiguration guidance. Probably none.

3. Commercialization possibilities under a lease agreement: Building 20 would be useful for any application requiring storage of energetic materials or general storage.

4. Commercialization under a sale agreement is unlikely in the short term. although there is a long-term possibility.

5. Deactivation effort should be moderate for the building, as it is contaminated with energetic materials. There is no radiological contamination associated with this building.

b) Facility Modifications Required for Likely Use

Probably no major building modification would be required for this use.

c) Facility Modifications Required for Other Uses

Unknown.

d) Changes to Safety Envelope

The facility use suggested above should be covered under standard industrial hazard category.

Any new work conducted in Building 20 may require that a safety assessment be performed to identify any new hazards involved in the process.

e) Cleanup Criteria for Each Future Use Scenario

Building 20 is contaminated with energetic materials, so some deactivation efforts will be required if the building is not to be used for storage of energetic materials.

f) Disposition of Surplus Equipment

There is no surplus equipment in Building 20. 


\section{BUILDING 21 PHYSICAL CHARACTERIZATION}

1) Current Mission Description

a) Facility Capabilities

Building 21 is currently scheduled for decontaminating and decommissioning (D\&D).

Building 21 is contaminated with the radiological material, thorium232.

This building was built in 1966 and has $4069 \mathrm{ft}^{2}$ of space. Building 21 was previously used for storage.

b) Resources Required to Support D\&D Operations

Not applicable.

c) Current Safety Envelope

Building 21 operations are classified as standard industrial hazard.

d) Current Status

1. No formal CAS review has been done. A quick condition assessment was done in July 1992.

2. No formal CAMP review has been done based on the latest Reconfiguration decision. A CAMP report was submitted on April 1, 1992, which focused on ES\&H needs, infrastructure maintenance, and consolidation projects.

2) Future Facility Use

None 
This page intentionally blank. 


\section{BUILDING 22 PHYSICAL CHARACTERIZATION}

1) Current Mission Description

a) Facility Capabilities

Building 22 is a $9090-\mathrm{ft}^{2}$ building used for storage and office space. Approximately one-third of the building is used for office space; the other two-thirds for storage. A line-item project is currently in the approval process that would convert the building to an LSA waste storage facility.

b) Resources Required to Support Operations

Primary Physical Resources:

Electricity

Potable water

Sanitary drainage

Physical security

Telecommunication devices

Fire protection, sprinklers, fire department

HVAC

Services:

Human Resources

Finance and Accounting

Environmental, Safety, and Health

Maintenance

Custodial

Payroll

Meal

Supply

c) Current Safety Envelope

Building 22 operations are classified as standard industrial hazard.

d) Current Status

1. No formal CAS review has been done. A quick condition assessment was done in July 1992.

2. No formal CAMP review has been done based on the latest Reconfiguration decision. A CAMP report was submitted on April 1, 1992, which focused on ES\&H needs, infrastructure maintenance, and consolidation projects. 
2) Future Facility Use

a) Alternate Future Use Scenarios

1. WFO in the same discipline is unknown under recent May 27, 1993, reconfiguration guidance. Probably none.

2. WFO in a new discipline is unknown under recent May 27, 1993, reconfiguration guidance. Probably none.

3. Commercialization possibility under a lease agreement:

Building 22 would be useful for any application requiring storage or office space.

4. Commercialization under a sale agreement is unlikely in the short term, although there is a long-term possibility.

5. Deactivation effort should be minimal; the building is not contaminated with either radiological or energetic materials.

b) Facility Modifications Required for Likely Use

Probably no major building modification would be required for this use.

c) Facility Modifications Required for Other Uses

Unknown.

d) Changes to Safety Envelope

The facility uise suggested above should be covered under standard industrial hazard category unless hazardous materials are involved. Any new work conducted in Building 22 may require that a safety assessment be performed to identify any new hazards involved in the process.

e) Cleanup Criteria for Each Future Use Scenario

Building 22 is not contaminated with radioactive or energetic materials.

f) Disposition of Surplus Equipment

Surplus equipment in Building 22 may be readily disposed of, as required. 


\section{BUILDING 23 PHYSICAL CHARACTERIZATION}

1) Current Mission Description

a) Facility Capabilities

Building 23 is a $3422-\mathrm{ft}^{2}$ building used as a warehouse for storing mixed and transuranic mixed waste. Also in the building is a drum scanning station for gamma radiation detection.

b) Resources Required to Support Operations

Primary Physical Resources:

Electricity

Sump for RCRA wastes

Physical security

Telecommunication devices

Fire protection, sprinklers, fire department

HVAC for drum scanning station

Heat for the warehouse

Services:

Human Resources

Finance and Accounting

Environmental, Safety, and Health

Payroll

Meal

Supply

c) Current Safety Envelope

An FSAR for Building 23 is currently scheduled to be completed in early 1995 .

d) Current Status

1. No formal CAS review has been done. A quick condition assessment was done in July 1992.

2. No formal CAMP review has been done based on the latest Reconfiguration decision. A CAMP report was submitted on April 1, 1992, which focused on ES\&H needs, infrastructure maintenance, and consolidation projects.

3. Building 23 currently stores all mixed waste that Mound generates. The facility is EM-funded. 
2) Future Facility Use

a) Alternate Future Use Scenarios

1. WFO in the same discipline is likely under recent May 27, 1993 , reconfiguration guidance.

2. WFO in a new discipline is unknown under recent May 27, 1993, reconfiguration guidance. Probably none.

3. Commercialization under a lease agreement is unlikely in the short term, although there is a long-term possibility.

4. Commercialization under a sale agreement is unlikely in the short term, although there is a long-term possibility.

5. RCRA Part B closure date for final D\&D of Building 23 is the year 2038.

b) Facility Modifications Required for Likely Use

No major building modification would be required for this use.

c) Facility Modifications Required for Other Uses

Unknown.

d) Changes to Safety Envelope

Any new work conducted in Building 23 may require that a safety assessment be performed to identify any new hazards involved in the process.

e) Cleanup Criteria for Each Future Use Scenario

Building 23 is contaminated with radioactive material and will be cleaned up in the D\&D effort.

f) Disposition of Surplus Equipment

Mixed waste drums in Building 23 will be disposed of during the D\&D effort. 


\section{BUILDING 31/31A PHYSICAL CHARACTERIZATION}

\section{1) Current Mission Description}

a) Facility Capabilities

Building 31/31A currently supports the Decommissioning and Decontamination (D\&:D) and Waste Management operations. The building is used for storing transuranic (TRU) wastes and as a staging area for the rnetal LSA boxes. Currently there is no approved disposal site for TR'U waste. The metal LSA boxes are touched up with paint, weighed, and labeled before being shipped to Nevada for burial. Building $31 / 31 \mathrm{~A}$ is an $8740-\mathrm{ft}^{2}$, prefabricated metal building. The original building is 27 years old. The B section is seven years old.

b) Resources Required to Support Operations

Primary Physical Resources:

Electricity

Physical security

Telecommunication device (phone)

Fire protection, sprinklers, fire department

Heating (no air conditioning)

Services:

Human Resources

Finance and Accounting

Environmental, Safety, and Health

Maintenance

Custodial

Payroll

Meal

Supply

c) Current Safety Envelope

Building $31 / 31 \mathrm{~A}$ operations are classified as standard industrial hazard.

d) Current Status

1. No formal CAS review has been done. A quick condition assessment was done in July 1992.

2. No formal CAMP review has been done based on the latest Reconfiguration decision. A CAMP report was submitted on 
April 1, 1992, which focused on ES\&H needs, infrastructure maintenance, and consolidation projects.

2) Future Facility Use

a) Alternate Future Use Scenarios

1. WFO in the same discipline is unknown under recent May 27, 1993, reconfiguration guidance. Probably none.

2. WFO in a new discipline is unknown under recent May 27, 1993, reconfiguration guidance. Probably none.

3. Commercialization possibilities under a lease agreement: Probably none.

4. Commercialization possibilities under a sale agreement: Probably none.

5. There are no future plans to D\&D Building 31/31A. However, $D \& D$ efforts should be minimal since the building itself is not contaminated with either radiological or energetic materials. The contaminated radiological materials are contained in the metal LSA boxes and TRU waste containers.

b) Facility Modifications Required for Likely Use

None. This building is currently supporting D\&D and Waste Management. Future use of the building would likely be the same.

c) Facility Modifications Required for Other Uses

Not applicable.

d) Changes to Safety Envelope

Not applicable.

e) Cleanup Criteria for Each Future Use Scenario

None.

f) Disposition of Surplus Equipment

Not applicable. 


\section{BUILDING 52 PHYSICAL CHARACTERIZATION}

1) Current Mission Description

a) Facility Capabilities

Building 52 is a $78-\mathrm{ft}^{2}$ magazine that is used for the storage of pyrotechnic materials. It is currently in active use for this purpose.

b) Resources Required to Support Operations

Primary Physical Resources:

Physical security: classified locks

Services:

Human Resources

Finance and Accounting

Environmental, Safety, and Health

Maintenance

Custodial

Payroll

Meal

Supply

c) Current Safety Envelope

Building 52 operations are classified as standard industrial hazard.

d) Current Status

1. No formal CAS review has been done. A quick condition assessment was done in July 1992.

2. No formal CAMP review has been done based on the latest Reconfiguration decision. A CAMP report was submitted on April 1, 1992, which focused on ES\&H needs, infrastructure maintenance, and consolidation projects.

2) Future Facility Use

a) Alternate Future Use Scenarios

1. WFO in the same discipline is unknown under recent May 27, 1993, reconfiguration guidance. Probably none. 
2. WFO in a new discipline is unknown under recent May 27, 1993, reconfiguration guidance. Probably none.

3. Commercialization possibilities under a lease agreement: Building 52 would be useful for any application requiring storage of energetic materials or general storage.

4. Commercialization under a sale agreement is unlikely in the short term, although there is a long-term possibility.

5. Deactivation effort should be moderate for the building as it is contaminated with energetic materials. There is no radiological contamination associated with this building.

b) Facility Modifications Required for Likely Use

Probably no major building modification would be required for this use.

c) Facility Modifications Required for Other Uses

Unknown.

d) Changes to Safety Envelope

The facility use suggested above should be covered under standard industrial hazard category.

Any new work conducted in Building 52 may require that a safety assessment be performed to identify any new hazards involved in the process.

e) Cleanup Criteria for Each Future Use Scenario

Building 52 is contaminated with energetic materials, so some deactivation efforts will be required if the building is not to be used for storage of energetic materials.

f) Disposition of Surplus Equipment

There is no surplus equipment in Building 52. 


\section{BUILDING 53 PHYSICAL CHARACTERIZATION}

1) Current Mission Description

a) Facility Capabilities

Building 53 is a 239- $\mathrm{ft}^{2}$ magazine that is used for the storage of energetic materials. It is currently in active use for this purpose.

b) Resources Required to Support Operations

Primary Physical Resources:

Physical security: classified locks

Services:

Human Resources

Finance and Accounting

Environmental, Safety, and Health

Maintenance

Custodial

Payroll

Meal

Supply

c) Current Safety Envelope

Building 53 operations are classified as standard industrial hazard.

d) Current Status

1. No formal CAS review has been done. A quick condition assessment was done in July 1992.

2. No formal CAMP review has been done based on the latest Reconfiguration decision. A CAMP report was submitted on April 1, 1992, which focused on ES\&H needs, infrastructure maintenance, and consolidation projects.

2) Future Facility Use

a) Alternate Future Use Scenarios

1. WFO in the same discipline is unknown under recent May 27, 1993, reconfiguration guidance. Probably none. 
2. WFO in a new discipline is unknown under recent May 27, 1993, reconfiguration guidance. Probably none.

3. Commercialization possibilities under a lease agreement: Building 53 would be useful for any application requiring storage of energetic materials or general storage.

4. Commercialization under a sale agreement is unlikely in the short term, although there is a long-term possibility.

5. Deactivation effort should be moderate for the building as it is contaminated with energetic materials. There is no radiological contamination associated with this building.

b) Facility Modifications Required for Likely Use

Probably no major building modification would be required for this use.

c) Facility Modifications Required for Other Uses

Unknown.

d) Changes to Safety Envelope

The facility use suggested above should be covered under standard industrial hazard category.

Any new work conducted in Building 53 may require that a safety assessment be performed to identify any new hazards involved in the process.

e) Cleanup Criteria for Each Future Use Scenario

Building 53 is contaminated with energetic materials, so some deactivation efforts will be required if the building is not to be used for storage of energetic materials.

f) Disposic on of Surplus Equipment

There is no surplus equipment in Building 53. 


\section{BUILDING 54 PHYSICAL CHARACAERIZATION}

1) Current Mission Description

a) Facility Capabilities

Building 54 is a $331-\mathrm{ft}^{2}$ magazine that is used for the storage of detonators and explosives for the explosives development group. It is currently in active use for this purpose.

b) Resources Required to Support Operations

Primary Physical Resources:

Physical security: classified locks

Services:

Human Resources

Finance and Accounting

Environmental, Safety, and Health

Maintenance

Custodial

Payroll

Meal

Supply

c) Current Safety Envelope

Building 54 operations are classified as standard industrial hazard.

d) Current Status

1. No formal CAS review has been done. A quick condition assessment was done in July 1992.

2. No formal CAMP review has been done based on the latest Reconfiguration decision. A CAMP report was submitted on April 1, 1992, which focused on ES\&H needs, infrastructure maintenance, and consolidation projects.

2) Future Facility Use

a) Alternate Future Use Scenarios

1. WFO in the same discipline is unknown under recent May 27, 1993, reconfiguration guidance. Probably none. 
2. WFO in a new discipline is unknown under recent May 27, 1993, reconfiguration guidance. Probably none.

3. Commercialization possibilities under a lease agreement: Building 54 would be useful for any application requiring storage of energetic materials or general storage.

4. Commercialization under a sale agreement is unlikely in the short term, although there is a long-term possibility.

5. Deactivation effort should be moderate for the building as it is contaminated with energetic materials. There is no radiological contamination associated with this building.

b) Facility Modifications Required for Likely Use

Probably no major building modification would be required for this use.

c) Facility Modifications Required for Other Uses

Unknown.

d) Changes to Safety Envelope

The facility use suggested above should be covered under standard industrial hazard category.

Any new work conducted in Building 54 may require that a safety assessment be performed to identify any new hazards involved in the process.

e) Cleanup Criteria for Each Future Use Scenario

Building 54 is contaminated with energetic materials. Some deactivation efforts will be required if the building is not to be used for storage of energetic materials.

f) Disposition of Surplus Equipment

There is no surplus equipment in Building 54 . 


\section{BUILDING 61 PHYSICAL CHARACTERIZATION}

1) Current Mission Description

a) Facility Capabilities

Building 61 is a $45,490-\mathrm{ft}^{2}$ building that serves Mound's needs in the areas of Contracting and Procurement, Shipping and Receiving, and Transportation. It is currently in active use for this purpose. Half of the building is taken up by offices; half by a warehousing and material handling facility. A variety of material handling equipment is used in the building. A large tank of liquid nitrogen outside the building is used to supply liquid nitrogen dewars throughout the site.

b) Resources Required to Support Operations

Primary Physical Resources:

Electricity

Potable water

Sanitary drainage

Physical security

Telecommunication devices

Fire protection, sprinklers, fire departmen $\imath$

HVAC

Services:

Human Resources

Finarice and Accounting

Environmental, Safety, and Health

Maintenance

Custodial

Payroll

Meal

Supply

c) Current Safety Envelope

Building 61 operations are classified as standard industrial hazard.

d) Current Status

1. No formal CAS review has been done. A quick condition assessment was done in July 1992.

2. No formal CAMP review has been done based on the latest Reconfiguration decision. A CAMP report was submitted on April 1, 1992, which focused on ES\&H needs, infrastructure maintenance, and consolidation projects. 
2) Future Facility Use

a) Alternate Future Use Scenarios

1. WFO in the same discipline is likely under recent May 27, 1993 , reconfiguration guidance. Any activities taking place at Mound are likely to need the services provided by Building 61 .

2. WFO in a new discipline is unknown under recent May 27, 1993, reconfiguration guidance.

3. Commercialization possibilities under a lease agreement: Building 61 would be ideal as a product distribution center for industry.

4. Commercialization under a sale agreement is unlikely in the short term, although there is a long-term possibility.

5. Deactivation effort should be minimal; the building is not contaminated with either radiological or energetic materials.

b) Facility Modifications Required for Likely Use

Probably no major building modification would be required for this use. The basic changes required may involve equipment.

c) Facility Modifications Required for Other Uses

Unknown.

d) Changes to Safety Envelope

The facility use suggested above should be covered under standard industrial hazard category unless hazardous materials are involved. Any new work in Building 61 may require that a safety assessment be performed to identify any new hazards involved in the process.

e) Cleanup Criteria for Each Future Use Scenario

Building 61 is not contaminated with radioactive or energetic materials.

f) Disposition of Surplus Equipment

There is a variety of surplus equipment stored in Building 61 , but none of it is very large or contaminated. It should be relatively easy to sell or dispose of. 


\section{BUILDING 64 PHYSICAL CHARACTERIZATION}

1) Current Mission Description

a) Facility Capabilities

Building 64 is a $72-\mathrm{ft}^{2}$ magazine that is used for storage of energetic materials to service Building 42 . It is currently in active use for this purpose.

b) Resources Required to Support Operations

Primary Physical Resources:

Physical security:

door locks

Services:

Human Resources

Finance and Accounting

Environmental, Safety, and Health

Maintenance

Custodial

Payroll

Meal

Supply

c) Current Safety Envelope

Building 64 operations are classified as standard industrial hazard.

d) Current Status

1. No formal CAS review has been done. A quick condition assessment was done in July 1992.

2. No formal CAMP review has been done based on the latest Reconfiguration decision. A CAMP report was submitted on April 1, 1992, which focused on ES\&H needs, infrastructure maintenance, and consolidation projects.

2) Future Facility Use

a) Alternate Future Use Scenarios

1. WFO in the same discipline is unknown under recent May 27, 1993, reconfiguration guidance. Probably none. 
2. WFO in a new discipline is unknown under recent May 27, 1993, reconfiguration guidance. Probably none.

3. Commercialization possibilities under a lease agreement: Building 64 would be useful for any application requiring storage of energetic materials or general storage.

4. Commercialization under a sale agreement is unlikely in the short term, although there is a long-term possibility.

5. Deactivation effort should be moderate for the building as it is contaminated with energetic materials. No radiological contamination is present.

b) Facility Modifications Required for Likely Use

Probably no major building modification would be required for this use.

c) Facility Modifications Required for Other Uses

Unknown.

d) Changes to Safety Envelope

The facility use suggested above should be covered under standard industrial hazard category. Any new work conducted in Building 64 may require that a safety assessment be performed to identify any new hazards involved in the process.

e) Cleanup Criteria for Each Future Use Scenario

Building 64 is contaminated with energetic materials so some deactivation of the building may be required if storage of energetic materials is not necessary.

f) Disposition of Surplus Equipment

There is no surplus equipment in Building 64 . 


\section{BUILDING 66 PHYSICAL CHARACTERIZATION}

1) Current Mission Description

a) Facility Capabilities

Building 66 is a $600-\mathrm{ft}^{2}$ modular wood building used for thermite development office space.

b) Resources Required to Support Operation

Primary Physical Resources:

Electricity

Physical security

Fire protection

HVAC

Telecommunication devices

Services:

Human Resources

Finance and Accounting

Environmental, Safety, and Health

Maintenance

Payroll

Meal

Supply

c) Current Safety Envelope

Building 66 is an office building. Operations in the building are classified standard industrial hazard.

d) Current Status

1. No formal CAS review has been done. A quick condition assessment was done in July 1992. The data sheet indicates contamination in Building 66 . However, the building manager claims there is no contamination there.

2. No formal CAMP review has been done based on the latest Reconfiguration decision. A CAMP report was submitted on April 1, 1992, which focused on ES\&H needs, infrastructure maintenance, and consolidation projects. 
2) Future Facility Use

a) Alternative Future Use Scenarios

1. WFO could continue under the same discipline.

2. Jsing the building for office space could continue for personnel assigned to a different discipline in WFO.

3. Commercialization under a lease agreement is unlikely.

4. Commercialization under a sale agreement is unlikely.

5. Deactivation effort should be minimal for the building. It is not contaminated with radiological, energetic, or asbestos materials. However, the soil under the building may be contaminated.

b) Facility Modifications Required for Likely Use

None.

c) Facility Modifications Required for Other Uses

None.

d) Changes to Safety Envelope

Any expected use of the building would be classified as standard industrial hazard.

e) Disposition of Surplus Equipment

Office furniture could be surplused to other DOE sites or sold at auction to private organizations. 


\section{BUILDING 68 PHYSICAL CHARACTERIZATION}

1) Current Mission Description

a) Facility Capabilities

Building 68 currently supports the Decommissioning and

Decontumination (D\&D) operations. Building 68 is used for staging $\mathrm{D} \& \mathrm{D}$ and maintenance materials. Building 68 is a $1990-\mathrm{ft}^{2}$ metal building. It was built in 1979 .

b) Resources Required to Support Operations

Primary Phissical Resources:

Electricity

Physical security

Fire sprinklers

Heating (no air sonditioning)

Services:

Human Resources

Finance and Accounting

Environmental, Safety, and Health

Maintenance

Custodial

Payroll

Meal

Supply

c) Current Safety Envelope

Building 68 operations are classified as standard industrial hazard.

d) Current Status

1. No formal CAS review has been done. A quick condition assessment was done in July 1992.

2. No formal CAMP review has been done based on the latest Reconfiguration decision. A CAMP report was submitted on April 1, 1992, which focused on ES\&H needs, infrastructure maintenance, and consolidation projects. 
2) Future Facility Use

a) Alternate Future Use Scenarios

1. WFO in the same discipline is likely under recent May 27, 1993, reconfiguration guidance.

2. WFO in a new discipline is unknown under recent May 27, 1993, reconfiguration guidance. Probably none.

3. Commercialization possibilities under a lease agreement: Probably none.

4. Commercialization possibilities under a sale agreement: Probably none.

5. There are no future plans to deactivate Building 68. However, deactivation efforts should be minimal, since the building itself is not contaminated with either radiological or energetic materials.

b) Facility Modifications Required for Likely Use

None. This building is currently supporting D\&D operations. Future use of the building as a staging or storage area would likely be the same for D\&D operations or any other business venture that the building could support.

c) Facility Modifications Required for Other Uses

None.

d) Changes to Safety Envelope

Not applicable.

e) Cleanup Criteria for Each Future Use Scenario

None.

f) Disposition of Surplus Equipment

Not applicable. 


\section{BUILDING 71 PHYSICAL CHARACTERIZATION}

1) Current Mission Description

a) Facility Capabilities

Building 71 is an $800-\mathrm{ft}^{2}$, metal building, open on two sides, that is used for storage of flammable liquids. It is currently in active use for this purpose.

b) Resources Required to Support Operations

Primary Physical Resources:

Electricity.

Physical security

Firø protection, fire department

Services:

Human Resources

Finance and Accounting

Environmental, Safety, and Health

Maintenance

Custodial

Payroll

Meal

Supply

c) Current Safety Envelope

Building 71 operations are classified as standard industrial hazard.

d) Current Status

1. No formal CAS review has been done. A quick condition assessment was done in July 1992.

2. No formal CAMP review has been done based on the latest Reconfiguration decision. A CAMP report was submitted on April 1, 1992, which focused on ES\&H needs, infrastructure maintenance, and consolidation projects. 
2) Future Facility Use

a) Alternate Future Use Scenarios

1. WFO in the same discipline is unknown under recent May 27, 1993, reconfiguration guidance. Probably none.

2. WFO in a new discipline is unknown under recent May 27, 1993, reconfiguration guidance. Probably none.

3. Commercialization possibilities under a lease agreement: Building 71 would be useful for any type of storage where ambient temperatures can be tolerated.

4. Commercialization under a sale agreement is unlikely in the short term, although there is a long-term possibility.

5. Deactivation effort should be minimal for the building, as it is not contaminated with either radiological or energetic materials.

b) Facility Modifications Required for Likely Use

Probably no major building modification would be required for this use.

c) Facility Modifications Required for Other Uses

Unknown.

d) Changes to Safety Envelope

The facility use suggested above should be covered under standard industrial hazard category. Any new work conducted in Building 71 may require that a safety assessment be performed to identify any new hazards involved in the process.

e) Cleanup Criteria for Each Future Use Scenario

Building 71 is not contaminated with any radioactive or energetic materials.

f) Disposition of Surplus Equipment

Removal of the flammable liquid supplies would empty the building. 


\section{BUILDING 72 PHYSICAL CHARACTERIZATION}

1) Current Mission Description

a) Facility Capabilities

Building 72 is a $2,400-\mathrm{ft}^{2}$ metal building, open on one side, and used for storage of hazardous waste. It is currently in active use for this purpose.

b) Resources Required to Support Operations

Primary Physical Resources:

Electricity

Physical security

Telecommunication devices

Fire protection, fire department

Services:

Human Resources

Finance and Accounting

Environmental, Safety, and Health

Maintenance

Custodial

Payroll

Meal

Supply

c) Current Safety Envelope

Building 72 operations are classified as standard industrial hazard.

d) Current Status

1. No formal CAS review has been done. A quick condition assessment was done in July 1992.

2. No formal CAMP review has been done based on the latest Reconfiguration decision. A CAMP report was submitted on April 1, 1992, which focused on ES\&H needs, infrastructure maintenance, and consolidation projects. 
2) Future Facility Use

a) Alternate Future Use Scenarios

1. WFO in the same discipline is unknown under recent May 27, 1993, reconfiguration guidance. Probably none.

2. WFO in a new discipline is unknown under recent May 27, 1993, reconfiguration guidance. Probably none.

3. Commercialization possibilities under a lease agreement:

Building 72 would be useful for any type of storage where it is not necessary to maintain a specific temperature.

4. Commercialization under a sale agreement is unlikely in the short term, although there is a long-term possibility.

5. Deactivation effort should be minimal for the building, as it is not contaminated with either radiological or energetic materials.

b) Facility Modifications Required for Likely Use

No major building modification would be required for this use.

c) Facility Modifications Required for Other Uses

Unknown.

d) Changes to Safety Envelope

The facility use suggested above should be covered under standard industrial hazard category. Any new work conducted in Building 72 may require that a safety assessment be performed to identify any new hazards involved in the process.

e) Cleanup Criteria for Each Future Use Scenario

Building 72 is not contaminated with any radioactive or energetic materials.

f) Disposition of Surplus Equipment

After removal of the hazardous chemicals, the building would be ready for other uses. 


\section{BUILDING 73 PHYSICAL CHARACTERIZATION}

1) Current Mission Description

a) Facility Capabilities

Building 73 is a $2200-\mathrm{ft}^{2}$, metal building, open on two sides, that is used for compressed gas cylinder storage. It is currently in active use for this purpose.

b) Resources Required to Support Operations

Primary Physical Resources:

Electricity

Physical security

Fire protection, fire department

Services:

Human Resources

Finance and Accounting

Environmental, Safety, and Health

Maintenance

Custodial

Payroll

Meal

Supply

c) Current Safety Envelope

Building 73 operations are classified as standard industrial hazard.

d) Current Status

1. No formal CAS review has been done. A quick condition assessment was done in July 1992.

2. No formal CAMP review has been done based on the latest Reconfiguration decision. A CAMP report was submitted on April 1, 1992, which focused on ES\&H needs, infrastructure maintenance, and consolidation projects. 
2) Future Facility Use

a) Alternate Future Use Scenarios

1. WFO in the same discipline is unknown under recent May 27, 1993, reconfiguration guidance. Probably none.

2. WFO in a new discipline is unknown under recent May 27, 1993, reconfiguration guidance. Probably none.

3. Commercialization possibilities under a lease agreement: Building 73 would be useful for any type of storage where ambient temperatures can be tolerated.

4. Commercialization under a sale agreement is unlikely in the short term, although there is a long-term possibility.

5. Deactivation effort should be minimal; the building is not contaminated with either radiological or energetic materials.

b) Facility Modifications Required for Likely Use

Probably no major building modification would be required for this use.

c) Facility Modifications Required for Other Uses

Unknown.

d) Changes to Safety Envelope

The facility use suggested above should be covered under standard industrial hazard category. Any new work conducted in Building 73 may require that a safety assessment be performed to identify any new hazards involved in the process.

e) Cleanup Criteria for Each Future Use Scenario

Building 73 is not contaminated with any radioactive or energetic materials.

f) Disposition of Surplus Fquipment

Removal of the compressed gas cylinder supplies would empty the building. 


\section{BUILDING 74 PHYSICAL CHARACTERIZATION}

\section{1) Current Mission Description}

a) Facility Capabilities

Building 74 is a $400-\mathrm{ft}^{2}$ building that is used for final packaging of explosives in support of defense programs. It is currently in active use for this purpose. The building contains a banding machine, tools, air guns, wooden boxes and pipes for the purpose of overpacking and labeling explosives for DOT transport.

b) Resources Required to Support Operations

Primary Physical Resources:

Electricity

Potable water

Sanitary drainage

Physical security

Telecommunication devices

Fire protection, sprinklers, fire department HVAC

Services:

Human Resources

Finance and Accounting

Environmental, Safety, and Health

Maintenance

Custodial

Payroll

Meal

Supply

Special Resources:

Compressed air

c) Current Safety Envelope

Building 74 operations are classified as standard industrial hazard.

d) Current Status

1. No formal CAS review has been done. A quick condition assessment was done in July 1992.

2. No formal CAMP review has been done based on the latest Reconfiguration decision. A CAMP report was submitted on April 1, 1992, which focused on ES\&H needs, infrastructure maintenance, and consolidation projects. 
2) Future Facility Use

a) Alternate Future Use Scenarios

1. WFO in the same discipline possible under recent May 27, 1993, reconfiguration guidance. The overpackaging facility would be useful to any enterprise needing to ship explosive materials.

2. WFO in a new discipline is unknown under recent May 27, 1993, reconfiguration guidance. Probably none.

3. Commercialization possibilities under a lease agreement: The overpackaging facility would be useful to any enterprise needing to ship explosive materials.

4. Commercialization under a sale agreement is unlikely in the short term, although there is a long-term possibility.

5. Deactivation effort should be minimal; the building is not contaminated with either radiological or energetic materials.

b) Facility Modifications Required for Likely Use

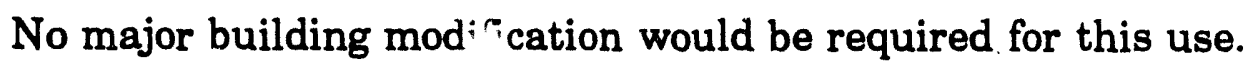

c) Facility Modifications Required for Other Uses

Unknown.

d) Changes to Safety Envelope

The facility use suggested above should be covered under standard industrial hazard category.

e) Cleanup Criteria for Each Future Use Scenario

Building 74 is not contaminated with any radioactive or energetic materials.

f) Disposition of Surplus Equipment

Surplus material has accumulated in Building 74, but it would not be difficult to dispose of. 


\section{BUILDING 80 PHYSICAL CHARACTERIZATION}

1) Current Mission Description

a) Facility Capabilities

Building 80 is a 314- $\mathrm{ft}^{2}$ magazine that is used for the storage of energetic materials. It is currently in active use for this purpose.

b) Resources Required to Support Operations

Primary Physical Resources:

Physical security:

classified locks

Services:

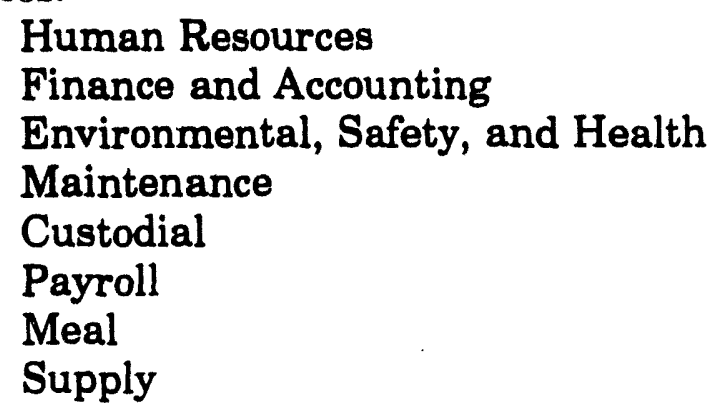

Human Resources

Finance and Accounting

Environmental, Safety, and Health

Maintenance

Custodial

Payroll

Meal

Supply

c) Current Safety Envelope

Building 80 operations are classified as standard industrial hazard.

d) Current Status

1. No formal CAS review has been done. A quick condition assessment was done in July 1992.

2. No formal CAMP review has been done based on the latest Reconfiguration decision. A CAMP report was submitted on April 1, 1992, which focused on ES\&H needs, infrastructure maintenance, and consolidation projects.

2) Future Facility Use

a) Alternate Future Use Scenarios

1. WFO in the same discipline is unknown under recent May 27, 1993, reconfiguration guidance. Probably none. 
2. WFO in a new discipline is unknown under recent May 27, 1993, reconfiguration guidance. Probably none.

3. Commercialization possibilities under a lease agreement: Building 80 would be useful for any application requiring storage of energetic materials or general storage.

4. Commercialization under a sale agreement is unlikely in the short term, although there is a lonf̧-term possibility.

5. Deactivation effort should be moderate for the building as it is contaminated with energetic materials. There is no radiological contamination associated with this building.

b) Facility Modifications Required for Likely Use

Probably no major building modification would be required for this use.

c) Facility Modifications Required for Other Uses

Unknown.

d) Changes to Safety Envelope

The facility use suggested above should be covered under standard industrial hazard category.

Any new work conducted in building 80 may require that a safety assessment be performed to identify any new hazards involved in the process.

e) Cleanup Criteria for Each Future Use Scenario

Building 80 is contaminated with energetic materials, so some deactivation efforts will be required if the building is not to be used for storage of energetic materials.

f) Disposition of Surplus Equipment

There is no surplus equipment in Building 80. 


\section{BUILDING 81 PHYSICAL CHARACTERIZATION}

1) Current Mission Description

a) Facility Capabilities

Building 81 is a 314- $\mathrm{ft}^{2}$ magazine that is used for the storage of energetic materials. It is currently in active use for this purpose.

b) Resources Required to Support Operations

Primary Physical Resources:

Physical security:

classified locks

Services:

Human Resources

Finance and Accounting

Environmental, Safety, and Health

Maintenance

Custodial

Payroll

Meal

Supply

c) Current Safety Envelope

Building 81 operations are classified as standard industrial hazard.

d) Current Status

1. No formal CAS review has been done. A quick condition assessment was done in July 1992.

2. No formal CAMP review has been done based on the latest Reconfiguration decision. A CAMP report was submitted on April 1, 1992, which focused on ES\&H needs, infrastructure maintenance, and consolidation projects.

2) Future Facility Use

a) Alternate Future Use Scenarios

1. WFO in the same discipline is unknown under recent May 27, 1993, reconfiguration guidance. Probably none. 
2. WFO in a new discipline is unknown under recent May 27, 1993, reconfiguration guidance. Probably none.

3. Commercialization possibilities under a lease agreement: Building 81 would be useful for any application requiring storage of energetic materials or general storage.

4. Commercialization under a sale agreement is unlikely in the short term, although there is a long-term possibility.

5. Deactivation effort should be moderate for the building as it is contaminated with energetic materials. There is no radiological contamination associated with this building.

b) Tacility Modifications Required for Likely Use

Probably no major building modification would be required for this use.

c) Facility Modifications Required for Other Uses

Unknown.

d) Changes to Safety Envelope

The facility use suggested above should be covered under standard industrial hazard category.

Any new work conducted in Building 81 may require that a safety assessment be performed to identify any new hazards involved in the process.

e) Cleanup Criteria for Each Future Use Scenario

Building 81 is contaminated with energetic materials so some deactivation efforts will be required if the building is not to be used for storage of energetic materials.

f) Disposition of Surplus Equipment

There is no surplus equipment in Building 81 . 


\section{BUILDING 82 PHYSICAL CHARACTERIZATION}

1) Current Mission Description

a) Facility Capabilities

Building 82 is a $314-\mathrm{ft}^{2}$ magazine that is used for the storage of energetic materials. It is currently in active use for this purpose.

b) Resources Required to Support Operations

Primary Physical Resources:

Physical security: classified locks

Services:

Human Resources

Finance and Accounting

Environmental, Safety, and Health

Maintenance

Custodial

Payroll

Meal

Supply

c) Current Safety Envelope

Building 82 operations are classified as standard industrial hazard.

d) Current Status

1. No formal CAS review has been done. A quick condition assessment was done in July 1992.

2. No formal CAMP review has been done based on the latest Reconfiguration decision. A CAMP report was submitted on April 1, 1992, which focused on ES\&H needs, infrastructure maintenance, and consolidation projects.

2) Future Facility Use

a) Alternate Future Use Scenarios

1. WFO in the same discipline is unknown under recent May 27, 1993, reconfiguration guidance. Probably none. 
2. WFO in a new discipline is unknown under recent May 27, 1993, reconfiguration guidance. Probably none.

3. Commercialization possibilities under a lease agreement: Building 82 would be useful for any application requiring storage of energetic materials or general storage.

4. Commercialization under a sale agreement is unlikely in the short term, although there is a long-term possibility.

5. Deactivation effort should be moderate for the building, as it is contaminated with energetic materials. There is no radiological contamination associated with this building.

b) Facility Modifications Required for Likely Use

Probably no major building modification would be required for this use.

c) Facility Modifications Required for Other Uses

Unknown.

d) Changes to Safety Envelope

The facility use suggested above should be covered under standard industrial hazard category.

Any new work conducted in Building 82 may require that a safety assessment be performed to identify any new hazards involved in the process.

e) Cleanup Criteria for Each Future Use Scenario

Building 82 is contaminated with energetic materials so some deactivation efforts will be required if the building is not to be used for storage of energetic materials.

f) Disposition of Surplus Equipment

There is no surplus equipment in Building 82 . 


\section{BUILDING 83 PHYSICAL CHARACTERIZATION}

1) Current Mission Description

a) Facility Capabilities

Building 83 is a 314- $\mathrm{ft}^{2}$ magazine that is used for the storage of energetic materials. It is currently in active use for this purpose.

b) Resources Required to Support Operations

Primary Physical Resources:

Physical security:

classified locks

Services:

Human Resources

Finance and Accounting

Environmental, Safety, and Health

Maintenance

Custodial

Payroll

Meal

Supply

c) Current Safety Envelope

Building 83 operations are classified as standard industrial hazard.

d) Current Status

1. No formal CAS review has been done. A quick condition assessment was done in July 1992.

2. No formal CAMP review has been done based on the latest Reconfiguration decision. A CAMP report was submitted on April 1, 1992, which focused on ES\&H needs, infrastructure maintenance, and consolidation projects.

2) Future Facility Use

a) Alternate Future Use Scenarios

1. WFO in the same discipline is unknown under recent May 27, 1993, reconfiguration guidance. Probably none. 
2. WFO in a new discipline is unknown under recent May 27, 1993, reconfiguration guidance. Probably none.

3. Commercialization possibilities under a lease agreement: Building 83 would be useful for any application requiring storage of energetic materials or general storage.

4. Commercialization under a sale agreement is unlikely in the short term, although there is a long-term possibility.

5. Deactivation effort should be moderate for the building as it is contaminated with energetic materials. There is no radiological contamination associated with this building.

b) Facility Modifications Required for Likely Use

Probably no major building modification would be required for this use.

c) Facility Modifications Required for Other Uses

Unknown.

d) Changes to Safety Envelope

The facility use suggested above should be covered under standard industrial hazard category.

Any new work conducted in Building 83 may require that a safety assessment be performed to identify any new hazards involved in the process.

e) Cleanup Criteria for Each Future Use Scenario

Building 83 is contaminated with energetic materials so some deactivation efforts will be required if the building is not to be used for storage of energetic materials.

f) Disposition of Surplus Equipment

There is no surplus equipment in Building 83. 


\section{BUILDING 84 PHYSICAL CHARACTERIZATION}

1) Curren.t Mission Description

a) Facility Capabilities

Building 84 is a $314-\mathrm{ft}^{2}$ magazine that is used for the storage of energetic materials. It is currently in active use for this purpose.

b) Resources Required to Support Operations

Primary Physical Resources:

Physical security: classified locks

Services:

Human Resources

Finance and Accounting

Environmental, Safety, and Health

Maintenance

Custodial

Payroll

Meal

Supply

c) Current Safety Envelope

Building 84 operations are classified as standard industrial hazard.

d) Current Status

1. No formal CAS review has been done. A quick condition assessment was done in July 1992.

2. No formal CAMP review has been done based on the latest Reconfiguration decision. A CAMP report was submitted on April 1, 1992, which focused on ES\&H needs, infrastructure maintenance, and consolidation projects.

2) Future Facility Use

a) Alternate Future Use Scenarios

1. WFO in the same discipline is unknown under recent May 27, 1993, reconfiguration guidance. Probably none. 
2. WFO in a new discipline is unknown under recent May 27, 1993, reconfiguration guidance. Probably none.

3. Commercialization possibilities under a lease agreement: Building 84 would be useful for any application requiring storage of energetic materials or general storage.

4. Commercialization under a sale agreement is unlikely in the short term, although there is a long-term possibility.

5. Deactivation effort should be moderate for the building as it is contaminated with energetic materials. There is no radiological contamination associated with this building.

b) Facility Modifications Required for Likely Use

Probably no major building modification would be required for this use.

c) Facility Modifications Required for Other Uses

Unknown.

d) Changes to Safety Envelope

The facility use suggested above should be covered under standard industrial hazard category.

Any new work conducted in Building 84 may require that a safety assessment be performed to identify any new hazards involved in the process.

e) Cleanup Criteria for Each Future Use Scenario

Building 84 is contaminated with energetic materials, so some deactivation efforts will be required if the building is not to be used for storage of energetic materials.

f) Disposition of Surplus Equipment

There is no surplus equipment in Building 84 . 


\section{BUILDING 89 PHYSICAL CHARACTERIZATION}

1) Current Mission Description

a) Facility Capabilities

Building 89 is used for long- and short-term storage of energetic materials that will be analyzed later in Building 48 . Building 89 is a $4830-\mathrm{ft}^{2}$, reinforced concrete building. It was built in 1985 .

b) Resources Required to Support Operations

Primary Physical Resources:

Electricity

Physical security

Fire protection, sprinklers, fire department

Services:

Human Resources

Finance and Accounting

Environmental, Safety, and Health

Maintenance

Custodial

Payroll

Meal

Supply

c) Current Safety Envelope

Building 89 operations are classified as standard industrial hazard.

d) Current Status

1. No formal CAS review has been done. A quick condition assessment was done in July 1992.

2. No formal CAMP review has been done based on the latest Reconfiguration decision. A CAMP report was submitted on April 1, 1992, which focused on ES\&H needs, infrastructure maintenance, and consolidation projects.

2) Future Facility Use

a) Alternate Future Use Scenarios

1. WFO in the same discipline is probable under recent May 27, 1993, reconfiguration guidance. Building 48 is currently doing work with energetic materials for the Department of Defense. Building 89 could then be used for the storage of these energetic materials. 
2. WFO in a new discipline is unknown under recent May 27, 1993, reconfiguration guidance. Probably none.

3. Commercialization under a lease agreement is possible under recent May 27, 1993, reconfiguration guidance. Building 89 could be used to store other energetic materials required by another industry before they are analyzed in Building 48 . One possibility would be companies that manufacture the energetic materials for air bags.

4. Commercialization under a sale agreement is possible under recent May 27, 1993, reconfiguration guidance. Building 89 could be used to store other energetic materials required by another industry before they are analyzed in Building 48. One possibility would be companies that manufacture the energetic materials for air bags.

5. Deactivation efforts should be minimal. The building is slightly contaminated with energetic materials, but not with radiological materials. A May 1993 Mound Asbestos survey determined that Building 89 does not contain any asbestos.

b) Facility Modifications Required for Likely Use

None. Building 89 currently supports Building 48 . As long as there is a need for the analytical work done in Building 48 on energetic materials, there will likely be a need for Building 89 .

c) Facility Modifications Required for Other Uses

Unknown.

d) Changes to Safety Envelope

Probably none.

e) Cleanup Criteria for Each Future Use Scenario

Cleanup efforts should be minimal; the building is slightly contaminated with energetic materials, but is not contaminated with radiological materials. A May 1993 Mound Asbestos survey determined that Building 89 does not contain any asbestos.

f) Disposition of Surplus Equipment

None. This building is used for storage. 


\section{BUILDING 106 PHYSICAL CHARACTERIZATION}

1) Current Mission Description

a) Facility Capabilities

Building 106 is a $180-\mathrm{ft}^{2}$ aluminum shed that is used for general storage for Building 43. It is currently in active use for this purpose.

b) Resources Required to Support Operations

Primary Physical Resources:

Electricity

Fire protection

Services:

Human Resources

Finance and Accounting

Environmental, Safety, and Health

Maintenance

Custodial

Payroll

Meal

Supply

c) Current Safety Envelope

Building 106 operations are classified as standard industrial hazard.

d) Current Status

1. No formal CAS review has been done. A quick condition assessment was done in July 1992.

2. No formal CAMP review has been done based on the latest Reconfiguration decision. A CAMP report was submitted on April 1, 1992, which focused on ES\&H needs, infrastructure maintenance, and consolidation projects.

2) Future Facility Use

a) Alternative Future Use Scenarios

1. WFO in the same discipline is unknown under the recent May 27, 1993, reconfiguration guidance. Probably none. 
2. WFO in a new discipline is unknown under the recent May 27, 1993, reconfiguration guidance. Probably none.

3. Commercialization possibilities under a lease agreement: Building 106 would be useful for any application requiring general storage.

4. Commercialization under a sale agreement is unlikely in the short term, although there is a long-term possibility.

5. Deactivation effort should be minimal for the building, as it is not contaminated with either radiological or energetic materials.

b) Facility Modifications Required for Likely Use

Probably no building modifications would be required for this use. The basic changes required would involve equipment.

c) Facility Modifications Required for Other Uses

Unknown.

d) Changes to Safety Envelope

The facility use suggested above should be covered under standard industrial hazard category, unless hazardous materials are involved.

Any new work conducted in Building 106 may require that a safety assessment be performed to identify any new hazards involved in the process.

e) Cleanup Criteria for Each Future Use Scenario

Building 106 is not contaminated with any radiological or energetic materials.

f) Disposition of Surplus Equipment

There is no surplus equipment in Building 106. 


\section{BUILDING 120 PHYSICAI. CHARACTERIZATION}

1) Current Mission Description

a) Facility Capabilities

Building 120 is a $350-\mathrm{ft}^{2}$ modular building that is used for storage of Radiological Assistance Team supplies. It is currently in active use for this purpose.

b) Resources Required to Support Operations

Primary Physical Resources:

Electricity

Potable water

Physical security

Telecommunication devices

Fire protection, sprinklers, fire department

HVAC

Services:

Human Resources

Finance and Accounting

Environmental, Safety, and Health

Maintenance

Custodial

Payroll

Meal

Supply

c) Current Safety Envelope

Building 120 operations are classified as standard industrial hazard.

d) Current Status

1. No formal CAS review has been done. A quick condition assessment was done in July 1992.

2. No formal CAMP review has been done based on the latest Reconfiguration decision. A CAMP report was submitted in April 1, 1992, which focused on ES\&H needs, infrastructure maintenance, and consolidation proiects. 
2) Future Facility Use

a) Alternate Future Use Scenarios

1. WFO in the same discipline is unknown under recent May 27, 1993, reconfiguration guidance. Probably none.

2. WFO in a new discipline is unknown under recent May 27, 1993, reconfiguration guidance. Probably none.

3. Commercialization possibilities under a lease agreement:

Building 120 would be useful for any application requiring storage or office space.

4. Commercialization under a sale agreement is unlikely in the short term, although there is a long-term possibility.

5. Deactivation effort should be minimal; the building is not contaminated with either radiological or energetic materials.

b) Facility Modifications Required for Likely Use

Probably no major building modification would be required for this use.

c) Facility Modifications Required for Other Uses

Unknown.

d) Changes to Safety Envelope

The facility use suggested above should be covered under standard industrial hazard category unless hazardous materials are involved. Any new work conducted in Building 120 may require that a safety assessment be performed to identify any new hazards involved in the process.

e) Cleanup Criteria for Each Future Use Scenario

Building 120 is not contaminated with any radioactive or energetic materials.

f) Disposition of Surplus Equipment

There is no surplus equipment in Building 120. 


\section{STRUCTURE 110 PHYSICAL CHARACTERIZATION}

1) Current Mission Description

a) Facility Capabilities

Structure 110 is for fuel storage. It consists of a 6000-gallon gasoline and a 4000-gallon diesel fuel storage tank inside a concrete diked area. The fuel is used for plant vehicles and emergency power diesel engines.

b) Resources Required to Support Operations

Primary Physical Services:

Electricity

Drainage for dike, administratively controlled

Physical security

Fire protection

Services:

Maintenance

This facility does not house any personnel.

c) Current Safety Envelope

Structure 110 operations are classified as standard industrial hazard.

d) Current Status

1. No formal CAS review has been done. A quick condition assessment was done in July 1992.

2. No formal CAMP review has been done based on the latest Reconfiguration decision. A CAMP report was submitted on April 1, 1992 which focused on ES\&H needs, infrastructure maintenance, and consolidation projects.

(2) Future Facility Use

a) Alternative Future Use Scenarios

1. WFO in the same discipline will occur under recent May 27, 1993 reconfiguration guidance. This facility is needed to service plant vehicles and emergency power systems. 
2. Probably no different discipline will be allowed for WFO.

3. Commercialization may be possible under a lease agreement.

4. Commercialization under a sale agreement is very unlikely.

5. Deactivation of this facility would require proper disposal of remaining tank inventories and cleanup of the tanks. There is no contamination with radiological, energetic or asbestos materials.

b) Facility Modifications Required for Likely Use

Probably none.

c) Facility Modifications Required for Other Use

Unknown, but probably none.

d) Changes to Safety Envelope

Probably none.

e) Cleanup Criteria for Each Future Use Scenario

Structure 110 is not cuntaminated with any radioactive, energetic, or asbestos materials.

f) Disposition of Surplus Equipment

This equipment will be used as long as there is activity at Mound. 


\section{SECTION 3: PRODUCTION BUIIDINGS}

A. Planning Basis: The production buildings are a functional unit consisting of production and production support facilities at Mound. The production facilities at Mound have, for the most part, been constructed in a piecemeal fashion to support specific products over the past 40 years.

Because of the current reduction in budget and workload, an effort is under way at Mound to consolidate facilities; that is, to shut down as much space as possible to the appropriate level of standby condition. Although a draft plan listing possible facilities and time frame of execution has been prepared for this effort, it is premature to detail its impact on this building functional unit.

1. Present Mission: The present mission of this function unit is to provide facilities required to meet the production needs of Mound's mission as described in the current AWLPG. This functional unit includes 24 buildings, namely: B, COS, HH, E, I, M, T, 1, 27, 28, 29, $30,36,37,38,42,49,50,60,63,65,67,85$, and 105 . Facility descriptions are provided below.

2. Material Condition and Expected Useful Life: The 24 facilities grouped within this functional unit range in age from original plant construction (1948) to quite new (1986). Construction type ranges from concrete block to brick and mortar. Overall condition of this unit is good.

Several of the buildings within this functional unit (namely: I, 1, 27, 42 , and 67) had been planned for replacement through various FCAP projects. However, because of reduced funding forecasts in the early 90 's and reduced workload projections, these projects were canceled in January 1991. Revised plans for these "poor" facilities are being formulated.

One facility, Building 29, Advanced Devices Plastics, has been placed in a "mothball" state because of shutdown of activities. 


\section{PRODUCTION BUILDINGS}

\begin{tabular}{|c|c|c|c|c|c|}
\hline BLDG & DESCRIPTION & CONDITION & $\begin{array}{c}\text { SQUARE } \\
\text { FOOTAGE } \\
\text { (X 1000) }\end{array}$ & $\underline{A G E}\left(Y_{\text {rs. }}\right)$ & $\begin{array}{l}\text { REMAINING } \\
\text { PROJECTED } \\
\text { USEFUL LIFE } \\
\end{array}$ \\
\hline B & Adv Dev Inert Prod & Good & 27.7 & $4 \varepsilon_{1}$ & 25 \\
\hline $\cos$ & Central Ops Supp & Excellent. & 64.7 & 7 & 63 \\
\hline $\mathbf{E}$ & Adv Dev Production & Fair & 47.8 & 45 & 25 \\
\hline $\mathrm{HH}$ & Isotope Separation & Good & 15.3 & 45 & 25 \\
\hline I & High Expl Prod & Poor & 25.7 & 45 & 15 \\
\hline $\mathbf{M}$ & Machine/Elect Shops & Good & 56.0 & 45 & 25 \\
\hline $\mathbf{T}$ & Nuclear Operations & Good & 173.0 & 45 & 35 \\
\hline 1 & Expl Prod Supp & Poor & 1.0 & 36 & 14 \\
\hline 27 & Adv Dev Programs & Poor & 5.3 & 25 & 15 \\
\hline 28 & Ceramic Production & Fair & 11.3 & 27 & 23 \\
\hline 29 & Adv Dev Plastics & Poor & 6.6 & 29 & 21 \\
\hline 30 & Adv Dev \& Health Phys & Fair & 0.7 & 29 & 21 \\
\hline 36 & RTG Support & Fair & 4.3 & 25 & 15 \\
\hline 37 & Adhesive Formulation & Fair & 2.5 & 25 & 15 \\
\hline 38 & Nuc Opns Prog \& D\&D & Poor & 44.3 & 23 & 7 \\
\hline 42 & High Expl Production & Poor & 2.9 & 24 & 16 \\
\hline 49 & Timer Fabrication & Fair & 14.9 & 23 & 27 \\
\hline 50 & RGT Assembly \& Test & Adequate & 14.8 & 22 & 48 \\
\hline 60 & Ceramic Production & Fair & 4.0 & 13 & 37 \\
\hline 63 & Quality/Product Test & Excellent & 16.5 & 13 & 37 \\
\hline 65 & Production Support & Fair & 2.4 & 12 (Wood & Mod) \\
\hline 67 & Energetic Material Supp & Fair & 3.8 & 11 & 29 \\
\hline & Powder Blend/Process & Excellent & 3.2 & 5 & 65 \\
\hline 105 (PM) & Parts Machining & Excellent & 38.0 & 7 & 63 \\
\hline
\end{tabular}

3. Key Activities and Upgrades: The types of projects planned for this functional unit over the next 20 years are generally Facilities Capability Assurance Program (FCAP) type projects such as heating, ventilating, and air conditioning (HVAC), and General Plant Projects (GPP) such as roof replacement projects necessary to maintain its acceptable condition.

4. ES\&H and S\&S Upgrades Required: In FY 1995 an ES\&H project, T (Technical) Building Life Safety Code Upgrades is required to upgrade the facility to meet today's stringent Life Safety Code. Other buildings within this functional unit will also receive similar Life Safety Code upgrades in FY 1995.

5. Decommissioning and Decontamination Activities: D\&D of a major portion of Building 38 has been in progress for the last several years and will continue through 1998. 
B. Description of Events and Projects: Events and projects are briefly described in the following narrative. The narratives are provided in chronological order.

1. In FY 1993, several production facility roofs will be replaced based on a survey conducted in FY 1992. (\$500K - FY 1993 GPP)

2. In FY 1995, an ES\&H project, $\mathrm{T}$ (Technical) Building Life Safety Code Upgrade, is required to return the facility to proper code compliance. This project was originally submitted as an FY 1993 Line Item. (\$2.9M - FY 1995 ES\&H Line Item)

3. In FY 1995, a Plant Life Safety Code Upgrade is planned, which will eliminate present life safety code discrepancies that have evolved over the years because of an increasingly stringent life safety code. A number of production facilities would be affected by this project. They include COS, E, M, and 38. (\$2.3M - FY 1995 ES\&H Line Item)

4. In FY 1996, the FCAP project, Cooling Systems Upgrades, will be initiated which will replace numerous outdated HVAC systems within the production facilities. (\$3.0M - FY 1996 FCAP Line Item)

5. In FY 2001, a GPP project to replace roofs on five production facilities will be executed. (\$300K - FY 2001 GPP)

6. In the year 2003, another HVAC replacement-type project will be initiated to provide for those air handling units which have reached the end of their useful life. (\$2.0M - FY 2003 FCAP Line Item)

All of the above projects are essential to maintaining the Production Buildings at a minimum level of suitability for their mission.

C. Functional Unit Maintenance Activities:

Current Funding Status: Many of the production buildings are in need of repairs of a more substantial nature than can be accomplished with in. house personnel. Funds for these type of activities, new roofs, HVAC equipment, major concrete repairs, etc., have been limited to less than 30 $40 \%$ of requests. Production losses beceuse of roof leaks are to be expected. Because of their importance, these facilities receive the highest priority for funds within the building functional units. 
This page intentionally blank. 


\section{B BUILDING PHYSICAL CHARACTERIZATION}

1) Current Mission Description

a) Facility Capabilities

B Building is a 27,735- $\mathrm{ft}^{2}$ building used for inert assembly of nonexplosive devices in support of defense programs. It is currently in active use for this purpose. Capabilities in B Building include a mold shop, a nondestructive testing lab, and laser-welding and laser-marking facilities.

b) Resources Required to Support Operations

Primary Physical Resources:

Electricity

Potable water

Sanitary drainage

Physical security

Telecommunication devices

Fire protection, sprinklers, fire department HVAC

Services:

Human Resources

Finance and Accounting

Environmental, Safety, and Health

Maintenance

Custodial

Payroll

Meal

Supply

Special Resources:

Bottled nitrogen and argon gas

Solvents

c) Current Safety Envelope

B Building operations are classified as standard industrial hazard.

d) Current Status

1. No formal CAS review has been done. A quick condition assessment was done in July 1992.

2. No formal CAMP review has been done based on the latest Reconfiguration decision. A CAMP report was submitted on April 1, 1992, which focused on ES\&H needs, infrastructure maintenance, and consolidation projects. 
2) Future Facility Use

a) Alternate Future Use Scenarios

1. WFO in the same discipline is unknown under recent May 27, 1993, reconfiguration guidance. Probably none.

2. WFO in a new discipline is unknown under recent May 27, : 1993, reconfiguration guidance. Probably none.

3. Commercialization possibilities under a lease agreement: B Building would be ideal for bench-scale production of small pieceparts. Part of the building consists of an eight-station, continuous-flow production setup. The availability of laser welding, laser marking, and nondestructive testing facilities in the same building is a significant advantage.

4. Commercialization under a sale agreement is unlikely in the short term, although there is a long-term possibility.

5. Deactivation effort should be minimal for the building, as it is not contaminated with radiological or energetic materials. A small amount of chemical contamination may be present. Asbestos has also been found in the building.

b) Facility Modifications Required for Likely Use

Probably no major building modification would be required for this use. The basic changes required would involve equipment.

c) Facility Modifications Required for Other Uses

Unknown.

d) Changes to Safety Envelope

The facility use suggested above should be covered under standard industrial hazard category unless hazardous materials are involved. Any new work may require that a safety assessment be performed to identify any new hazards involved in the process.

e) Cleanup Criteria for Each Future Use Scenario

B Building is not contaminated with radioactive or energetic materials. There is asbestos in the building, and there may be a small amount of chemical contamination which could require cleanup before - future use, depending on contract requirements.

f) Disposition of Surplus Equipment

None. 


\section{COS BUILDING PHYSICAL CHARACTERIZATION}

1) Current Mission Description

a) Facility Capabilities

COS Building is a $64,654-\mathrm{ft}^{2}$ building that provides production support for weapons components. It is currently in active use for this purpose.

Specialized facilities in COS Building include:

Offices

Conference rooms

Explosives laboratories

Tape lab for production of flexible circuits

Standards lab, including:

Large constant-humidity chambers

Constant temperature baths

Ovens

Airflow chamber

Robotics lab, including:

Several robots and controllers

Stepper motors

Linear slides

Computers

Video cameras

Microscope

Image processors

Machine shop

b) Resources Required to Support Operations

Primary Physical Resources:

Electricity

Potable water

Sanitary drainage

Physical security

Telecommunication devices

Fire protection, sprinklers, fire department

HVAC

Services:

Human Resources

Finance and Accounting

Environmental, Safety, and Health 
Maincenance

Custodial

Payroll

Meal

Supply

Special Resources:

Liquid nitrogen

Bottled gases

c) Current Safety Envelope

COS Building operations are classified as low hazard.

d) Current Status

1. No formal CAS review has been done. A quick condition assessment was done in July 1992.

2. No formal CAMP review has been done based on the latest Reconfiguration decision. A CAMP report was submitted on April 1, 1992, which focused on ES\&H needs, infrastructure maintenance, and consolidation projects.

2) Future Facility Use

a) Alternate Future Use Scenarios

1. WFO in the same discipline is possible under recent May 27, 1993, reconfiguration guidance. The tape processing lab could be used to produce flexible circuits for many applications. The robotics lab could be useful in automating operations including dispensing and pressing of energetic powders, laser cutting and welding, and fiberoptic multiplexing. In addition, any development or production quality program may require instrument calibration.

2. WFO in a new discipline is unknown under recent May 27, 1993, reconfiguration guidance. Probably none.

3. Commercialization possibilities under a lease agreement: The tape processing lab could be used to produce flexible circuits for many applications. The robotics lab could be useful in automating operations including dispensing and pressing of energetic powders, laser cutting and welding, and fiberoptic 
multiplexing. In addition, any development or production quality program may require instrument calibration.

4. Commercialization under a sale agreement is unlikely in the short term, although there is a long-term possibility.

5. COS Building may be slightly contaminated with energetic materials. This contamination may conceivably require cleanup before deactivation.

b) Facility Modifications Required for Likely Use

Probably no major building modification would be required for the above uses. The stairway discharge into the penthouse may need to be reworked to meet the Life Safety Code. Also, a ramp may be needed to improve handicapped access.

c) Facility Modifications Required for Other Uses

Unknowr.

d) Changes to Safety Envelope

The facility uses suggested above should be covered under low hazard category unless larger quantities of hazardous materials are involved.

Any new work conducted in $\operatorname{COS}$ Building may require that a safety assessment be performed to identify any new hazards involved in the process.

e) Cleanup Criteria for Each Future Use Scenario

COS Building is slightly contaminated with energetic materials. This contamination may require cleanup before unrestricted commercial use of the building, depending on contract requirements.

f) Disposition of Surplus Equipment

There is some bulky laser equipment in use in COS Building. Because of its size, this equipment may be difficult to dispose of at the end of its useful life. 
This page intentionally blank. 


\section{E BUILDING PHYSICAL CHARACTERIZATION}

\section{1) Current Mission Description}

a) Facility Capabilities

E Building (including E-Annex) is a 47,755- $\mathrm{ft}^{2}$ building used for environmental analysis, general analytical services, and mechanical assembly of products in support of a wide range of Mound programs. It is currently in active use for this purpose. Laboratories occupy $80 \%$ of $E$ Building, with the remainder of the building being occupied by offices. The building contains one conference room that is now being used for another purpose, and two raised-floor areas that are intended as computer rooms.

b) Resources Required to Support Operations

Primary Physical Resources:

Electricity

Potable water

Sanitary drainage

Physical security

Telecommunication devices

Fire protection, sprinklers, fire department

HVAC

Services:

Human Resources

Finance and Accounting

Environmental, Safety, and Health

Maintenance

Custodial

Payroll

Meal

Supply

Special Resources:

Bottled gas and compressed air

Chemicals

Chemical storage and disposal

Liquid nitrogen 
c) Current Safety Envelope

E Building operations are classified as standard industrial hazard. No formal risk assessment of the building has been done.

d) Current Status

1. No formal CAS review has been done. A quick condition assessment was done in July 1992.

2. No formal CAMP review has been done based on the latest Reconfiguration decision. A CAMP report was submitted on April 1, 1992, which focused on ES\&H needs, infrastructure maintenance, and consolidation projects.

2) Future Facility Use

a) Alternate Future Use Scenarios

1. WFO in the same discipline is likely under recent May 27, 1993, reconfiguration guidance. Many yentures, both defense and commercial, are in need of analytical services.

2. WFO in a new discipline is unknown under recent May 27, 1993, reconfiguration guidance. Probably none.

3. Commercialization possibilities under a lease agreement: $\mathrm{E}$ Building could be used as an independent environmental analytical laboratory. It could also support analytical services for other Mound business.

4. Commercialization under a sale agreement is unlikely in the short term, although there is a long-term possibility.

5. Deactivation effort should be minor for the building, as it is not contaminated with either radiological or energetic materials. A small amount of chemical contamination may be present. Asbestos has been found in the building, and may require abatement.

b) Facility Modifications Required for Likely Use

Probably no major building modification would be required for this use. The basic changes required would involve equipment. 
One existing problem with the building is the lack of an elevator in the two-story section of the building, limiting handicapped access. Several minor safety issues should be resolved to bring the building into compliance with all applicable codes and regulations.

c) Facility Modifications Required for Other Uses

Unknown.

d) Changes to Safety Envelope

The facility use suggested above should be covered under standard industrial hazard category unless significant amounts of hazardous materials are involved.

Any new work conducted in $\mathrm{E}$ Building may require that a safety assessment be performed to identify any new hazards involved in the process.

e) Cleanup Criteria for Each Future Use Scenario

E Building is not contaminated with any radioactive or energetic materials. A small amount of chemical contamination may be present, requiring limited cleanup. Asbestos abatement may be required before commercial use, depending on contract requirements.

f) Disposition of Surplus Equipment

None. 
This page intentionally blank. 


\section{HH BUILDING PHYSICAL CHARACTERIZATION}

1) Current Mission Description

a) Facility Capabilities

$\mathrm{HH}$ Building is a $15,276-\mathrm{ft}^{2}$ building used as an isotope separation facility. Isotopes, mostly in the gas phase, are produced and packaged in the building.

b) Resources Required to Support Operations

Primary Physical Resources:

Electricity

Potable water

Sanitary drainage

Physical security

Telecommunication devices

Fire protection, sprinklers, fire department

HVAC

Liquid nitrogen

Services:

Human Resources

Finance and Accounting

Environmental, Safety, and Health

Maintenance

Custodial

Payroll

Meal

Supply

c) Current Safety Envelope

HH Building operations are classified as standard industrial hazard.

d) Current Status

1. No formal CAS review has been done. A quick condition assessment was done in July 1992.

2. No formal CAMP review has been done based on the latest Reconfiguration decision. A CAMP report was submitted on April 1, 1992, which focused on ES\&H needs, infrastructure maintenance, and consolidation projects. 
2) Future Facility Use

a) Alternate Future Use Scenarios

1. WFO in the same discipline is unknown under recent May 27, 1993, reconfiguration guidance. Probably none.

2. WFO in a new discipline is unknown under recent May 27, 1993, reconfiguration guidance. Probably none.

3. Commercialization under a lease agreement possibility: $\mathrm{HH}$ Building would be useful as a facility for producing and packaging isotopes.

4. Commercialization under a sale agreement is unlikely in the short term, although there is a long-term possibility.

5. Deactivation effort should be minimal for most of the building, as it is not contaminated with either radiological or energetic materials. A small portion of the building no longer in use is radiologisally contaminated and is scheduled for D\&D completion in 1997.

b) Facility Modifications Required for Likely Use

Probably no major building modification would be required for this use. The basic changes required would involve equipment.

c) Facility Modifications Required for Other Uses

Unknown.

d) Changes to Safety Envelope

The facility use suggested above should be covered under standard industrial hazard category unless hazardous materials are involved. Any new work conducted in $\mathrm{HH}$ Building may require that a safety assessment be performed to identify any new hazards involved in the process.

e) Cleanup Criteria for Each Future Use Scenario

The isotope separation area is not contaminated with any radioactive or energetic materials.

f) Disposition of Surplus Equipment

Surplus equipment in HH Building may be disposed as required. 


\section{BUILDING PHYSICAL CHARACTERIZATION}

1) Current Mission Description

a) Facility Capabilities

I Building is a 25,736- $\mathrm{ft}^{2}$ building that is used for loading and testing of explosive actuators in support of defense programs. It is currently in active use for this purpose.

The building contains facilities and equipment uniquely suited to the handling of explosive materials, including:

- Explosion-proof electrical service

- Conductive surfaces

- Extra grounding and lightning protection

- Heavy-walled building construction

- Blowout cells for explosives handling

- Clean air hoods

- Presses for explosive materials

b) Resources Required to Support Operations

Primary Physical Resources:

Electricity

Potable water

Sanitary drainage

Physical security

Telecommunication devices

Fire protection, sprinklers, fire department

HVAC

Services:

Human Resources

Finance and Accounting

Environmental, Safety, and Health

Maintenance

Custodial

Payroll

Meal

Supply

Special Resources:

Argon, nitrogen and compressed air

Explosion-proof electrical service 
c) Current Safety Envelope

A safety analysis has been performed in I Building, and the building is classified as a low hazard facility.

d) Current Status

1. No formal CAS review has been done. A quick condition assessment was done in July 1992.

2. No formal CAMP review has been done based on the latest Reconfiguration decision. A CAMP report was submitted on April 1, 1992, which focused on ES\&H needs, infrastructure maintenance, and consolidation projects.

2) Future Facility Use

a) Alternate Future Use Scenarios

1. WFO in the same discipline is unknown under recent May 27, 1993, reconfiguration guidance. Probably none.

2. WFO in a new discipline is unknown under recent May 27, 1993, reconfiguration guidance. Probably none.

3. Commercialization possibilities under a lease agreement: I Building is suited to any type of laboratory operations, but is especially well-suited to the handling of explosive materials.

4. Commercialization under a sale agreement is unlikely in the short term, although there is a long-term possibility.

5. The building is probably contaminated with small amounts of energetic materials. In addition, asbestos has been found. This contamination may conceivably require cleanup before building deactivation.

b) Facility Modifications Required for Likely Use

Probably no major building modification would be required for this use. The basic changes required would involve equipment.

c) Facility Modifications Required for Other Uses

Unknown. 
d) Changes to Safety Envelope

The facility use suggested above should be covered under either the standard industrial hazard category or the low hazard category unless larger quantities of explosives are involved.

Any new work conducted in I Building may require that a safety assessment be performed to identify any new hazards involved in the process.

e) Cleanup Criteria for Each Future Use Scenario

I Building is contaminated with energetic materials, and also contains asbestos. Characterization and cleanup of this contamination may be required before any future use of the facility, depending on contractual requirements.

f) Disposition of Surplus Equipment

There are two large presses in I Building that are currently not in use and should be disposed of. They are both contaminated with small amounts of energetic materials, and they also have acbestos insulation.

Most other equipment in I Building may very well be useful in any new business opportunities. 
This page intentionally blank. 


\section{BUILDING PHYSICAL CHARACTERIZATION}

1) Current Mission Description

a) Facility Capabilities

The current active capabilities of M Building include:

* 1. An electroplating shop

2. A MW Heat Source surveillance facility

3. Electronics maintenance shop

4. ESH office space

* 5. Electrical substation that services the main buildings

6. M Building has the following assets:

- A high bay area with wood floors and with a crane spanning the area.

- Dimensions approximately $140 \mathrm{ft}$ long by $40 \mathrm{ft}$ wide and $26 \mathrm{ft}$ high, with $161 / 2 \mathrm{ft}$ below the crane.

- Two mezzanine areas for offices totalling approximately $5800 \mathrm{ft}^{2}$.

- Other low bay areas (excluding the electroplating shop and electrical substation) totalling approximately $39,500 \mathrm{ft}^{2}$.

- However, the building has no standard loading dock.

* These capabilities stay in the building. The other capabilities will be moved.

b) Resources Required to Support Operations

Primary Physical Resources

Electricity

Potable water

Sanitary drainage

Physical security

Telecommunication devices

Fire protection, sprinklers, fire department

HVAC 
Services

Human Resources

Finance and Accounting

Environmental, Safety, and Health

Maintenance

Custodial

Payroll

Meal

Supply

c) Current Safety Envelope

M Building operations are classified as standard industrial hazard.

Fumes generated in the plating shop from cleaning, pickling, and plating are passed through a scrubber. The liquid wastes are drummed up for disposal by an outside waste management firm.

d) Current Status

1. No formal CAS review has been done. A quick condition assessment was done in July 1992.

2. No formal CAMP review has been done based on the latest Reconfiguration decision. A CAMP report was submitted on April 1, 1992, which focused on ES\&H needs, infrastructure maintenance, and consolidation projects.

2) Future Facility Use

a) Alternate Future Use Scenarios

1. WFO in the same discipline is unknown under recent May 27, 1993, reconfiguration guidance. Probably none.

2. WFO in a new discipline is unknown under recent May 27, 1993, reconfiguration guidance. Probably none.

3. Commercialization possibilities under a lease agreement:

- Training area for machinist apprentices

- Isotope separation - high bay area for contacting columns

- Warehouse

- Hydrogen fuel cycle development for large equipment (for example, automotive equipment) 
- Miscellaneous manufacturing/assembly area

- Printed circuit boards

4. Commercialization under a sale agreement is unlikely in the short term, although there is a long-term possibility.

5. Deactivation effort should be minimal for the building itself. However, an assessment should be made of the building and the land it sits on. No apparent need for radiological decontamination exists because this building was never used for anything involving radioactive materials.

b) Facility Modifications Required for Likely Use

A likely use for M Building would be for hydrogen fuel cycle development. Probably no major building modification would be required for this use. However, ventilation requirements for use of $\mathrm{H}_{2}$ in the building would have to be examined. The basic changes required would involve equipment.

Questions of interest are:

- How do you generate hydrogen without generating other problems such as $\mathrm{CO}_{2}$ and how do you do it cheaply?

- How do you store hydrogen safety and conveniently?

- What modifications need to be made to automobiles and aircraft so that they will burn hydragen as fuel?

- What are the effects of $\mathrm{H}_{2}$ on materials of construction?

c) Facility Modification Required for Other Uses

Use of M Building for a warehouse or for a training center for machinist apprentices would not require a large capital expenditure.

Use of $\mathrm{M}$ Building for isotope separation would require relocation of equipment and offices from $\mathrm{HH}$ Building or installation of new equipment.

For manufacturing requiring clean room facilities, the ventilation would have to be modified to include HEPA filters and adequate ventilation for the clean rooms and air locks. The clean rooms and air locks would be built in the high bay area. 
d) Changes to Safety Envelope

All of the facility uses suggested above should be covered under standard industrial hazard category, unless uranium would be used in hydrogen fuel cycle work.

Any new work conducted in $M$ Building may require that a safety assessment be performed to identify any new hazards involved in the process.

e) Cleanup Criteria for Each Future Use Scenario

M Building is not contaminated with any radioactive or energetic materials. An unknown quantity of hazardous chemical contamination is believed to be present, consisting primarily of arsenic, cyanide, heavy metals and oils used in machining. (Refer to "Defense Programs - Facility Data Sheet" - G. F. Nafziger, 4-27-93.) Characterization and cleanup of these contaminants may be required before any future use of the facility, depending on contractual requirements.

f) Disposition of Surplus Equipment

M Building, at this time, holds a variety of milling machines, work benches, office furniture, heat treating furnaces and a hydroforming press that are not in use. These items are of broad usefulness to industry. Materials and equipment in good working order could potentially be applied to the new business venture in $M$ Building or sold to private industry. Equipment that is not in good condition could be sold for scrap. 


\section{T BUILDING PHYSICAL CHARACTERIZATION}

1) Current Mission Description

a) Facility Capabilities

T Building is a $172,963-\mathrm{ft}^{2}$ building used for tritium operations, tritium recovery, calorimetry production, tritium commercial sales, heat source calibration, x-ray facility, and safeguards gamma scanning support. $\mathrm{T}$ Building is one of the original buildings constructed at Mound. Designed by Giffels and Vallet Inc. of Detroit, Michigan, it was built in 1947-1948. T Building is an underground, massively constructed, reinforced concrete structure containing two floors.

b) Resources Required to Support Operations

Primary Physical Resources:

Electricity

Physical security

Fire protection, sprinklers, fire department

Potable water

Sanitary drains

HVAC

Breathing air

Liquid nitrogen

Helium, nitrogen, argon gas

Elevators

Services:

Human Resources

Finance and Accounting

Environmental, Safety, and Health

Maintenance

Custodial

Payroll

Meal

Supply

c) Current Safety Envelope

T Building is a Category II facility based on DOE standard 1027-92. DOE-approved FSARs and OSRs are in place for all operations conducted in T Building except the Tritium Engineering Development Laboratory (TEDL) for which the FSAR is pending. FSAR documents are: 


$\begin{array}{ll}\text { KYLE } & \text { MLM-CF-83-11-0001 } \\ \text { TAWRS } & \text { MLM-ML-85-46-0001 } \\ \text { HISS } & \text { MLM-ML-86-43-0001 } \\ \text { SROC } & \text { MLM-CF-83-0600001 } \\ \text { TEDL } & \text { Pending } \\ \text { TERF } & \text { MLM-ML-91-45-0004 }\end{array}$

The Operational Safety Requirements (OSRs) for $\mathrm{T}$ Building are defined in Technical Manual MD-10290. Limiting Conditions of Operation (LCOs) form a part of MD-10290.

\section{d) Current Status}

1. No formal CAS review has been done. A quick condition assessment was done in July 1992.

2. No formal CAMP review has been done based on the latest Reconfiguration decision. A CAMP roport was submitted on April 1, 1992, which focused on ES\&H. needs, infrastructure maintenance, and consolidation projects.

2) Future Facility Use

a) Alternate Future Use Scenarios

1. WFO in the same discipline is possible under recent May 27, 1993, reconfiguration guidance.

2. WFO in a new discipline is unknown under recent May 27, 1993, reconfiguration guidance. Probably none.

3. Commercialization possibilities under a lease agreement are unknown under recent May 27, 1993, reconfiguration guidance.

4. Commercialization under a sale agreement under May 27, 1993 , reconfiguration guidance is possible in the commercial tritium sales business and calorimeter fabrication business.

5. T Building and its equipment are contaminated with radiological material. Extensive asbestos abatement was done in 1990 in preparation for the Nuclear Facilities Modernization project. 
b) Facility Modifications Required for Likely Use

None. Loading of tritium reservoirs for commercial sales is done in the existing glovebox lines. Tritium recovery facilities could be used for the deactivation of tritium operation areas. Calorimeter production could continue in $\mathrm{T}$ Building without any facility modifications.

c) Facility Modifications Required for Other Uses

Unknown.

d) Changes to Safety Envelope

Unknown.

e) Cleanup Criteria for Each Future Use Scenario

$\mathrm{T}$ Building is contaminated with radiological materials.

f) Disposition of Surplus Equipment

Unknown. 
This page intentionally blank.

$3 \cdot 28$ 


\section{BUILDING 1 PHYSICAL CHARACTERIZATION}

1) Current Mission Description

a) Facility Capabilities

Building 1 is a $986-\mathrm{ft}^{2}$ building used for packaging and repackaging of energetic materials in support of defense programs. It is currently in active use for this purpose. Building 1 consists of four heavy-walled rooms, each of which can handle 10-pound quantities of energetic materials.

b) Resources Required to Support Operations

Primary Physical Resources:

Electricity

Potable water

Sanitary drainage

Physical security

Telecommunication devices

Fire protection, sprinklers, fire department

HVAC

Services:

Human Resources

Finance and Accounting

Environmental, Safety, and Health

Maintenance

Custodial

Payroll

Meal

Supply

c) Current Safety Envelope

Building 1 operations are classified as moderate hazard, because of the large quantities of energetic materials processed.

d) Current Status

1. No formal CAS review has been done. A quick condition assessment was done in July 1992.

2. No formal CAMP review has been done based on the latest Reconfiguration decision. A CAMP report was submitted on 
April 1, 1992, which focused on ES\&H needs, infrastructure maintenance, and consolidation projects.

2) Future Facility Use

a) Alternate Future Use Scenarios

1. WFO in the same discipline is likely under recent May 27 , 1993, reconfiguration guidance. This packaging facility could support any work involving energetic materials at Mound.

2. WFO in a new discipline is unknown under recent May 27, 1993, reconfiguration guidance. Probably none.

3. Commercialization possibilities under a lease agreement: Building 1 would be useful for any application requiring packaging or repackaging of large quantities of energetic materials.

4. Commercialization under a sale agreement is unlikely in the short term, although there is a long-term possibility.

5. Deactivation effort should be minimal; the building is not contaminated with significant quantities of radiological or energetic materials. Asbestos has been found in the building and may require abatement.

b) Facility Modifications Required for Likely Use

Probably no major building modification would be required for this use. The basic changes required may involve equipment.

c) Facility Modifications Required for Other Uses

Unknown.

d) Changes to Safety Envelope

The safety classification for Building 1 should not change as a result of the likely use above. It is possible that the safety classification may even drop to a lower hazard class if the quantities of energetic materials handled should decrease. Any new work conducted in Building 1 may require that a safety assessment be performed to identify any new hazards involved in the process. 
e) Cleanup Criteria for Each Future Use Scenario

There is no significant contamination from radiological or energetic materials in the building. However, the building does contain asbestos, which may require abatement before some commercial uses, depending on contractual requirements.

f) Disposition of Surplus Equipment

Several large powder-blending machines are stored in Building 1. These machines are contaminated with energetic materials and would require decontamination before they could be sold or discarded. 
This page intentionally blank. 


\section{BUILDING 27 PHYSICAL CHARACTERIZATION}

1) Current Mission Description

a) Facility Capabilities

Building 27 is a 5,285- $\mathrm{ft}^{2}$ building that houses the explosive process operations to manufacture explosive powders. This building has bays that have 1-ft thick walls and ceilings protected by a heavy-duty sprinkler system. All electrical wiring is explosion-proof and the building has a process drainage system. The general condition of the building is good. A fence is scheduled to be built around the building.

b) Resources Required to Support Operations

Primary Phyøical Resources:

Electricity

Potable water

Sanitary drainage

Physical security

Telecommunication devices

Fire protection, sprinklers, fire department

HVAC (air conditioning needs major work)

Services:

Human Resources

Environmental, Safety, and Health

Maintenance

Custodial

Supply

c) Current Safety Envelope

Building 27 operations are classified as standard industrial hazard.

d) Current Status

1. No formal CAS review has been done.

2. No formal CAMP review has been done based on the latest Reconfiguration decision. 
2) Future Facility Use

a) Alternate Future Use Scenarios

1. WFO in the same discipline is possible under recent May 27, 1993, reconfiguration guidance.

2. WFO in a new discipline is unknown under recent May 27, 1993, reconfiguration guidance. Probably none.

3. Commercialization possibilities under a lease agreement: None.

4. Commercialization under a sale agreement is unlikely in the short term, although there is a long-term possibility.

5. Deactivation effort should be minimal for the building, as it is not contaminated with either radiological or energetic materials.

b) Facility Modifications Required for Likely Use

Probably no major building modification would be required for this use. The basic changes required would involve equipment.

c) Facility Modifications Required for Other Uses

Unknown.

d) Changes to Safety Envelope

The facility use suggested above should be covered under standard industrial hazard category.

Any new work conducted in Building 27 may require that a safety assessment be performed to identify any new hazards involved in the process.

e) Cleanup Criteria for Each Future Use Scenario

Building 27 is not contaminated with any radioactive or energetic materials.

f) Disposition of Surplus Equipment

None. 


\section{BUILDING 28 PHYSICAL CHARACTERIZATION}

1) Current Mission Description

a) Facility Capabilities

Building 28 is a $11,329-\mathrm{ft}^{2}$ building that is used for ceramics development and production. It is currently in active use for this purpose. Building 28 contains several large ceramics furnaces.

b) Resources Required to Support Operations

Primary Physical Resources:

Electricity

Potable water

Sanitary drainage

Physical security

Telecommunication devices

Fire protection, sprinklers, fire department HVAC

Services:

Human Resources

Finance and Accounting

Environmental, Safety, and Health

Maintenance

Custodial

Payroll

Meal

Supply

Special Resources:

Bottled gases

c) Current Safety Envelope

Building 28 operations are classified as low hazard.

d) Current Status

1. No formal CAS review has been done. A quick condition assessment was done in July 1992.

2. No formal CAMP review has been done based on the latest Reconfiguration decision. A CAMP report was submitted on 
April 1, 1992, which focused on ES\&H needs, infrastructure maintenance, and consolidation projects.

2) Future Facility Use

a) Alternate Future Use Scenarios

1. WFO in the same discipline possible under recent May 27, 1993 , reconfiguration guidance. Building 28 could be used in development of a variety of ceramic components, as well as for low-volume, high-quality production of ceramic products.

2. WFO in a new discipline is unknown under recent May 27, 1993, reconfiguration guidance. Probably none.

3. Commercialization possibilities under a lease agreement: Building 28 could be used in the development of a variety of ceramic components, as well as for low-volume, high-quality production of ceramic products.

4. Commercialization under a sale agreement is unlikely in the short term, although there is a long-term possibility.

5. Deactivation effort should be minimal for the building, as it is not contaminated with either radiological or energetic materials. However, asbestos has been found in the building, and may require abatement.

b) Facility Modifications Required for Likely Use

Probably no major building modification would be required for this use. The basic changes required may involve equipment.

c) Facility Modifications Required for Other Uses

Unknown.

d) Changes to Safety Envelope

The facility use suggested above should be covered under low hazard category.

Any new work conducted in Building 28 may require that a safety assessment be performed to identify any new hazards involved in the process. 
e) Cleanup Criteria for Each Future Use Scenario

Building 28 is not contaminated with any radioactive or energetic materials. However, asbestos has been found in the building, and may require abatement before any commercial use, depending on contract requirements.

\section{f) Disposition of Surplus Equipment}

The furnases in Building 28 are now in active use, but their large size may make them difficult to dispose of in the future. Any future use of the building should assume that the furnaces will remain in place. 
This page intentionally blank. 


\section{BUILDING 29 PHYSICAL CHARACTERIZATION}

1) Current Mission Description

a) Facility Capabilities

Building 29 is in a standby reserve condition. It was formerly used as a plastics formulation and manufacturing facility.

b) Resources Required to Support Operations.

Primary Physical Resources:

Electricity

Potable water

Sanitary drainage

Physical security

Telecommunication devices

Fire protection, sprinklers, fire department HVAC

Other Resources required if taken off standby reserve condition and reactivated.

Services:

Human Resource Services

Finance and Accounting Services

ES\&H Services

Maintenance Services

Custodial Services

Payroll Services

Meal Service

Supply Services

c) Current Safety Envelope

The former Building 29 operations were considered to be standard industrial hazard. However, some of the equipment in Building 29 is contaminated with asbestos since asbestos was often used for filler and reinforcing in plastic formulations.

d) Current Status

1. No formal CAS review has been done. A quick condition assessment was done in July 1992 . See the data sheet in the document, Quick Condition Assessment for Facilities Identified for Defense Program Shutdown.

2. No formal CAMP review has been done based on the latest Reconfiguration decision. A CAMP report, Capital Assets Management Process FY 1944 Submission April 1, 1992, was 
submitted which focused on ES\&H needs, infrastructure, maintenance, and consolidation projects.

2) Future Facility Use

a) Alternate Future Use Scenarios

1. WFO in the same discipline is unknown under recent May 25, 1993, reconfiguration guidance. Probably none.

2. WFO in a new discipline is unknown under recent May 25, 1993, reconfiguration guidance. Probably none.

3. Commercialization possibilities under lease agreement: Not likely.

4. Commercialization possibilities under a sales agreement: Not likely.

5. Deactivation cost for future use was estimated at $\$ 5,538,000$ (in Quick Condition Assessment for Facilities Identified for Defense Program Shutdown (FIP) EG\&G Mound, Miamisburg, Ohio) largely because of asbestos abatement costs.

b) Facility Modification Required for Likely Uses

None.

c) Facility Modifications Required for Other Uses

Unlikely.

d) Changes to Safety Envelope

None.

e) Cleanup Criteria for Each Future Use Scenario

Unknown.

f) Disposition of Surplus Equipment

Probably no equipment will be surplused, but will be sent to a suitable landfill for asbestos-contaminated materials. 


\section{BUILDING 30 PHYSICAL CHARACTERIZATION}

1) Current Mission Description

a) Facility Capabilities

Building 30 is a $740-\mathrm{ft}^{2}$ building that serves as an office and storage area supporting the Environmental, Safety, and Health Department. It is surrently in active use for this purpose.

b) Resources Required to Support Operations

Primary Physical Resources:

Electricity

Potable water

Sanitary drainage

Physical security

Telecommunication devices

Fire Protection, sprinklers, fire department

HVAC

Services:

Human Resources

Finance and Accounting

Environmental, Safety, and Health

Maintenance

Custodial

Payroll

Meal

Supply

c) Current Safety Envelope

Building 30 operations are classified as standard industrial hazard. Flammable chemicals, including liquid scintillation cocktail, are stored there.

d) Current Status

1. No formal CAS review has been done. A quick condition assessment was done in July 1992.

2. No formal CAMP review has been done based on the latest Reconfiguration decision. A CAMP report was submitted in 
April 1, 1992, which focused on ES\&H needs, infrastructure maintenance, and consolidation projects.

2) Future Facility Use

a) Alternate Future Use Scenarios

1. WFO in the same discipline is unknown under recent May 27, 1993, reconfiguration guidance. Probably none.

2. WFO in a new discipline is unknown under recent May 27, 1993, reconfiguration guidance. Probably none.

3. Commercialization possibility under a lease agreement is unlikely.

4. Commercialization under a sale agreement is unlikely.

5. Building 30 is slightly contaminated with radioactive plutonium-238. In addition, the building contains asbestos. This contamination may require cleanup before building deactivation.

b) Facility Modifications Required for Likely Use

None.

c) Facility Modifications Required for Other Uses

Unknown.

d) Changes to Safety Envelope

None. Any new work conducted in Building 30 may require that a safety assessment be performed to identify any new hazards involved in the process.

e) Cleanup Criteria for Each Future Use Scenario

Building 30 is slightly contaminated with radioactive materials. Cleanup of this contamination may be required before any future use.

f) Disposition of Surplus Equipment

None. 


\section{BUILDING 36 PHYSICAL CHARACTERIZATION}

1) Current Mission Description

a) Facility Capabilities

Building 36 is a $4255-\mathrm{ft}^{2}$ building that supports the GPHS testing operations. It was built in 1968.

There are three high-temperature bake-out ovens and a long-term temperature facility that operate continuously. GPHS requires the long-term temperature study for several more years.

This building also houses a degreasing facility for cleaning hardware.

b) Resources Required to Support Operations

Primary Physical Resources:

Electricity

$\mathrm{Ph}$, sical security

Fire protection, sprinklers, fire department

Potable water

Sanitary drains

HVAC

Chilled vrater

Liquid nitrogen

Services:

Human Resources

Finance and Accounting

Environmental, Safety, and Health

Maintenance

Custodial

Payroll

Meal

Supply

c) Current Safety Envelope

Building 36 operations are classified as standard industrial hazard.

d) Current Status

1. No formal CAS review has been done. A quick condition assessment was done in July 1992.

2. No formal CAMP review has been done based on the latest Reconfiguration decision. A CAMP report was submitted on 
April 1, 1992, which focused on ES\&H needs, infrastructure maintenance, and consolidation projects.

2) Future Facility Use

a) Alternate Future Use Scenarios

1. WFO in the same discipline is unknown under recent May 27, 1993, reconfiguration guidance. Probably none.

2. WFO in a new discipline is unknown under recent May 27, 1993, reconfiguration guidance. Probably none.

3. Commercialization possibilities under a lease agreement: Probably none.

4. Commercialization possibilities under a sale agreement: Probably none.

5. Deactivation effort should be minimal for the building, as it is not contaminated with either radiological or energetic materials.

A May 1993 Mound Asbestos Survey identified asbestos in the thermal insulation systems of Building 36 .

There are no near future plans to deactivate this building, since the building supports the GPHS program.

b) Facility Modifications Required for Likely Use

None. This building is currently supporting the GPHS program.

Future use of the building would likely be the same.

c) Facility Modifications Required for Other Uses

Not applicable.

d) Changes to Safety Envelope

Not applicable.

e) Cleanup Criteria for Each Future Use Scenario

Not applicable.

f) Disposition of Surplus Equipment

Not applicable. 


\section{BUILDING 37 PHYSICAL CHARACTERIZATION}

1) Current Mission Description

a) Facility Capabilities

Building 37 is a $2463-\mathrm{ft}^{2}$ building used for two functions. The first is research, development, and pilot plant production in conjunction with the U.S. Advanced Battery Consortium (USABC). The second function is converting processes with freon or other hazardous materials to processes that use safer materials as part of the Environmental Response Cleaning Program. Major equipment in the building are furnaces, presses, fumehoods, polymer processing equipment, and mechanical testing equipment. There is also space in the building for two offices.

b) Resources Required to Support Operations

Primary Physical Resources:

Electricity

Potable water

Sanitary drainage

Physical security

Telecommunication devices

Fire protection, sprinklers, fire department

HVAC

Compressed air

Services:

Human Resources

Finance and Accounting

Environmental, Safety, and Health

Maintenance

Custodial

Payroll

Meal

Supply

c) Current Safety Envelope

Building 37 operations are classified as standard industrial hazard. 
d) Current Status

1. No formal CAS review has been done. A quick condition assessment was done in July 1992.

2. No formal CAMP review has been done based on the latest Reconfiguration decision. A CAMP report was submitted on April 1, 1992, which focused on ES\&H needs, infrastructure maintenance, and consolidation projects.

3. In association with the Environmental Response Cleaning Program, activities in Building 37 are involved with other DOE sites through several working groups. The groups are the Interagency Manufacturing Operations Group, the Solvent Substitute Interagency Working Group, and the Superfluid Critical Technology Working Group.

\section{2) Future Facility Use}

a) Alternate Future Use Scenarios

1. WFO in the same discipline is unknown under recent May 27, 1993, reconfiguration guidance. Probably none.

2. WFO in a new discipline is unknown under recent May 27, 1993, reconfiguration guidance. Probably none.

3. Commercialization under a lease agreement possibility: Building 37 would be useful for continuing work for the USABC via a CRADA. Building 37 would also be useful for applications requiring special polymer processing.

4. Commercialization under a sale agreement is unlikely in the short term, although there is a long-term possibility.

5. Deactivation effort should be minimal; the building is not contaminated with either radiological or energetic materials.

b) Facility Modifications Required for Likely Use

Probably no major building modification would be required for this use. The basic changes required would involve equipment. 
c) Facility Modifications Required for Other Uses

Unknown.

d) Changes to Safety Envelope

The facility use suggested above should be covered under standard industrial hazard category. Any new work in Building 37 may require that a safety assessment be performed to identify any new hazards involved in the process.

e) Cleanup Criteria for Each Future Use Scenario

Building 37 is not contaminated with any radioactive or energetic materials.

f) Disposition of Surplus Equipment

Surplus equipment in Building 37 may be readily disposed of, as required. 
This page intentionally blank. 


\section{BUILDING 38 PHYSICAL CHARACTERIZATION}

1) Current Mission Description

a) Facility Capabilities

Building 38 is a $44,327-\mathrm{ft}^{2}$ building which is partly being

decommissioned in the basement, but also supports the assembly and testing of RTGs. These other activities are supported in Building 38:

- Respirator cleaning facility

- Calibration facility for HP equipment

- Orphan source

- Analytical facility

b) Resources Required to Support Operations

Primary Physical Resources:

Electricity

Physical security

Fire protection, sprinklers, fire department

Potable water

Sanitary drains

HVAC

HEPA filtration

Emergency generator

Breathing air

Services:

Human Resources

Finance and Accounting

Environmental, Safety, and Health

Maintenance

Custodial

Payroll

Meal

Supply

c) Current Safety Envelope

Building 38 currently operates under OSR MD-10305, and FSAR MLM-ENG-105.

d) Current Status

1. No formal CAS review has been done. A quick condition assessment was done in July 1992.

2. No formal CAMP review has been done based on the latest Reconfiguration decision. A CAMP report was submitted on 
April 1, 1992, which focused on ES\&H needs, infrastructure maintenance, and consolidation projects.

\section{2) Future Facility Use}

\section{a) Alternate Future Use Scenarios}

1. WFO in the same discipline is unknown under recent May 27, 1993, reconfiguration guidance.

2. WFO in a new discipline is unknown under recent May 27, 1993, reconfiguration guidance.

3. Commercialization possibilities under a lease agreement are unknown under recent May 27, 1993, reconfiguration guidance.

4. Commercialization possibilities under a sale agreement are unknown under recent May 27, 1993, reconfiguration guidance.

5. There are no near future plans to further D\&D this building other than the basement, because the building supports the RTG program.

b) Facility Modifications Required for Likely Use

None. Building is currently supporting the RTG program. Future use of the building would likely be the same.

c) Facility Modifications Required for Other Uses

Unknown.

d) Changes to Safety Envelope

Unknown.

e) Cleanup Criteria for Each Future Use Scenario

Building 38 is contaminated with radiological materials.

f) Disposition of Surplus Equipment

Unknown. 


\section{BUILDING 42 PHYSICAL CHARACTERIZATION}

1) Current Mission Description

a) Facility Capabilities

Building 42 is a $2892-\mathrm{ft}^{2}$ building that is used for production of pyrotechnics and thermites and for materials compatibility studies in support of defense programs. It is currently in active use for this purpose.

Specialized equipment in the building includes:

Vacuum chambers

Blending equipment

Remote manipulators

Fire hoods

Explosive barricades

Analytical equipment such as:

FTIR

GC

LC

Photoacoustic GC

ARC

DSC

b) Resources Required to Support Operations

Primary Physical Resources:

Electricity

Potable water

Sanitary drainage

Physical security

Telecommunication devices

Fire protection, sprinklers, fire department

HVAC

Services:

Human Resources

Finance and Accounting

Environmental, Safety, and Health

Maintenance

Custodial

Payroll

Meal

Supply 
Special Resources:

Explosion-proof electrical service

Conductive flooring

Additional grounding

Humidity control

Liquid nitrogen

Bottled gases

c) Current Safety Envelope

Building 42 operations are classified as low hazard.

d) Current Status

1. No formal CAS review has been done. A quick condition assessment was done in July 1992.

2. No formal CAMP review has been done based on the latest Reconfiguration decision. A CAMP report was submitted on April 1, 1992, which focused on ES\&H needs, infrastructure maintenance, and consolidation projects.

2) Future Facility Use

a) Alternate Future Use Scenarios

1. WFO in the same discipline possible under recent May 27, 1993, reconfiguration guidance. Manufacture of pyrotechnics and thermites could be carried out for a wide range of customers.

2. WFO in a new discipline is unknown under recent May 27, 1993, reconfiguration guidance. Probably none.

3. Commercialization possibilities under a lease agreement:

Manufacture of pyrotechnics and thermites could be carried out for a wide range of customers. The building would also be useful as a small-scale component manufacturing facility.

4. Commercialization under a sale agreement is unlikely in the short term, although there is a long-term possibility.

5. Building 42 is contaminated with energetic materials. In addition, asbestos has been found in the building. Deactivation effort may conceivably require cleanup of this contamination. 
b) Facility Modifications Required for Likely Use

Probably no major building modification would be required for the above uses. The basic changes required may involve equipment.

c) Facility Modifications Required for Other Uses

Unknown.

d) Changes to Safety Envelope

The facility uses suggested above should be covered under low hazard or standard industrial hazard category unless large quantities of hazardous materials are involved.

Any new work conducted in Building 42 may require that a safety assessment be performed to identify any new hazards involved in the process.

e) Cleanup Criteria for Each Future Use Scenario

Building 42 is contaminated with energetic materials. It also contains asbestos. This contamination may require cleanup before unrestricted commercial use of the facility, depending on contract requirements.

\section{f) Disposition of Surplus Equipment}

Some of the equipment in Building 42 is contaminated with energetic material and may be difficult to dispose of at the end of its useful life. The explosive barricades are large and may need to be reduced in size before disposal at the end of their useful lives. 
This page intentionally blank. 


\section{BUILDING 49 PHYSICAL CHARACTERIZATION}

\section{1) Current Mission Description}

\section{a) Facility Capabilities}

Building 49 is a $14,929-1 t^{2}$ building used for explosive timer production. The building contrins a few offices, a rest room, explosive storage areas, and the production facility. A few of the areas are on standby (empty). The production facility includes fumehoods, thermal chambers, and presses.

\section{b) Resources Required to Support Operations}

Primary Physical Resources:

Electricity

Potable water

Sanitary drainage

Physical security

Telecommunication devices

Fire protection, sprinklers, fire department HVAC

Services:

Human Resources

Finance and Accounting

Environmental, Safety, and Health

Maintenance

Custodial

Payroll

Meal

Supply

c) Current Safety Envelope

Building 49 operations are classified as standard industrial hazard.

d) Current Status

1. No formal CAS review has been done. A quick condition assessment was done in July 1992.

2. No formal CAMP review has been done based on the latest Reconfiguration decision. A CAMP report was submitted on April 1, 1992, which focused on ES\&H needs, infrastructure maintenance, and consolidation projects. 
2) Future Facility Use

a) Alternate Future Use Scenarios

1. WFO in the same discipline is unknown under recent May 27, 1993, reconfiguration guidance. Probably none.

2. WFO in a new discipline is unknown under recent May 27, 1993, reconfiguration guidance. Probably none.

3. Commercialization possibility under a lease agreement: Building 49 would be useful for any application requiring large environmental conditioning chambers or presses.

4. Commercialization under a sale agreement is unlikely in the short term, although there is a long-term possibility.

5. Deactivation effort should be minimal; the building is not contaminated with either radiological or energetic materials.

b) Facility Modifications Required for Likely Use

Probably no major building modification would be required for this use. The basic changes required would involve equipment.

c) Facility Modifications Required for Other Uses

Unknown.

d) Changes to Safety Envelope

The facility use suggested above should be covered under standard industrial hazard category unless hazardous materials are involved. Any new work conducted in Building 49 may require that a safety assessment be performed to identify any new hazards involved in the process.

e) Cleanup Criteria for Each Future Use Scenario

Building 49 is not contaminated with radioactive or energetic materials.

f) Disposition of Surplus Equipment

Equipment in Building 49 may be readily disposed as required. 


\section{BUILDING 50 PHYSICAL CHARACTERIZATION}

1) Current Mission Description

a) Facility Capabilities

Building 50 is a $14,849-\mathrm{ft}^{2}$ building that is used to assemble and test RTGs. It was built in 1971 .

b) Resources Required to Support Operations

Primary Physical Resources:

Electricity

Physical security

Fire protection, sprinklers, fire department

Potable water

Sanitary drains

HVAC

HEPA filtration

Breathing air

Services:

Human Resources

Finance and Accounting

Environmental, Safety, and Health

Maintenance

Custodial

Payroll

Meal

Supply

c) Current Safety Envelope

Building 50 currently operates under OSR MD-10296, and FSAR MLM-ML-9152005.

d) Current Status

1) No formal CAS review has been done. A quick condition assessment was done in July 1992.

2) No formal CAMP review has been done based on the latest Reconfiguration decision. A CAMP report was submitted on April 1, 1992, which focused on ES\&H needs, infrastructure maintenance, and consolidation projects. 
2) Future Facility Use

a) Alternate Future Use Scenarios

1. WFO in the same discipline is unknown under recent May 27, 1993, reconfiguration guidance. Probably none.

2. WFO in a new discipline is unknown under recent May 27, 1993, reconfiguration guidance. Probably none.

3. Co.nmercialization possibilities under a lease agreement: Probably none.

4. Commercialization possibilities under a sale agreement: Probably none.

5. There are no near future plans to $D \& D$ this building, as it supports the RTG program.

b) Facility Modifications Required for Likely Use

None. This building is currently supporting the RTG program. Future use of the building would likely be the same.

c) Facility Modifications Required for Other Uses

Not applicable.

d) Changes to Safety Envelope

Not applicable.

e) Cleanup Criteria for Each Future Use Scenario

Not applicable.

f) Disposition of Surplus Equipment

Not applicable. 


\section{BUILDING 60 PHYSICAL CHARACTERIZATION}

\section{1) Current Mission Description}

a) Facility Capabilities

Building 60 is a $3958-\mathrm{ft}^{2}$ building that is used for ceramic development and nondestructive testing. It is currently in active use for this purpose.

b) Resources Required to Support Operations

Primary Physical Resources:

Electricity

Potable water

Sanitary drainage

Telecommunication devices

Fire protection, sprinklers, fire department

HVAC

Services:

Human Resources

Finance and Accounting

Environmental, Safety, and Health

Maintenance

Custodial

Payroll

Meal

Supply

c) Current Safety Envelope

Building 60 operations are classified as standard industrial hazard.

d) Current Status

1. No formal CAS review has been done. A quick condition assessment was done in July 1992.

2. No formal CAMP review has been done based on the latest Reconfiguration decision. A CAMP report was submitted on April 1, 1992, which focused on ES\&H needs, infrastructure maintenance, and consolidation projects. 
2) Future Facility Use

a) Alternate Future Use Scenarios

1. WFO in the same discipline is unknown under recent May 27, 1993, reconfiguration guidance. Probably none.

2. WFO in a new discipline is unknown under recent May 27, 1993, reconfiguration guidance. Probably none.

3. Commercialization possibilities under a lease agreement: Building 60 would be useful for any application requiring ceramic development or research.

4. Commercialization under a sale agreement is unlikely in the short term, although there is a long-term possibility.

5. Deactivation effort should be minimal; the building is not contaminated with either radiological or energetic materials.

b) Facility Modifications Required for Likely Use

Probably no major building modification would be required for this use. The basic changes required would involve equipment.

c) Facility Modifications Required for Other Uses

Unknown.

d) Changes to Safety Envelope

The facility use suggested above should be covered under standard industrial hazard category unless hazardous materials are involved. Any new work conducted in Building 60 may require that a safety assessment be performed to identify any new hazards involved in the process.

e) Cleanup Criteria for Each Future Use Scenario

Building $6 U$ is not contaminated with any radioactive or energetic materials.

f) Disposition of Surplus Equipment

There is a large furnace and a hot press located in Building 60 . These two items will need to be removed if the future use of the building does not require these services. 


\section{BUILDING 63E PHYSICAL CHARACTERIZATION}

1) Current Mission Description

a) Facility Capabilities

Building $63 \mathrm{E}$ is a $13,418-\mathrm{ft}^{2}$ building dedicated to test systems design and development. The building is scheduled to be vacated very soon.

Building 63E has the following facilities:

Office and design space on the second floor.

Conference room.

Machine shop.

Computer room.

Darkroom.

b) Resources Required to Support Operations

Primary Physical Resources:

Electricity

Potable water

Sanitary drainage

Physical security

Telecommunication devices

Fire protection, sprinklers, fire department

HVAC

Services:

Human Resources

Finance and Accounting

Environmental, Safety, and Health

Maintenance

Custodial

Payroll

Meal

Supply

c) Current Safety Envelope

Building $63 \mathrm{E}$ operations are classified as standard industrial hazard.

d) Current Status

1. No formal CAS review has been done. A quick condition assessment was done in July 1992. 
2. No formal CAMP review has been done based on the latest Reconfiguration decision. A CAMP report was submitted on April 1, 1992, which focused on ES\&H needs, infrastructure maintenance, and consolidation projects.

2) Future Facility Use

a) Alternate Future Use Scenarios

1. WFO in the same discipline is unknown under recent May 27, 1993, reconfiguration guidance. Probably none.

2. WFO in a new discipline is unknown under recent May 27, 1993, reconfiguration guidance. Probably none.

3. Commercialization possibilities under a lease agreement: Building $63 \mathrm{E}$ would be ideal as a self-contained design and development facility for applications such as automation or small-scale machining.

4. Commercialization under a sale agreement is unlikely in the short term, although there is a long-term possibility.

5. Deactivation effort should be minimal for the building, as it is not contaminated with either radiological or energetic materials. However, asbestos has been found in the building, and may require abatement.

b) Facility Modifications Required for Likely Use

Probably no major building modification would be required for this use. The basic changes required would involve equipment. One concern is that the building is two stories tall and has no elevator. It may be necessary to improve handicapped access.

c) Facility Modifications Required for Other Uses

Unknown.

d) Changes to Safety Envelope

The facility use suggested above should be covered under standard industrial hazard category unless hazardous materials are involved. 
Any new work conducted in Building $63 \mathrm{E}$ may require that a safety assessment be performed to identify any new hazards involved in the process.

e) Cleanup Criteria for Each Future Use Scenario

Building $63 \mathrm{E}$ is not contaminated with any radioactive or energetic materials. Asbestos abatement may be required prior to any commercial use of the building, depending on contract requirements.

f) Disposition of Surplus Equipment

Building $63 \mathrm{E}$, after it is vacated, will contain only a small quantity of desks and partitions. These items are of broad usefulness. Materials in good working order could potentially be applied to the new business venture in Building $63 \mathrm{E}$ or sold to private industry. Equipment that is not in good condition could be sold for scrap. 
This page intentionally blank. 


\section{BUILDING 63W PHYSICAL CHARACTERIZATION}

\section{1) Current Mission Description}

a) Building $63 \mathrm{~W}$ is a $3050-\mathrm{ft}^{2}$ building used for long-term environmental conditioning studies in support of defense programs. It is currently in active use for this purpose. Half of Building $63 \mathrm{~W}$ is taken up by offices and half is taken up by large environmental storage and conditioning chambers, including ovens, and a spin test facility.

b) Resources Reguired to Support Operations

Primary Physical Resources:

Electricity

Potable water

Sanitary drainage

Physical security

Telecommunication devices

Fire protection, sprinklers, fire department

HVAC

Services:

Human Resources

Finance and Accounting

Environmental, Safety, and Health

Maintenance

Custodial

Payroll

Meal

Supply

c) Current Safety Envelope

Building $63 \mathrm{~W}$ is classified as a low hazard facility. The quantities of explosives handled in the building are between three grams and one kilogram.

d) Current Status

1. No formal CAS review has been done. A quick condition assessment was done in July 1992.

2. No formal CAMP review has been done based on the latest Reconfiguration decision. A CAMP report was submitted on April 1, 1992, which focused on ES\&H needs, infrastructure maintenance, and consolidation projects. 
2) Future Facility Use

a) Alternate Future Use Scenarios

1. WFO in the same discipline is unknown under recent May 27, 1993, reconfiguration guidance. Probably none.

2. WFO in a new discipline is unknown under recent May 27, 1993, reconfiguration guidance. Probably none.

3. Commercialization possibilities under a lease agreement: Building $63 \mathrm{~W}$ would be useful for any application requiring large environmental conditioning chambers.

4. Commercialization under a sale agreement is unlikely in the short term, although there is a long-term possibility.

5. Deactivation effort should be minimal for the building, as it is not contaminated with either radiological or energetic materials. Asbestos has been found in the building and abatement may be required.

b) Facility Modifications Required for Likely Use

Probably no major building modification would be required for this use. The basic changes required would involve equipment.

c) Facility Modifications Required for Other Uses

Unknown.

d) Changes to Safety Envelope

The facility use suggested above should be covered under the category of standard industrial hazard or low hazard unless larger quantities of explosives are involved. Any new work conducted in Building 63W may require that a safety assessment be performed to identify any new hazards involved in the process.

e) Cleanup Criteria for Each Future Use Scenario

Building $63 \mathrm{~W}$ is not contaminated with any radioactive or energetic materials. Asbestos abatement may be required before any commercial use of the building, depending on contract requirements.

f) Disposition of Surplus Equipment

The environmental chambers in Building 63W are large and would be very costly to move. Any future use of the facility should be planned on the assumption that the environmental chambers will remain in place. 


\section{BUILDING 65 PHYSICAL CHARACTERIZATION}

1) Current Mission Description

a) Facility Capabilities

Building 65 is a $2400-\mathrm{ft}^{2}$ building used as an office area. The building contains about ten offices, two general open areas (computer rooms), a conference room, and one bathroom.

b) Resources Required to Support Operations

Primary Physical Resources:

Electricity

Potable water

Sanitary drainage

Physical security

Telecommunication devices

Fire protection, sprinklers, fire department

HVAC

Services:

Human Resources

Finance and Accounting

Environmental, Safety, and Health

Maintenance

Custodial

Payroll

Meal

Supply

c) Current Safety Envelope

Building 65 operations are classified as standard industrial hazard.

d) Current Status

1. No formal CAS review has been done. A quick condition assessment was done in July 1992.

2. No formal CAMP review has been done based on the latest Reconfiguration decision. A CAMP report was submitted on April 1, 1992, which focused on ES\&H needs, infrastructure maintenance, and consolidation projects. 
2) Future Facility Use

a) Alternate Future Use Scenarios

1. WFO in the same discipline is unknown under recent May 27, 1793, reconfiguration guidance. Probably none.

2. WFO in a new discipline is unknown under recent May 27, 1993, reconfiguration guidance. Probab'y none.

3. Commercialization possibilities under a lease agreement: Building 65 would be useful as general office space.

4. Commercialization under a sale agreement is unlikely in the short term, although there is a long-term possibility.

5. Deactivation effort should be minimal; the building is not contaminated with either radiological or energetic materials.

b) Facility Modifications Required for Likely Use

Probably no major building modification would be required for this use. The basic changes required would involve equipment.

c) Facility Modifications Required for Other Uses

Unknown.

d) Changes to Safety Envelope

The facility use suggested above should be covered under standard industrial hazard category unless hazardous materials are involved. Any new work conducted in Building 65 may require that a safety assessment be performed to identify any new hazards involved in the process.

e) Cleanup Criteria for Each Future Use Scenario

Building 65 is not contaminated with any radioactive or energetic materials.

f) Disposition of Sirplus Equipment

Surplus equiprnent in Building 65 may be readily disposed as required. 


\section{BUILDING 67 PHYSICAL CHARACTERIZATION}

\section{1) Current Mission Description}

a) Facility Capabilities

Building 67 is a $3,787-\mathrm{ft}^{2}$ concrete-covered, polystyrene foam building used for operational support offices for Buildings 27 and 42 . Only personnel trained in explosive handling are allowed to use this building because of potential explosion hazards in Buildings 27 and 42.

b) Resources Required to Support Operations

$$
\begin{aligned}
& \text { Primary Physical Resources: } \\
& \text { Electricity } \\
& \text { Potable water } \\
& \text { Sanitary drainage } \\
& \text { Physical security } \\
& \text { Telecommunication devices } \\
& \text { Fire protection and sprinklers } \\
& \text { HVAC }
\end{aligned}
$$

Services:

Human Resources

Finance and Accounting

Environmental, Safety, and Health

Maintenance

Payroll

Meal

Supply

c) Current Safety Envelope

Building 67 operations are classified as standard industrial hazard.

d) Current Status

1. No formal CAS review has been done. A quick condition assessment was done in July 1992. The data sheet indicates contamination in Building 67. However, the building manager says there is no contamination there.

2. No formal CAMP review has been done based on the latest Reconfiguration decision. A CAMP report was submitted on 
April 1, 1992, which focused on ES\&H needs, infrastructure maintenance, and consolidation projects.

2) Future Facility Use

a) Alternative Future Use Scenarios

1. WFO in the same discipline continues under the recent May 27, 1993, reconfiguration guidance. The facilities, Building 27 and Building 42 , which this facility supports provide energetic materials to other government agencies outside the DOE complex.

2. WFO in a new discipline is unlikely.

3. Commercialization under a lease agreement is unlikely.

4. Commercialization under a sale agreement is unlikely.

5. Deactivation effort should be minimal for the building. It is not contaminated with radiological, energetic or asbestos materials. However, the ground under the building may have been contaminated from prior activities.

b) Facility Modifications Required for Likely Use

No building modifications would be required for this use.

c) Facility Modifications Required for Other Uses

Unknown.

d) Changes to Safety Envelope

Any expected use of the building would be classified as standard industrial hazard.

e) Cleanup Criteria for Each Future Use Scenario

No special cleanup activity is expected beyond ordinary housekeeping.

f) Disposition of Surplus Equipment

Office furniture could be surplused to other DOE sites or sold at auction to private organizations. 


\section{BUILDING 85 PHYSICAL CHARACTERIZATION}

\section{1) Current Mission Description}

a) Facility Capabilities

Building 85 was built in 1987 as a Class I Powder Processing facility. This 3,160- $\mathrm{ft}^{2}$ building contains a range of powder drying and blending equipment. Many of the machines can be remotely operated. Building 85 has the following assets:

- A high bay area.

- Large control room for remote operations.

- Three-foot thick reinforced concrete walls and ceiling.

- Explosion-proof electrical system.

b) Resources Required to Support Operations

Building 85 has never been used. In order to fulfill its stated purpose, the following resources would be needed in addition to Primary Physical Resources (such as electricity, potable water, etc.) and services (such as Payroll, Maintenance, etc.).

- Develop procedures especially for waste handling.

- Operational Readiness Review (ORR).

- Final Safety Analysis Report (FSAR).

- Replace dust collection system that has deteriorated as a result of neglect.

c) Current Safety Envelope

Because Building 85 has never been used it can be classified as a standard industrial hazard.

d) Currer. Status

1. No formal CAS review has been done. A quick condition assessment was done in July 1992.

2. No formal CAMP review has been done based on the latest Reconfiguration decision. A CAMP report was submitted in April 1, 1992, which focused on ES\&H needs, infrastructure maintenance, and consolidation projects. 
a) Alternate Future Use Scenarios

1. WFO in the same discipline is unknown under recent May 27, 1993 reconfiguration guidance. Probably none.

2. WFO in a new discipline is unknown under recent May 27, 1993, reconfiguration guidance. Probably none.

3. Commercialization possibilities under a lease agreement:

- Hazardous operations using remotely-operated equipment.

- Isotope separation using the high bay area for contacting columns.

- Clean room operations - high bay area will accommodate necessary HVAC equipment.

- Warehouse

4. Commercialization under a sale agreement is unlikely in the short term, although there is a long-term possibility.

5. Deactivation effort should be minimal since the building was never used.

b) Facility Modifications Required for Likely Use

If hazardous processing is performed in the building, a new air treatment system and a safety analysis will probably be required.

New equipment, suitable to the new operation, may be brought in.

c) Facility Modification Required for Other Uses

Use of the facility for isotope separation or clean room operations would require new equipment. Also, clean room operations would require clean room construction and IIVAC modifications. Use of Building 85 as a warehouse would probably require minimal modifications.

d) Changes to Safety Envelope

Use of Building 85 as a warehouse would be covered under the category of standard industrial hazard. Any other work proposed for 
Building 85 may require that a safety assessment be performed to identify any new hazards involved in the process.

e) Cleanup Criteria for Each Future Use Scenario

Building 85 is not contaminated with any radioactive or energetic materials at this time. Any proposed future use for the building should include a waste management plan to prevent future problems.

f) Disposition of Surplus Equipment

The powder processing equipment currently located in Building 85 may or may not be useful in any proposed new business venture. Any surplus equipment may be sold or scrapped. 
This page intentionally blank. 


\section{BUILDING 105 PHYSTCAL CHARACTERIZATION}

1) Current Mission Description

a) Facility Capabilities

The current active capabilities of Building 105 (PM Building) include:

- Ceramic machining

- Machining of small, tight tolerance parts, often made of exotic materials

- Metrology - automated

- CNC programmable milling machines

- CAD/CAM capabilities

b) Resources Required to Operate Building Include:

Primary Physical Resources:

Electricity

Potable water

Sanitary drainage

Physical security

Telecommunication devices

Fire protection, sprinklers, fire department

HVAC

Services:

Human Resource

Finance and Accounting

Environmental, Safety, and Health

Maintenance

Custodial

Payroll

Meal

Supply

c) Current Safety Envelope

Building 105 operations are under the classification of standard industrial hazard.

d) Current Status

1. No formal CAS review has been done. A quick condition assessment was done in July 1992. This information is on the 
page for Building 105 of the document Quick Condition Assessment for Facilities Identified for Defense Program Shutdown.

2. No formal CAMP review has been done based on the latest Reconfiguration decision. A CAMP report was submitted on April 1, 1992, which focused on ES\&H needs, infrastructure maintenance, and consolidation projects. The information on Parts Machining is covered under "Life Cycle Plan for Production Buildings Functional Unit No. 13" in the document Capital Assets Management Process FY 1994 Submission April $1,1992$.

2) Future Facility Use

a) Alternate Future Use Scenarios

1. WFO in the same discipline is feasible under recent May 27, 1993, reconfiguration guidance. This would include both weapons-related and nonweapons-related machining of both classified and unclassified parts for DOE or other federal agencies.

2. WFO in a new discipline is feasible under recent May 27, 1993, reconfiguration guidance. This could include a wide range of precision machining applications.

3. Commercialization possibilities under a lease agreement:

- High tech machine shop

- Training center for apprentice machinists

4. Commercialization under a sales agreement unlikely on a short-term basis, but possible on a long-term basis.

5. No deactivation will be required for conversion to the above activities. For transfer of the building to ER, equipment can be excessed in place.

b) Facility Modification Required for Likely Uses

None. 
c) Facility Modification Required for Other Uses

Unknown.

d) Changes to Safety Envelope

Changes to safety envelope should be minimal since the operations would be similar to current operations.

e) Cleanup Criteria for Each Future Use Scenario

Building 105 is not contaminated with any radioactive or energetic materials. There may be small quantities of nontoxic oils and solvents to clean up. (Refer to Defense Programs - Facility Data Sheet, for property ID - 105, G. F. Nafziger, 4-27-93.) However, any cleanup required will depend on future use and contractual commitments.

f) Disposition of Surplus Equipment

At this time there is no surplus equipment expected if the use of the building continues as forecasted. 


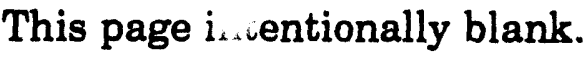

3. 78 


\section{SECTION 4: SERVICE BUILDINGS}

A. Planning Basis: The service buildings are a functional unit consisting of all facilities that are predominantly used for providing service to the plant.

Because of the current reduction in budget and workload, an effort is under way at Mound to consolidate facilities; that is, to shut down as much space as possible to the appropriate level of standby condition. Although a draft plan listing possible facilities and time frame of execution has been prepared for this effort, it is premature to detail its affect on this building functional unit.

1. Present Mission: The present mission of this functional unit is to provide facilities required to meet the service requirements of Mound. The various types of service and their associated buildings, identified by their respective building number or letter, follows. Further identification is provided in paragraph A.2.

Security training, change rooms, and vehicle shelter (three buildings): GP1, GP44, and 96 .

Maintenance and other repair (six buildings): G, PS, W, 26, 39, and 104.

Fire Protection and Emergency Services (one building): 98

Laundry, metrological, and printing services (four buildings): $\mathrm{H}, 25,33$, and 40 .

The total floor space for these 14 buildings is approximately $97,000 \mathrm{ft}^{2}$. The expected duration of this mission extends throughout the entire planning period.

2. Material Condition and Expected Useful Life: The material condition of the capital assets in this functional unit is generally good, and with some upgrade replacement of roofs and equipment, they are expected to retain their useful life throughout the entire planning period. 


\section{SERVICE BUILDINGS}

\begin{tabular}{|c|c|c|c|c|c|}
\hline BLDG & DESCRIPTION & CONDITION & $\begin{array}{c}\text { SQUARE } \\
\text { FOOTAC'E } \\
\text { (X 1000! }\end{array}$ & AGE (Yrs.) & $\begin{array}{c}\text { REMAINING } \\
\text { PROJECTED } \\
\text { USEFUL LIFE } \\
\end{array}$ \\
\hline G & Garage & Fair & 7.5 & 45 & 25 \\
\hline GP1 & Guand Post \#1 & Good & 7.8 & 44 & 16 \\
\hline GP-44 & Clothing Issue & Fair & 0.4 & 30 & 20 \\
\hline & Laundry & Fair & 17.3 & 45 & 25 \\
\hline PS & Paint Shop & Good & 8.3 & 30 & 20 \\
\hline $\mathbf{w}$ & Maintenance Shops & Good & 82.5 & 45 & 25 \\
\hline 25 & Weather Station & Poor & 0.4 & 27 & 13 \\
\hline 26 & Maintenance Shop & Fair & 0.8 & 28 & 12 \\
\hline 33 & SM Area Maintenance & Fair & 1.3 & 28 & 22 \\
\hline 39 & Nuclear Opns Support & Fair & 3.5 & 26 & 24 \\
\hline 40 & Printing Shop & Good & 12.2 & 25 & 35 \\
\hline 96 & Armored Vehicle Shelter & Poor & 0.4 & $\boldsymbol{9}$ & 11 \\
\hline 98 & Central Fire Station & Good & 8.5 & 7 & 53 \\
\hline 104 & Test Fire Maintenance & Excellent & 1.8 & 3 & 57 \\
\hline
\end{tabular}

3. Key Activities and Upgrades: Key activities essential to maintain the acceptable condition of this functional unit include the upgrades of roofs, heating, ventilation, and cooling systems, and mechanical and control systems as they reach the end of their normal life expectancy. An extensive HVAC and roof replacement project has just been completed for Building GP-1, which upgraded its condition to good. The weather station's (Building 25) condition deficiency is more functional than physical. Its condition will be upgraded with some minor capital equipment procurement in the late 1990's. Plans for the remaining facilities rated as poor or having less than 20 years remaining projected useful life are indefinite but are of no significance because the total square footage in question is less than 1200. Minor GPP/GPM funds will be invested as required, if the facilities (26 and 96) are not to be razed.

4. ES\&H and S\&S Upgrades Required: No specific activities are currently projected as upgrades necessary to meet present or expected requirements in environment, health, or in safeguards and security.

5. Decommissioning and Decontamination Activities: There are presently no standby or D\&D activities planned for this functional unit. 
B. Description of Events and Projects

1. In FY 1999, sanitary sewer lines will need to be replaced in Buildings $\mathrm{W}$ and $40 .(\$ 1.0 \mathrm{M} \cdot$ Line Item)

2. In FY 2001, the roofs will need to be replaced on Buildings G, PS, W, 40, 96, and 98. ( $\$ 460 \mathrm{~K}$ - GPP)

3. In FY 2003 the HVAC systems will need to be replaced in Buildings $\mathrm{PS}, \mathrm{W}, 40$, and 98 . (\$750K - Line Item)

4. In FY 2006, the domestic water lines will need to be replaced in Buildings $\mathrm{W}$ and 49 . (\$790K - Line Item)

C. Functional Unit Maintenance Activities:

Current Funding Status: Many of the service buildings are in need of repairs of a more substantial nature than can be accomplished with inhouse personnel. Funds for these type of activities, new roofs, HVAC equipment, major concrete repairs, etc., have been limited to less than 30 $40 \%$ of requests. 
This page intentionally blank. 


\section{G BUILDING PHYSICAL CHARACTERIZATION}

1) Current Mission Description

a) Facility Capabilities

G Building is a 7518- $\mathrm{ft}^{2}$ building that is used for the maintenance and repair of all plant GSA vehicles. In that capacity the building has several hydraulic lifts. The building is also used as storage for yards and grounds equipment and tools. The building has some office space and a conference room.

b) Resources Required to Support Operations

Primary Physical Resources:

Electricity

Potable water

Sanitary drainage

Physical security

Telecommunication devices

Fire protection, sprinklers, fire department

Heat

Compressed air

Services:

Human Resources

Finance and Accounting

Environmental, Safety, and Health

Maintenance

Custodial

Payroll

Meal

Supply

c) Current Safety Envelope

G Building operations are classified as standard industrial hazard.

d) Current Status

1. No formal CAS review has been done. A quick condition assessment was done in July 1992.

2. No formal CAMP review has been done based on the latest Reconfiguration decision. A CAMP report was submitted on April 1, 1992, which focused on ES\&H needs, infrastructure maintenance, and consolidation projects. 
a) Alternate Future Use Scenarios

1. WFO in the same discipline is unknown under recent May 27, 1993, reconfiguration guidance. Probably none.

2. WFO in a new discipline is unknown under recent May 27, 1993, reconfiguration guidance. Probably none.

3. Commercialization under a lease agreement possibility: $G$ Building would be useful for any application requiring the servicing of vehicles. G Building would also be useful for any application requiring a high bay area.

4. Commercialization under a sale agreement is unlikely in the short term, although there is a long-term possibility.

5. Deactivation effort should be minimal; the building is not contaminated with either radiological or energetic materials.

b) Facility Modifications Required for Likely Use

Probably no major building modification would be required for this use. The basic changes required would involve equipment.

c) Facility Modifications Required for Other Uses

Unknown.

d) Changes to Safety Envelope

The facility use suggested above should be covered under standard industrial hazard category unless hazardous materials are involved. Any new work conducted in G Building may require that a safety assessment be performed to identify any new hazards involved in the process.

e) Cleanup Criteria for Each Future Use Scenario

$\mathrm{G}$ Building is not contaminated with any radioactive or energetic materials.

f) Disposition of Surplus Equipment

Surplus equipment in G Building may be readily disposed as required. 


\section{GP1 BUILDING PHYSICAL CHARACTERIZATION}

1) Current Mission Description

a) Facility Capabilities

GP1 Building is a $7792-\mathrm{ft}^{2}$ building used for security training. It contains an indoor firing range, physical fitness equipment, the alternate security communications center, one office, and both a men's and women's change room.

b) Resources Required to Support Operations

Primary Physical Resources:

Electricity

Potable water

Sanitary drainage

Physical security

Telecommunication devices

Fire protection, sprinklers, fire department HVAC

Services:

Human Resources

Finance and Accounting

Environmental, Safety, and Health

Maintenance

Custodial

Payroll

Meal

Supply

c) Current Safety Envelope

The firing range in GP1 Building has an SAR. The rest of the GP1 Building operations are classified as standard industrial hazard.

d) Current Status

1. No formal CAS review has been done. A quick condition assessment was done in July 1992.

2. No formal CAMP review has been done based on the latest Reconfiguration decision. A CAMP report was submitted on April 1, 1992, which focused on ES\&H needs, infrastructure maintenance, and consolidation projects. 
2) Future Facility Use

a) Alternate Future Use Scenarios

1. WFO in the same discipline is unknown under recent May 27, 1993, reconfiguration guidance. Probably none.

2. WFO in a new discipline is unknown under recent May 27, 1993, reconfiguration guidance. Probably none.

3. Commercialization under a lease agreement possibility: GP1 Building would be useful for a firing range for local law enforcement agencies.

4. Commercialization under a sale agreement is unlikely in the short term, although there is a long-term possibility.

5. Deactivation effort should be minimal for the building, as it is not contaminated with either radiological or energetic materials. Lead from the firing range is routinely cleaned on a quarterly basis. Mound security force will not require the firing range after 1997 or 1998.

b) Facility Modifications Required for Likely Use

No major building modification would be required for this use.

c) Facility Modifications Required for Other Uses

Unknown.

d) Changes to Safety Envelope

If used as a firing range, as suggested above, the facility should be covered under standard industrial hazard category. Any new work conducted in GP1 Building may require that a safety assessment be performed to identify any new hazards involved in the process.

e) Cleanup Criteria for Each Future Use Scenario

GP1 Building is not contaminated with any radioactive or energetic materials.

f) Disposition of Surplus Equipment

Surplus equipment in GP1 Building may be readily disposed as required. 


\section{BUILDING GP-44 PHYSICAL CHARACTERIZATION}

1) Current Mission Description

a) Facility Capabilities

Building GP-44 is a $365-\mathrm{ft}^{2}$ building that is used for security records storage. The remaining two-thirds is used for uniform storage, laundry, and issue. It is currently in active use for this purpose.

b) Resources Required to Support Operations

Primary Physical Resources:

Electricity

Physical security

Telecommunication devices

Services:

Human Resources

Finance and Accounting

Environmental, Safety, and Health

Maintenance

Custodial

Payroll

Meal

Supply

c) Current Safety Envelope

Building GP-44 operations are classified as standard industrial hazard.

d) Current Status

1. No formal CAS review has been done. A quick condition assessment was done in July 1992.

2. No formal CAMP review has been done based on the latest Reconfiguration decision. A CAMP report was submitted on April 1, 1992, which focused on ES\&H needs, infrastructure maintenance, and consolidation projects. 


\section{2) Future Facility Use}

a) Alternate Future Use Scenarios

1. WFO in the same discipline is unknown under recent May 27, 1993, reconfiguration guidance. Probably none.

2. WFO in a new discipline is unknown under recent May 27, 1993, reconfiguration guidance. Probably none.

3. Commercialization possibilities under a lease agreement: Building GP-44 would be useful for any application requiring storage or issuing of materials, uniforms, etc.

4. Commercialization under a sale agreement is unlikely in the short term, although there is a long-term possibility.

5. Deactivation effort should be minimal; the building is not contaminated with either radiological or energetic materials.

b) Facility Modifications Required for Likely Use

Probably no major building modification would be required for this use.

c) Facility Modifications Required for Other Uses

Unknown.

d) Changes to Safety Envelope

The facility use suggested above should be covered under standard industrial hazard category unless hazardous materials are involved. Any new work conducted in building GP-44 may require that a safety assessment be performed to identify any new hazards involved in the process.

e) Cleanup Criteria for Each Future Use Scenario

Building GP-44 is not contaminated with any radioactive or energetic materials.

f) Disposition of Surplus Equipment

There is no surplus equipment in building GP-44. 


\section{H BUILDING PHYSICAL CHARACTERIZATION}

1) Current Mission Description

a) Facility Capabilities

$\mathrm{H}$ Building is a $17,334-\mathrm{ft}^{2}$ building that houses a laundry facility, a bioassay laboratory, the credit union, a men's change room, a women's change room, a small maintenance shop, and some office space.

b) Resources Required to Support Operations

Primary Physical Resources:

Electricity

Potable water

Sanitary drainage

Physical security

Telecommunication devices

Fire protection, sprinklers, fire department

HVAC

Services:

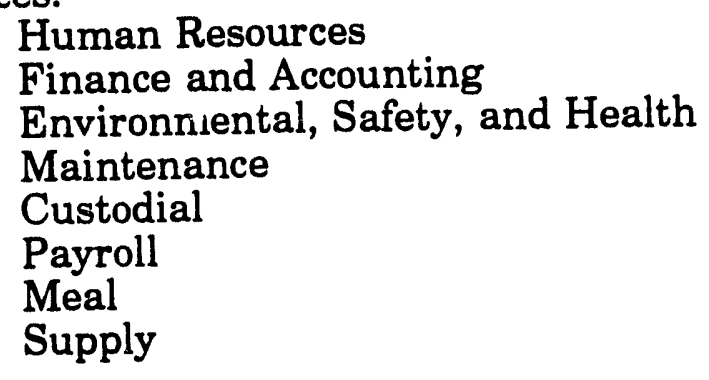

c) Current Safety Envelope

$\mathrm{H}$ Building operations are classified as standard industrial hazard.

d) Current Status

1. No formal CAS review has been done. A quick condition assessment was done in July 1992.

2. No formal CAMP review has been done based on the latest Reconfiguration decision. A CAMP report was submitted on April 1, 1992, which focused on ES\&H needs, infrastructure maintenance, and consolidation projects.

3. The bioassay laboratory in $\mathrm{H}$ Building does analyze or has analyzed samples for Pantex, Pinellas, Battel, and the U.S. Army. 
a) Alternate Future Use Scenarios

1. WFO in the same discipline is unknown under recent May 27, 1993, reconfiguration guidance. Probably none.

2. WFO in a new discipline is unknown under recent May 27, 1993, reconfiguration guidance. Probably none.

3. Commercialization under a lease agreement possibility: $\mathrm{H}$ Building would be useful for any application requiring bioassay sample analyses.

4. Commercialization under a sale agreement is unlikely in the short term, although there is a long-term possibility.

5. H Building is radiologically contaminated and may have to be decontaminated depending upon its future use.

b) Facility Modifications Required for Likely Use

Probably no major building modification would be required for this use. The basic changes required would involve equipment.

c) Facility Modifications Required for Other Uses

Unknown.

d) Changes to Safety Envelope

The facility use suggested above should be covered under standard industrial hazard category unless hazardous materials are involved.

Any new work conducted in $\mathrm{H}$ Building may require that a safety assessment be performed to identify any new hazards involved in the process.

e) Cleanup Criteria for Each Future Use Scenario

The need to clean $\mathrm{H}$ Building of radiological materials is dependent upon each use.

f) Disposition of Surplus Equipment

Surplus equipment in $\mathrm{H}$ Building may be readily disposed of as required. The washers and dryers in the laundry facility may be removed with riggers. 


\section{PS BUILDING PHYSICAL CHARACTERIZATION}

1) Current Mission Description

a) Facility Capabilities

PS Building is a 2288- $\mathrm{ft}^{2}$ building that is used for storage and as a paint shop. It is currently in active use for this purpose. The building contains an EPA-permitted paint spray booth, with a specially designed ventilation and filtration system to trap volatiles.

b) Resources Required to Support Operations

Primary Physical Resources:

Electricity

Potable water

Sanitary drainage

Physical security

Telecommunication devices

Fire protection, sprinklers, fire department

HVAC

Services:

Human Resources

Finance and Accounting

Environmental, Safety, and Health

Maintenance

Custodial

Payroll

Meal

Supply

c) Current Safety Envelope

PS Building operations are classified as standard industrial hazard.

d) Current Status

1. No formal CAS review has been done. A quick condition assessment was done in July 1992.

2. No formal CAMP review has been done based on the latest Reconfiguration decision. A CAMP report was submitted on April 1, 1992, which focused on ES\&H needs, infrastructure maintenance, and consolidation projects. 
2) Future Facility Use

a) Alternate Future Use Scenarios

1. WFO in the same discipline possible under recent May 27, 1993 , reconfiguration guidance. The building could continue to be used as a paint shop.

2. WFO in a new discipline is unknown under recent May 27, 1993, reconfiguration guidance. Probably none.

3. Commercialization possibilities under a lease agreement: The building could continue to be used as a paint shop.

4. Commercialization under a sale agreement is unlikely in the short term, although there is a long-term possibility.

5. Asbestos has been found in PS Building. This building may also be contaminated with solvents and paint. This contamination should be characterized, and may need to be cleaned up before unrestricted commercial use of the building.

b) Facility Modifications Required for Likely Use

No major building modification would be required for this use.

c) Facility Modifications Required for Other Uses

Unknown.

d) Changes to Safety Envelope

The facility use suggested above should be covered under standard industrial hazard category unless more hazardous materials are involved. Any new work conducted in PS Building may require that a safety assessment be performed to identify any new hazards involved in the process.

e) Cleanup Criteria for Each Future Use Scenario

PS Building may be contaminated with solvents and paint, and it contains asbestos. This contamination may require cleanup before future use, depending on contract requirements.

f) Disposition of Surplus Equipment

None. 


\section{W BUILDING PHYSICAL CHARACTERIZATION}

1) Current Mission Description

a) Facility Capabilities

W Building is a $32,484-\mathrm{ft}^{2}$ building housing trade shops and offices. The first floor contains several offices, a rest room, and the trade shops, including mechanic, sheet metal, carpenter, pipefitter/welder, and electric shops. On the second floor at the east end of the building are offices and a conference room.

b) Resources Required to Support Operations

Primary Physical Resources:

Electricity

Potable water

Sanitary drainage

Physical security

Telecommunication devices

Fire protection, sprinklers, fire department

HVAC, including a dust collection system

Glycol

Argon

Nitrogen

Oxygen

Compressed air

Carbon dioxide

Services:

Human Resources

Finance and Accounting

Environmental, Safety, and Health

Maintenance

Custodial

Payroll

Meal

Supply

c) Current Safety Envelope

W Building operations are classified as sta idard industrial hazard. 
d) Current Status

1. No formal CAS review has been done. A quick condition assessment was done in July 1992.

2. No formal CAMP review has been done based on the latest Reconfiguration decision. A CAMP report was submitted on April 1, 1992, which focused on ES\&H needs, infrastructure maintenance, and consolidation projects.

3. Work performed in the trade shops in W Building supports maintenance and project activities at Mound.

2) Future Facility Use

a) Alternate Future Use Scenarios

1. WFO in the same discipline is unknown under recent May 27, 1993, reconfiguration guidance. Probably none.

2. WFO in a new discipline is unknown under recent May 27, 1993, reconfiguration guidance. Probably none.

3. Commercialization under a lease agreement possibility: The shops in W Building would be useful for any commercial application in the plant requiring trade support. W Building would also be useful as a warehouse and staging area.

4. Commercialization under a sale agreement is unlikely in the short term, although there is a long-term possibility.

5. Deactivation effort should be minimal; the building is not contaminated with either radiological or energetic materials.

b) Facility Modifications Require? for Likely Use

Probably no major building modification would be required for use as trades shop. The basic changes required would involve equipment.

c) Facility Modifications Required for Other Uses

The trades equipment on the first floor of $\mathrm{W}$ Building would need to be removed if W Building is used as a warehouse. 
d) Changes to Safety Envelope

The facility uses suggested above should be covered under standard industrial hazard category unless hazardous materials are involved. Any new work in $\mathrm{W}$ Building may require that a safety assessment be performed to identify any new hazards involved in the process.

e) Cleanup Criteria for Each Future Use Scenario

W Building is not contaminated with radioactive or energetic materials.

f) Disposition of Surplus Equipment

If $\mathrm{W}$ Building is to be used as warehouse space, the trades equipment would need to be moved with a rigger. 
This page intentionally blank. 


\section{BUILDING 25 PHYSICAL CHARACTERIZATION}

1) Current Mission Description

a) Facility Capabilities

Building 25 is a $430-\mathrm{ft}^{2}$ building that is used for collecting information on local weather conditions as part of Mound's environmental monitoring program. It is currently in active use for this purpose.

Data from two weather-monitoring towers onsite go to computers in Building 25. These computers are connected to computers at Lawrence Livermore Laboratory that can use the information to predict dispersion patterns in the event of any airborne releases.

Also, some telephone switching equipment is located in Building 25 .

b) Resources Required to Support Operations

Primary Physical Resources:

Electricity

Physical security

Telecommunication devices

Fire protection, sprinklers, fire department

HVAC

Services:

Human Resources

Finance and Accounting

Environmental, Safety, and Health

Maintenance

Custodial

Payroll

Meal

Supply

c) Current Safety Envelope

Building 25 operations are classified as standard industrial hazrad.

d) Current Status

1. No formal CAS review has been done. A quick condition assessment was done in July 1992.

2. No formal CAMP review has been done based on the latest Reconfiguration decision. A CAMP report was submitted in April 1, 1992, which focused on ES\&H needs, infrastructure maintenance, and consolidation projects. 
2) Future Facility Use

a) Alternate Future Use Scenarios

1. WFO in the same discipline is possible under recent May 27, 1993, reconfiguration guidance. As long as significant quantities of hazardous materials are handled at Mound, there could be a need for detailed weather information.

2. WFO in a new discipline is unknown under recent May 27, 1993, reconfiguration guidance. Probably none.

3. Commercialization possibilities under a lease agreement: Unlikely.

4. Commercialization under a sale agreement is unlikely.

5. Deactivation effort should be minimal for the building as it is not contaminated with either radiological or energetic materials. However, asbestos has been found in the building, and may require abatement.

b) Facility Modifications Required for Likely Use

Probably no major building modification would be required for this use.

c) Facility Modifications Required for Other Uses

Unknown.

d) Changes to Safety Envelope

The facility use suggested above should be classified as standard industrial hazard.

Any new work conducted in Building 25 may require that a safety assessment be performed to identify any new hazards involved in the process.

e) Cleanup Criteria for Each Future Use Scenario

Building 25 is not contaminated with any radioactive or energetic materials. However, the building does contain asbestos, which may requirs abatement before any commercial use of the facility, depending on contract requirements.

f) Disposition of Surplus Equipment

None. 


\section{BUILDING 26 PHYSICAL CHARACTERIZATION}

1) Current Mission Description

a) Facility Capabilities

Building 26 is an $800-\mathrm{ft}^{2}$ building used as a maintenance shop serving SW, R, COS, DS, and E Buildings. Currently in active use for this purpose, the building contains a welding shop, material storage area, and three offices.

b) Resources Required to Support Operations

Primary Physical Resources:

Electricity

Potable water

Sanitary drainage

Physical security

Telecommunication devices

Fire Protection, sprinklers, fire department

HVAC

Services:

Human Resources

Finance and Accounting

Environmental, Safety, and Health

Maintenance

Custodial

Payroll

Meal

Supply

Special Resources:

Bottled gas

c) Current Safety Envelope

Building 26 operations are classified as standard industrial hazard.

d) Current Status

1. No formal CAS review has been done. A quick condition assessment was done in July 1992.

2. No formal CAMP review has been done based on the latest Reconfiguration decision. A CAMP report was submitted in April 1, 1992, which focused on ES\&H needs, infrastructure maintenance, and consolidation projects. 
2) Future Facility Use

a) Alternate Future Use Scenarios

1. WFO in the same discipline is possible under recent May 27, 1993, reconfiguration guidance. Any operations that take place in the above mentioned buildings may need maintenance support.

2. WFO in a new discipline is unknown under recent May 27, 1993, reconfiguration guidance. Probably none.

3. Commercialization is possible under a lease agreement in its current discipline.

4. Commercialization under a sale agreement is unlikely in the short term, although there is a long-term possibility.

5. Deactivation effort should be minimal; the building is not contaminated with either radiological or energetic materials.

b) Facility Modifications Required for Likely Use

Probably no major building modification would be required for this use. The basic changes required would involve equipment.

c) Facility Modifications Required for Other Uses

Unknown.

d) Changes to Safety Envelope

The facility use suggested above should be covered under standard industrial hazard category unless hazardous materials are involved.

Any new work conducted in Building 26 may require that a safety assessment be performed to identify any new hazards involved in the process.

e) Cleanup Criteria for Each Future Use Scenario

Building 26 is not contaminated with any radioactive or energetic materials.

f) Disposition of Surplus Equipment

There is surplus equipment stored in Building 26, but for the most part it consists of small, commonly-used powered hand tools that could be easily sold or disposed of. 


\section{BUILDING 33 PHYSICAL CHARACTERIZATION}

1) Current Mission Description

a) Facility Capabilities

Building 33 is scheduled for decontamination and decommissioning (D\&D).

Building 33 is currently being used by Decontamination and Decommission operations (D\&D) as a storage facility.

The grounds around Building 33 are radiologically contaminated. A May 1993 Mound Asbestos Survey identified Building 33 as a building that contains thermal system insulation containing asbestos.

Building 33 was built in 1965 and has $1344 \mathrm{ft}^{2}$ of space.

b) Systems Required to Support Operations

Primary Physical Resources:

Electrical

Physical security

Fire protection, sprinklers, fire department

Mechanical

Services:

Human Resources

Finance and Accounting

Environmental, Safety, and Health

Maintenance

Custodial

Payroll

Meal

Supply

c) Current Safety Envelope

Building 33 operations are classified as standard industrial hazard. 
d) Current Status

1. No formal CAS review has been done. A quick condition assessment was done in July 1992.

2. No formal CAMP review has been done based on the latest Reconfiguration decision. A CAMP report was submitted on April 1, 1992, which focused on ES\&H needs, infrastructure maintenance, and consolidation projects.

2) Future Facility Use

None 


\section{BUILDING 39 PHYSICAL CHARACTERIZATION}

1) Current Mission Description

a) Facility Capabilities

Building 39 is a $3515-\mathrm{ft}^{2}$ building that is used as a maintenance shop. It is currently in active use for this purpose.

b) Resources Required to Support Operations

Primary Physical Resources:

Electricity

Potable water

Sanitary drainage

Physical security

Telecommunication devices

Fire protection, sprinklers, fire department

HVAC

Services:

Human Resources

Finance and Accounting

Environmental, Safety, and Health

Maintenance

Custodial

Payroll

Meal

Supply

Special Resources:

Bottled gases

c) Current Safety Envelope

Building 39 operations are classified as standard industrial hazard.

d) Current Status

1. No formal CAS review has been done. A quick condition assessment was done in July 1992.

2. No formal CAMP review has been done based on the latest Reconfiguration decision. A CAMP report was submitted on April 1, 1992, which focused on ES\&H needs, infrastructure maintenance, and consolidation projects. 
2) Future Facility Use

a) Alternate Future Use Scenarios

1. WFO in the same discipline possible under recent May 27, 1993, reconfiguration guidance. This facility currently provides fabrication and repair services to the SM/PP area. It could continue to provide service in this area.

2. WFO in a new discipline is unknown under recent May 27, 1993, reconfiguration guidance. Probably none.

3. Commercialization under a lease agreement is unlikely.

4. Commercialization under a sale agreement is unlikely.

5. Deactivation effort should be minimal; the building is not contaminated with either radiological or energetic materials.

b) Facility Modifications Required for Likely Use

Probably no major building modification would be required for this use. The basic changes required may involve equipment.

c) Facility Modifications Required for Other Uses

Unknown.

d) Changes to Safety Envelope

The facility use suggested above should be covered under standard industrial hazard category unless hazardous materials are involved. Any new work conducted in Building 39 may require that a safety assessment be performed to identify any new hazards involved in the process.

e) Cleanup Criteria for Each Future Use Scenario

Building 39 is not contaminated with any radioactive or energetic materials.

f) Disposition of Surplus Equipment

Equipment in Building 39 includes machine tools sush as lathes and welders. Any equipment not required in the future use of the building can probably be sold. 


\section{BUILDING 40 PHYSICAL CHARACTERIZATION}

1) Current Mission Description

a) Facility Capabilities

Building 40 is a $12,227-\mathrm{ft}^{2}$ building used for plant printing services. The first floor contains printing and microfilming equipment, a small storage area, and a vault for classified documents. The second floor of the building contains office space.

b) Resources Required to Support Operations

Primary Physical Resources:

Electricity

Potable wator

Sanitary drainage

Physical security

Telecommunication devices

Fire protection, sprinklers, fire department

HVAC

Services:

Human Resources

Finance and Accounting

Environmental, Safety, and Health

Maintenance

Custodial

Payroll

Meal

Supply

c) Current Safety Envelope

Building 40 operations are classified as standard industrial hazard.

d) Current Status

1. No formal CAS review has been done. A quick condition assessment was done in July 1992.

2. No formal CAMP review has been done based on the latest Reconfiguration decision. A CAMP report was submitted on April 1, 1992, which focused on ES\&H needs, infrastructure maintenance, and consolidation projects. 
2) Future Facility Use

a) Alternate Future Use Scenarios

1. WFO in the same discipline is unknown under recent May 27, 1993, reconfiguration guidance. Probably none.

2. WFO in a new discipline is unknown under recent May 27, 1993, reconfiguration guidance. Probably none.

3. Commercialization under a lease agreement possibility: Building 40 would be useful for any application requiring printing or microfilming services.

4. Commercialization under a sale agreement is unlikely in the short term, although there is a long-term possibility.

5. Deactivation effort should be minimal; the building is not contaminated with either radiological or energetic materials.

b) Facility Modifications Required for Likely Use

Probably no major building modification would be required for this use. The basic changes required would involve equipment.

c) Facility Modifications Required for Other Uses

Unknown.

d) Changes to Safety Envelope

The facility use suggested above should be covered under standard industrial hazard category unless hazardous materials are involved. Any new work conducted in Building 40 may require that a safety assessment be performed to identify any new hazards involved in the process.

e) Cleanup Criteria for Each Future Use Scenario

Building 40 is not contaminated with any radioactive or energetic materials.

f) Disposition of Surplus Equipment

Surplus equipment in Building 40 may be readily disposed of, as required. 


\section{BUILDING 96 PHYSICAL CHARACTERIZATION}

\section{1) Current Mission Description}

a) Facility Capabilities

Building 96 is a $432-\mathrm{ft}^{2}$ prefabricated metal building that is used for storage of supplies in support of the Mound security force. It is currently in active use for this purpose.

A document shredder is located in the rear half of Building 96; however, plans are to remove it in the near future.

b) Resources Required to Support Operations

Primary Physical Resources:

Electricity

Physical security

Fire protection, fire department

Heating

Services:

Human Resources

Finance and Accounting

Environmental, Safety, and Health

Maintenance

Custodial

Payroll

Meal

Supply

c) Current Safety Envelope

Building 96 operations are classified as standard industrial hazard.

d) Current Status

1. No formal CAS review has been done. A quick condition assessment was done in July 1992.

2. No formal CAMP review has been done based on the latest Reconfiguration decision. A CAMP report was submitted on April 1, 1992, which focused on ES\&H needs, infrastructure maintenance, and consolidation projects. 
2) Future Facility Use

a) Alternate Future Use Scenarios

1. WFO in the same discipline is unknown under recent May 27, 1993, reconfiguration guidance. Probably none.

2. WFO in a new discipline is unknown under recent May 27, 1993, reconfiguration guidance. Probably none.

3. Commercialization possibilities under a lease agreement: Building 96 would be useful for vehicular or material storage

4. Commercialization under a sale agreement is unlikely in the short term, although there is a long-term possibility.

5. Deactivation effort should be minimal; the building is not contaminated with either radiological or energetic materials.

b) Facility Modifications Required for Likely Use

Probably no major building modification would be required for this use.

c) Facility Modifications Required for Other Uses

Unknown.

d) Changes to Safety Envelope

The facility use suggested above should be covered under standard industrial hazard category unless hazardous materials are involved. Any new work conducted in. Building 96 may require that a safety assessment be performed to identify any new hazards involved in the process.

e) Cleanup Criteria for Each Future Use Scenario

Building 96 is not contaminated with any radioactive or energetic materials.

f) Disposition of Surplus Equipment

The disposition cost of the supplies and shelving would be minimal. 


\section{BUILDING 98 PHYSICAL CHARACTERIZATION}

1) Current Mission Description

a) Facility Capabilities

Building 98 is a $8517-\mathrm{ft}^{2}$ building that is the fire house for the site. It is currently in active use for this purpose. Equipment housed in the building includes two fire engines, an ambulance, breathing air equipment, a trailer and spare fire-fighting materials. The building is manned by 17 personnel trained in fire fighting and HazMat control.

b) Resources Required to Support Operations

Primary Physical Resources:

Electricity

Potable water

Sanitary drainage

Physical security

Telecommunication devices

Fire protection and sprinklers

HVAC

Services:

Human Resources

Finance and Accounting

Environmental, Safety, and Health

Maintenance

Payroll

Meal

Supply

c) Current Safety Envelope

Building 98 operations are classified as standard industrial hazard.

d) Current Status

1. No formal CAS review has been done. A quick condition assessment was done in July 1992.

2. No formal CAMP review has been done based on the latest Reconfiguration decision. A CAMP report was submitted on April 1, 1992, which focused on ES\&H needs, infrastructure maintenance, and consolidation projects. 
2) Future Facility Use

a) Alternative Future Use Scenarios

1. WFO in the same discipline can occur under recent May 27, 1993, reconfiguration guidance. This facility currently provides fire protection, HazMat, and ambulance service for the plant site.

2. WFO in a new discipline is can occur under recent May 27, 1993, reconfiguration guidance.

3. Commercialization under a lease agreement is likely.

4. Commercialization under a sale agreement is very unlikely.

5. Deactivation effort should be minimal for the building, as it is not contaminated with radiological, energetic, or asbestos materials.

b) Facility Modifications Required for Likely Use

Probably no major building modification would be required for this use. Some equipment and personnel training changes may be necessary.

c) Facility Modifications Required for Other Uses

Unknown.

d) Changes to Safety Envelope

The facility uses expected now would be covered under standard industrial hazard category.

e) Cleanup Criteria for Each Future Use Scenario

Building 98 is not contaminated with any radioactive, energetic or asbestos materials.

f) Disposition of Surplus Equipment

Equipment in Building 98 includes fire engines, an ambulance, and other fire fighting or HazMat control equipment. Any equipment not required in the future use of the building probably can be sold. 


\section{BUILDING 104 PHYSICAL CHARACTERIZATION}

1) Current Mission Description

a) Facility Capabilities

Building 104 is an $1800-\mathrm{ft}^{2}$ building that is used as a maintenance shop and offices. It is currently in active use for this purpose.

b) Resources Required to Support Operations

Primary Physical Resources:

Electricity

Potable water

Sanitary drainage

Physical security

Telecommunication devices

Fire protection, sprinklers, fire department

HVAC

Services:

Human Resources

Finance and Accounting

Environmental, Safety, and Health

Maintenance

Custodial

Payroll

Meal

Supply

Special Resources:

Bottled gases

c) Current Safety Envelope

Building 104 operations are classified as standard industrial hazard.

d) Current Status

1. No formal CAS review has been done. A quick condition assessment was done in July 1992.

2. No formal CAMP review has been done based on the latest Reconfiguration decision. A CAMP report was submitted on April 1, 1992, which focused on ES\&H needs, infrastructure maintenance, and consolidation projects. 
a) Alternate Future Use Scenarios

1. WFO in the same discipline possible under recent May 27, 1993, reconfiguration guidance. This facility currently provides fabrication and repair services to the Test Fire area. It could continue to provide service in this area.

2. WFO in a new discipline is unknown under recent May 27, 1993, reconfiguration guidance. Probably none.

3. Commercialization under a lease agreement is unlikely.

4. Commercialization under a sale agreement is unlikely.

5. Deactivation effort should be minimal for the building, as it is not contaminated with either radiological or energetic materials. It may be contaminated with chemicals such as painto and cutting oils.

b) Facility Modifications Required for Likely Use

Probably no major building modification would be required for this use. The basic changes required may involve equipment.

c) Facility Modifications Required for Other Uses

Unknown.

d) Changes to Safety Envelope

The facility use suggested above should be covered under standard industrial hazard category unless hazardous materials are involved.

Any new work conducted in Building 104 may require that a safety assessment be performed to identify any new hazards involved in the process.

e) Cleanup Criteria for Each Future Use Scenario

Building 104 is not contaminated with any radioactive or energetic materials. The building should be surveyed for chemical contamination before unrestricted commercial use.

f) Disposition of Surplus Equipment

Equipment in Building 104 includes machine tools such as lathes and welders. Any equipment not required in the future use of the building can probably be sold. 


\section{SECTION 5: LABORATORY BUILDINGS}

A. Planning Basis:

1. Present Mission: The laboratory buildings are a functional unit having as its mission the research, development, and production support for the Mound mission as described in the current AWLPG.

Because of the current reduction in budget and workload, an effort is underway at Mound to consolidate facilities, that is, to shut down as much space as possible to the appropriate level of standby condition. Although a draft plan listing possible facilities and time frame of execution has been prepared for this effort, it is premature to detail its affect on this functional unit.

The functional unit consists of 18 buildings including the DS, R, SM, SW, $2,3,35,43,45,46,48,51,55,58,59,87$, and 94 Buildings. Operations in these buildings include primarily product research, development, and testing.

2. Relationship to Other Functional Units: By the nature of the facilities and equipment contained within this functional unit, these facilities described herein are used to support the various missions of Mound, with the primary support being to Production.

3. Material Condition and Expected Useful Life: The oldest building, R, was constructed when Mound Plant was built in 1948, while the newest building, 87, was completed in 1987. Except for the SM Building, a metal structure which is now being demolished, all structures are slab-on-grade, poured concrete, concrete block or brick exteriors, with built-up roofs.

Most of the buildings are in fair to good condition. The uses and plans for each building follow and will be further described in the Description of Events and Projects. The expected life varies, depending upon the age of the facility and anticipated longevity of the mission, for each building.

4. Key Activities and Upgrades: Several key projects such as cooling system replacements are planned in the near term to ensure the viability of this functional unit. 


\section{LABORATORY BUIIDINGS}

\begin{tabular}{|c|c|c|c|c|c|}
\hline BLDG & DESCRIPTION & CONDITION & $\begin{array}{c}\text { SQUARE } \\
\text { FOOTAGE } \\
\text { (X 1000) }\end{array}$ & AGE (Yrs.) & $\begin{array}{l}\text { REMAINING } \\
\text { PROJECTED } \\
\text { USEFUL LIFE } \\
\end{array}$ \\
\hline DS & Dev. \& Stds. Lab & Fair & 47.8 & 27 & 23 \\
\hline $\mathbf{R}$ & Research Lab & Fair & 55.0 & 44 & 26 \\
\hline SM & Idle & D\&D & 21.7 & 32 & 0 \\
\hline sw & Tritium R\&D & Fair & 43.1 & 42 & 28 \\
\hline 2 & Explosives Testing & Fair & 6.3 & 41 & 19 \\
\hline 3 & Explosives Testing & Fair & 12.4 & 28 & 22 \\
\hline 35 & Neutron Radiography & Fair & 2.5 & 27 & 13 \\
\hline 43 & Thermite Develop't & Fair & 1.5 & 23 & 17 \\
\hline 45 & Health Physics & Good & 2.8 & 22 & 28 \\
\hline 46 & Welding Dev. & Fair & 2.4 & 23 & 17 \\
\hline 48 & Surveillance & Fair & 8.0 & 22 & 28 \\
\hline 51 & Development & Fair & 3.5 & 20 & 20 \\
\hline 55 & Waste Mgmt. & Adequate & 0.3 & 19 & 11 \\
\hline 58 & Filter Bank & Good & 6.1 & 15 & 35 \\
\hline 59 & Neutron Radiography & Poor & 0.7 & 24 & 6 \\
\hline 87 & Explosives Testing & Excellent & 38.9 & 6 & 44 \\
\hline 94 & Mat's Compatibility & Excellent & 1.2 & 8 & 17 \\
\hline
\end{tabular}

5. ES\&H and S\&S Upgrades Required: The ES\&H type projects Emergency Notification System and ES\&H Plant Life Safety Code Upgrades are necessary to correct existing code and compliance deficiencies.

6. Decommissioning and Decontamination (D\&D) Activities: Three buildings are to be demolished. The SM Building demolition began in FY 1983, with completion scheduled for FY 1997. Operations in Building 35 have been shut down for three years; disposition of the facility is now being determined.

B. Description of Events and Projects: Events and projects are briefly described in the following narrative.

1. In FY 1995, egress will be brought into compliance with the Life Safety Code in the R and SW Buildings. (\$2.3M - FY 1995 ES\&H Line Item)

2. In FY 1996, cooling equipment will be replaced in the DS, R, 3, 46, and 48 Buildings. (\$3M - FY 1996 FCAP Line Item) 
3. In FY 1999, sanitary sewers piping will be replaced. (\$1M - FY 1999 FCAP Line Item)

4. In FY 1999, roof replacements will be accomplished with GPP funds for the Development and Standards (DS), Research (R), Semi-Works (SW), $2,3,35,43,45,46,48,51,58,59$, and 94 Buildings. ( $\$ 500 \mathrm{~K}$ FY 1999 GPP)

All of the above projects are essential to maintaining the Laboratory Functional Unit at a minimum level of operability to meet the mission.

C. Functional Unit Maintenance Activities:

Maintenance Planning: Facilities-planned maintenance activities scheduling has begun the process of automating these functions. Routine inspections of roofs, filters, exit lights, HVAC equipment, lightning protection equipment, etc., have all been computerized. These routine preventive maintenance activities, minor repairs, and safety problems generate small repair projects that are routinely handled. Scheduling of these activities is now automated.

Activities that are beyond the scope of in-house personnel are documented in routine surveys with participation of building management personnel as well as input from Engineering. These identified deficiencies are then appropriately grouped in manageable units and completed using Line Item, GPP, GPM, or expense funds as appropriate to the situation. On a yearly basis these needs are evaluated and prioritized for completion.

Current Funding Status: Many of the laboratory buildings are in need of repairs of a more substantial nature than can be accomplished with inhouse personnel. Funds for these types of activities, new roofs, HVAC equipment, major concrete repairs, etc., have been limited to less than 30 $40 \%$ of requests.

Future Capital funding through the FCAP program and/or GPP funding is required to ensure the integrity of these buildings. Should such funding not materialize or be substantially delayed, maintenance fund requirements will exponentially increase over the life of this functional unit. 
This page intentionally blank. 


\section{DS BUILDING PHYSICAL CHARACTERIZATION}

\section{1) Current Mission Description}

a) Facility Capabilities

DS Building is a $47,810-\mathrm{ft}^{2}$ building that is used for metrology, explosives production, and development in support of defense programs. It is currently in active use for this purpose.

Specialized facilities in DS Building include:

Calibration laboratories

Electronic and optical diagnostic equipment

Environmental chambers

Lasers

Tape processing development

Nondestructive testing

Timer disassembly

Heavy-wall explosives chambers

Detonator and pyrotechnic production

Explosives development

Energetic material packaging

Explosives shipping and receiving

Welding development

Physical vapor deposition clean room

b) Resources Required to Support Operations

Primary Physical Resources:

Electricity

Potable water

Sanitary drainage

Physical security

Telecommunication devices

Fire protection, sprinklers, fire department

HVAC

Services:

Human Resources

Finance and Accounting

Environmental, Safety, and Health

Maintenance

Custodial

Payroll

Meal

Supply 
Special Resources:

Bottled gases and compressed air

Chemicals

Liquid nitrogen and liquid argon

Class III explosion-proof electrical service

Enhanced grounding and lightning protection

Clean room facilities

c) Current Safety Envelope

Some operations in DS Building are classified as low hazard because of the amounts of energetic materials used.

d) Current Status

1. No formal CAS review has been done. A quick condition assessment was done in July 1992.

2. No formal CAMP review has been done based on the latest Reconfiguration decision. A CAMP report was submitted on April 1, 1992, which focused on ES\&H needs, infrastructure maintenance, and consolidation projects.

2) Future Facility Use

a) Alternate Future Use Scenarios

1. WFO in the same discipline is possible under recent May 27, 1993, reconfiguration guidance. Some examples are:

- Physical vapor deposition applications

- Flexible circuit development and production

- Development, production, or characterization of energetic devices

- Detonator production; e.g., for ejection seats or auto air bags

- Product packaging, especially of products involving explosives

- Metrology

- Nondestructive testing

- Process research

2. WFO in a new discipline is unknown under recent May 27, 1993, reconfiguration guidance. Probably none. 
3. Commercialization possibilities under a lease agreement: Refer to Item 1, above.

4. Commercialization under a sale agreement is unlikely in the short term, although there is a long-term possibility.

5. Deactivation effort should be minimal for the building, as it is either uncontaminated or only slightly contaminated with radioactive and/or energetic materials. However, asbestos has been found in the building.

b) Facility Modifications Required for Likely Use

Probably no major building modification would be required for the above uses. The basic changes required may involve equipment.

c) Facility Modifications Required for Other Uses

Unknown.

d) Changes to Safety Envelope

The facility uses suggested above should be covered under either the standard industrial hazard or low hazard category unless larger quantities of hazardous materials are involved.

Any new work conducted in DS Building may require that a safety assessment be performed to identify any new hazards involved in the process.

e) Cleanup Criteria for Each Future Use Scenario

DS Building is not known to be contaminated with any radioactive or energetic materials. Because these materials have been handled in the building, a contamination survey should be conducted before unrestricted commercial use of the facility. Asbestos abatement may be required, depending on contract requirements.

f) Disposition of Surplus Equipment

Several large equipment items are located in DS Building, including four walk-in ovens and some large powder presses. As these items would be difficult to discard, future use of the building should probably be planned on the assumption that they will remain. 
This page intentionally blank.

$$
5-8
$$




\section{R BUILDING PHYSICAL CHARACTERIZATION}

1) Current Mission Description

a) Facility Capabilities

$\mathrm{R}$ Building, a 55,003- $\mathrm{ft}^{2}$ building, is one of the original buildings built at Mound in 1948. The "cold" side of R Building houses the library, offices, respirator fitting facility, and research and development laboratories. The "hot" side is used for tritium recovery and analytical support. R-140, on the "cold" side, is scheduled for D\&D. The remainder of the "cold" side is scheduled for deactivation during FY 1994.

b) Resources Required to Support Operations

Primary Physical Resources:

Electricity

Physical security

Fire protection, sprinklers, fire department

Potable water

Alpha and beta drains

Sanitary drains

HVAC

Breathing air

Helium, nitrogen, argon gas

Services:

Human Resources

Finance and Accounting

Environmental, Safety, and Health

Maintenance

Custodial

Payroll

Meal

Supply

c) Current Safety Envelope

The "cold" side of $\mathrm{R}$ Building operations is classified as standard industrial hazard. The "hot" side operates under the pending FSAR for SW building. 
d) Current Status

1. No formal CAS review has been done. A quick condition assessment was done in July 1992.

2. No formal CAMP review has been done based on the latest Reconfiguration decision. A CAMP report was submitted on April 1, 1992, which focused on ES\&H needs, infrastructure maintenance, and consolidation projects.

\section{2) Future Facility Use}

a) Alternate Future Use Scenarios

1. WFO in the same discipline is unknown under recent May 27, 1993, reconfiguration guidance. Probably none.

2. WFO in a new discipline is unknown under recent May 27, 1993, reconfiguration guidance. Probably none.

3. Commercialization possibilities under a lease agreement are unknown under recent May 27, 1993, reconfiguration guidance. Probably none.

4. Commercialization possibilities under a sale agreement are unknown under recent May 27, 1993, reconfiguration guidance. Probably none.

5. R Building and equipment on the "hot" side are contaminated with radiological material. The "cold" side has undergone D\&D (except for R-140) but there are probably "warm" spots on the "cold" side. $R-140$ is on the D\&D schedule.

Both the "hot" and "cold" sides of $\mathrm{R}$ Building are contaminated with asbestos.

b) Facility Modifications Required for Likely Use

Unknown for the "cold" jide of R Building. None for the "hot" side of $R$ Building. The likely use for the tritium recovery facilities on the "hot" side of $\mathrm{R}$ Building would be to recover tritium from the deactivated tritium production areas. 
c) Facility Modifications Required for Other Uses

Unknown. Probably none.

d) Changes to Safety Envelope

Unknown.

e) Cleanup Criteria for Each Future Use Scenario

$R$ Building is contaminated with radiological and energetic materials. "Hot" spots also exist on the "cold" side of $R$ Building. Asbestoscontaining materials are located in $\mathrm{R}$ Building.

f) Disposition of Surplus Equipment

Unknown. 
This page intentionally blank.

$5 \cdot 12$ 


\section{SM BUILDING PHYSICAL CHARACTERIZATION}

1) Current Mission Description

a) Facility Capabilities

SM Building is currently being decontaminated and decommissioned.

b) Resources Required to Support D\&D Operations

Primary Physical Resources:

Electricity

Physical security

Fire protection, sprinklers, fire department

Potable water

Sanitary drains

HVAC

HEPA filtration

Services:

Human Resources

Finance and Accounting

Environmental, Safety, and Health

Maintenance

Custodial

Payroll

Meal

Supply

c) Current Safety Envelope

SM Building operations are classified as standard industrial hazard.

d) Current Status

1. No formal CAS review has been done. A quick condition assessment was done in July 1992.

2. No formal CAMP review has been done based on the latest Reconfiguration decision. A CAMP report was submitted on April 1, 1992, which focused on ES\&H needs, infrastructure maintenance, and consolidation projects.

\section{2) Future Facility Use}

None. 
This page intentionally blank.

$5 \cdot 14$ 


\section{SW BUILDING PHYSICAL CHARACTERIZATION}

1) Current Mission Description

a) Facility Capabilities

SW Building is a 43,066- $\mathrm{ft}^{2}$ building used for tritium component development (CD), component evaluation operations (CEO), tritium recovery (TR), and Material Analysis (MA). Originally constructed in 1950, the SW complex has undergone thirteen major additions.

b) Resources Required to Support Operations

Primary Physical Resources:

Electricity

Physical security

Fire protection, sprinklers, fire department

Potable water

Sanitary drains

HVAC

Breathing air

Liquid nitrogen

Helium, nitrogen, argon gas

Alpha and beta "hot" drains

HEPA filtration

Services:

Human Resources

Finance and Accounting

Environmental, Safety, and Health

Maintenance

Custodial

Payroll

Meal

Supply

c) Current Safety Envelope

The SW Building operates under the FSAR (Final Safety Analysis Report) MLM-ML-92-42-0001.

d) Current Status

1. No formal CAS review has been done. A quick condition assessment was done in July 1992. 
2. No formal CAMP review has been done based on the latest Reconfiguration decision. A CAMP report was submitted on April 1, 1992, which focised on ES\&H needs, infrastructure maintenance, and consolidation projects.

\section{2) Future Facility Use}

a) Alternate Future Use Scenarios

1. WFO in the same discipline is unknown under recent May 27, 1993, reconfiguration guidance. Probably none.

2. WFO in a new discipline is unknown under recent May 27, 1993, reconfiguration guidance. Probably none.

3. Commercialization possibilities under a lease agreement: Unknown under recent May 27, 1993, reconfiguration guidance. Probably none.

4. Commercialization possibilities under a sale agreen snt: Unknown under recent May 27, 1993, reconfiguration guidance. Probahly none

5. SW Building ipment is contaminated with radiological materials. A Mu, 993 Mound Asbestos Survey identified SW as a building that contained asbestos.

b) Facility Modifications Required for Likely Use

None. Tritium recovery facilities could be used for the deactivation of tritium operation areas.

c) Facility Modifications Required for Other Uses

Unknown.

d) Changes to Safety Envelope

Unknown.

e) Cleanup Criteria for Each Future Use Scenario

SW Building is contaminated with radiological materials and asbestos.

f) Disposition of Surplus Equipment

Unknown. 


\section{BUILDING 2 PHYSICAL CHARACTERIZATION}

1) Current Mission Description

a) Facility Capabilities

Building 2 is a $6291-\mathrm{ft}^{2}$ building that is used for destructive test firing of explosives in support of defense programs. It is currently in active use for this purpose, but will soon be phased out.

The building contains steel test cells rated at 225 grams of explosive material. Testing is controlled remotely from a control room.

b) Resources Required to Support Operations

Primary Physical Resources:

Electricity

Potable water

Sanitary drainage

Physical security

Telecommunication devices

Fire protection, sprinklers, fire department HVAC

Services:

Human Resources

Finance and Accounting

Environmental, Safety, and Health

Maintenance

Custodial

Payroll

Meal

Supply

c) Current Safety Envelope

Building 2 is considered to be a low hazard facility, as it procosses quantities greater than 3 grams of erplosives, but less than 1 kilogram.

d) Current Status

1. No formal CAS review has been done. A quick condition assessment was done in July 1992.

2. No formal CAMP review has been done based on the latest Reconfiguration decision. A CAMP report was submitted on April 1, 1992, which focused on ES\&H needs, infrastructure maintenance, and consolidation projects. 
2) Future Facility Use

a) Alternate Future Use Scenarios

1. WFO in the same discipline is unknown under recent May 27, 1993, reconfiguration guidance. Probably none.

2. WFO in a new discipline is unknown under recent May 27, 1993, reconfiguration guidance. Probably none.

3. Commercialization possibilities under a lease agreement: Building 2 would be useful for any application requiring remote testing of energetic or explosive materials.

4. Commercialization under a sale agreement is unlikely in the short term, although there is a long-term possibility.

5. Asbestos has been found in Building 2. The building is probably contaminated with small amounts of energetic materials. This contamination will conceivably require cleanup before building deactivation.

b) Facility Modifications Required for Likely Use

Probably no major building modification would be required for the above use. The basic changes required would involve equipment.

c) Facility Modifications Required for Other Uses

Unknown.

d) Changes to Safety Envelope

The facility use suggested above should be covered under the same category of "low hazard facility" unless larger quantities of explosives are involved. Any new work conducted in Building 2 may require that a safety assessment be performed to identify any new hazards involved in the process.

e) Cleanup Criteria for Each Future Use Scenario

Building 2 is contaminated with energetic materials and contains asbestos. Characterization and cleanup of this contamination may be required before any future use of the facility, depending on contractual requirements.

f) Disposition of Surplus Equipment

Unknown. 


\section{BUILDING 3 PHYSICAL CHARACTERIZATION}

\section{1) Current Mission Description}

a) Facility Capabilities

Building 3 is a $12,391-\mathrm{ft}^{2}$ building used for destructive test firing and environmental testing of explosives in support of defense programs. It is currently in active use for this purpose. The building contains steel test firing cells rated at 225 grams of explosive material, Testing is controlled remotely from a control room. Environmental test equipment in the building includes a centrifuge, as well as instruments to test the effects of shock, vibration, thermal stress, and humidity.

b) Resources Required to Support Operations

Primary Physical Resources:

Electricity

Potable water

Sanitary drainage

Physical security

Telecommunication devices

Fire protection, sprinklers, fire department HVAC

Services:

Human Resources

Finance and Accounting

Environmental, Safety, and Health

Maintenance

Custodial

Payroll

Meal

Supply

c) Current Safety Envelope

Building 3 is classified as a low hazard facility, because quantities greater than three grams of explosives, but less than one kilogram, are processed there. A safety analysis for the facility is currently being prepared.

d) Current Status

1. No formal CAS review has been done. A quick condition assessment was done in July 1992.

2. No formal CAMP review has been done based on the latest Reconfiguration decision. A CAMP report was submitted on April 1, 1992, which focused on ES\&H needs, infrastructure maintenance, and consolidation projects. 
2) Future Facility Use

a) Alternate Future Use Scenarios

1. WFO in the same discipline is unknown under recent May 27, 1993, reconfiguration guidance. Probably none.

2. WFO in a new discipline is unknown under recent May 27, 1993, reconfiguration guidance. Probably none.

3. Commercialization possibilities under a lease agreement: Building 3 would be useful for any application requiring remote testing of energetic or explosive materials. The environmental test facilities in Building 3 would be of broad usefulness in testing a wide range of products for their resistance to shock, vibration, heat, cold, and humidity.

4. Commercialization under a sale agreement is unlikely in the short term, although there is a long-term possibility.

5. Asbestos has been found in Building 3. The building is probably contaminated with small amounts of energetic materials, which will require cleanup before building deactivation.

b) Facility Modifications Required for Likely Use

Probably no major building modification would be required for the above uses. The basic changes required may involve equipment.

c) Facility Modifications Required for Other Uses

Unknown.

d) Changes to Safety Envelope

The facility use suggested above should be covered under either the category of "low hazard facility" or "standard industrial hazard" unless larger quantities of explosives are involved. Any new work conducted in Building 3 may require that a safety assessment be performed to identify any new hazards involved in the process.

e) Cleanup Criteria for Each Future Use Scenario

Building 3 is contaminated with energetic materials and also contains asbestos. Characterization and cleanup of this contamination may be required before any future use of the facility, depending on contractual requirements.

f) Disposition of Surplus Equipment

Unknown. 


\section{BUILDING 35 PHYSICAL CHARACTERIZATION}

1) Current Mission Description

a) Facility Capabilities

Building 35 was built in 1970 . Its current active capabilities include $\mathrm{x}$-ray and eddy current nondestructive testing. Building 35 is also a $2500-\tilde{t}^{2}$ control room for the californium-252, multiplier, (CFX) neutron radiography facility located in Building 59. The neutron radiography facility has not operated since 1989.

Californium-252 is used as a neutron source; aluminum-clad enriched uranium-235 acts as the multiplier. The californium and uranium are located in Building 59. Mound plans to return the californium neutron source, which has about 2-3 years of useful service, to Oak Ridge in October 1993, and to return the aluminum-clad uranium to Sandia in approximately one year. The University of Cincinnati has a contract to develop a plan for the removal of the uranium from Building 59.

b) Resources Required to Support Operations

Primary Physical Resources:

Electricity

Physical security

Telecommunication device (phone)

Fire protection, sprinklers, fire department

Potable water

Sanitary drainage

HVAC

Services:

Human Resources

Finance and Accounting

Environmental, Safety, and Health

Maintenance

Custodial

Payroll

Meal

Supply

c) Current Safety Envelope

Building 35 operations are classified as standard industrial hazard.

d) Current Status

1. No formal CAS review has been done. A quick condition assessment was done in July 1992.

2. No formal CAMP review has been done based on the latest 
Reconfiguration decision. A CAMP report was submitted on April 1, 1992, which focused on ES\&H needs, infrastructure maintenance, and consolidation projects.

\section{2) Future Facility Use}

\section{a) Alternate Future Use Scenarios}

1. WFO in the same discipline is possible under recent May 27, 1993 , reconfiguration guidance, but only if the WFO can be identified before the californium source is returned to Oak Ridge. The cost for a new source is $\$ 100-200 \mathrm{~K}$.

2. WFO in a new discipline is unknown under recent May 27, 1993, reconfiguration guidance. Probably none.

3. Commercialization is possible under a lease agreement, but only if the WFO can be identified before the californium source is returned to Oak Ridge. Cost for a new source is $\$ 100-200 \mathrm{~K}$.

4. Commercialization is possible under a sale agreement, but only if the WFO can be identified before the californium source is returned to Oak Ridge. The cost for a new source is $\$ 100-200 \mathrm{~K}$.

5. Deactivation effort should be minimal; the building is not contaminated with radiological or energetic materials. The May 1993 Asbestos Survey identified thermal system insulation that contains asbestos.

b) Facility Modifications Required for Likely Use

None. WFO or commercial ventures could use the neutron radiography facility without modifications to the facility.

c) Facility Modifications Required for Other Uses

Unknown.

d) Changes to Safety Envelope

Changes to the safety envelope should be minimal since the operations would be similar to current operations.

e) Cleanup Criteria for Each Future Use Scenario

Building 35 contains no radiological or energetic materials. A May 1993 Asbestos Survey found asbestos in the thermal system insulation.

f) Disposition of Surplus Equipment

None. 


\section{BUILDING 43 PHYSICAL CHARACTERIZATION}

1) Current Mission Description

a) Facility Capabilities

Building 43 is a 1516- $\mathrm{ft}^{2}$ building used for thermite development work in support of defense programs. It is currently in active use for this purpose. The building contains equipment including two powder presses, a lathe, and a milling machine.

b) Resources Required to Support Operations

Primary Physical Resources:

Electricity

Potable water

Sanitary drainage

Physical security

Telecommunication devices

Fire protection, sprinklers, fire department

HVAC

Services:

Human Resources

Finance and Accounting

Environmental, Safety, and Health

Maintenance

Custodial

Payroll

Meal

Supply

Special Resources:

Blowout work for explosives work

Explosion-proof electrical service

c) Current Safety Envelope

Building 43 operations are classified as low hazard because of the presence of energetic materials. A safety analysis of the thermite machining operation in Building 43 has been completed in preparation for an Operational Readiness Review.

d) Current Status

1. No formal CAS review has been done. A quick condition assessment was done in July 1992.

2. No formal CAMP review has been done based on the latest Reconfiguration decision. A CAMP report was submitted on April 1, 19S2, which focused on ES\&H needs, infrastructure 
maintenance, and consolidation projects.

2) Future Facility Use

a) Alternate Future Use Scenarios

1. WFO in the same discipline possible under recent May 27, 1993, reconfiguration guidance. Building 43 would be useful for small pilot runs or custom machining of energetic materials.

2. WFO in a new discipline is unknown under recent May 27, 1993, reconfiguration guidance. Probably none.

3. Commercialization possibilities under a lease agreement: Building 43 would be useful for small pilot runs or custom machining of energetic materials.

4. Commercialization under a sale agreement is unlikely.

5. The building is contaminated with energetic materials and asbestos. Deactivation effort may conceivably require cleanup of this contamination.

b) Facility Modifications Required for Likely Use

Probably no major building modification would be required for this use. The basic changes required may involve equipment.

c) Facility Modifications Required for Other Uses

Unknown.

d) Changes to Safety Envelope

The facility use suggested above should be covered under the low hazard category unless larger quantities of hazardous materials are involved. Any new work conducted in Building 43 may require that a safety assessment be performed to identify any new hazards involved in the process.

e) Cleanup Criteria for Each Future Use Scenario

Building 43 is contaminated with energetic materials and contains asbestos. Cleanup of this contamination may be required before commercial use of the building, depending on contract requirements.

f) Disposition of Surplus Equipment

All equipment in Building 43 is considered to be contaminated with energetic materials. Even though thermites are considered to pose only a minor danger, disposal of surplus equipment may be difficult. 


\section{BUILDING 45 PHYSICAL CHARACTERIZATION}

1) Current Mission Description

a) Facility Capabilities

Building 45 will be a $9500-\mathrm{ft}^{2}$ building after its addition is completed. The building is used for repair and calibration of radiation instrumentation and for dosimetry. It is currently in active use for this purpose. Specialized equipment in the building includes:

Electrometers

Source irradiators

X-ray units

Special ion chambers

b) Resources Required to Support Operations

Primary Physical Resources:

Electricity

Potable water

Sanitary drainage

Physical security

Telecommunication devices

Fire protection, sprinklers, fire department HVAC

Services:

Human Resources

Finance and Accounting

Environmental, Safety, and Health

Maintenance

Custodial

Payroll

Meal

Supply

Special Resources:

Radioactive sources - traceable to National Institute of Standards and Technology

Compressed air

Precise temperature and humidity controls

Safety features such as interlocks and automatic shutdown 
c) Current Safety Envelope

Building 45 operations are classified as low hazard. A safety assessment has been approved for Building $\mathbf{4 5}$ operations.

d) Current Status

1. No formal CAS review has been done. A quick condition assessment was done in July 1992.

2. No formal CAMP review has been done based on the latest Reconfiguration decision. A CAMP report was submitted on April 1, 1992, which focused on ES\&H needs, infrastructure maintenance, and consolidation projects.

2) Future Facility Use

a) Alternate Future Use Scenarios

1. WFO in the same discipline possible under recent May 27, 1993, reconfiguration guidance. Any radioactive work performed at Mound may require dosimetry and/or the calibration of radiation instruments.

2. WFO in a new discipline is unknown under recent May 27, 1993, reconfiguration guidance. Probably none.

3. Commercialization possibilities under a lease agreement: Building 45 could be used to perform instrument calibration for outside concerns such as universities, military bases, and other DOE facilities.

4. Commercialization under a sale agreement is unlikely in the short term, although there is a long-term possibility.

5. Deactivation effort should be minimal for the building, as it is not contaminated with either radiological or energetic materials. However, asbestos has been found in the building and may require abatement.

b) Facility Modifications Required for Likely Use

Probably no major building modification would be required for this use. The basic changes required may involve equipment. 
c) Facility Modifications Required for Other Uses

Unknown.

d) Changes to Safety Envelope

The facility use suggested above should be covered under the low hazard category.

Any now work conducted in Building $\mathbf{4 5}$ may require that a safety assessment be performed to identify any new hazards involved in the process.

e) Cleanup Criteria for Each Future Use Scenario

Building 45 is not contaminated with any radioactive or energetic materials. Asbestos has been found in the building and $\mathrm{m} \varepsilon \mathrm{y}$ require abatement, depending on contractual requirements.

f) Disposition of Surplus Equipment

None. 
This page intentionally blank. 


\section{BUILDING 46 PHYSICAL CHARACTERIZATION}

\section{1) Current Mission Description}

a) Facility Capabilities

Building 46 is a $2439-\mathrm{ft}^{2}$ building that is used for welding development efforts in support of the heat source program. Some welding development for energetic materials is also performed in the building. It is currently in active use for these purposes.

Specialized facilities include:

Electron beam welder

Two AMET controllers for gas tungsten arc (GTA) welding

PC-controlled GTA welder

Two gloveboxes with recirculating atmospheres for high-purity welding

b) Resources Required to Support Operations

Primary Physical Resources:

Electricity

Potable water

Sanitary drainage

Physical security

Telecommunication devices

Fire protection, sprinklers, fire department HVAC

Services:

Human Resources

Finance and Accounting

Environmental, Safety, and Health

Maintenance

Custodial

Payroll

Meal

Supply

Si ecial Resources:

Bottled gas

Chilled water 
c) Current Safety Envelope

Building 46 operations are classified as standard industrial hazard.

d) Current Status

1. No formal CAS review has been done. A quick condition assessment was done in July 1992.

2. No formal CAMP review has been done based on the latest Reconfiguration decision. A CAMP report was submitted on April 1, 1992, which focused on ES\&H needs, infrastructure maintenance, and consolidation projects.

2) Future Facility Use

a) Alternate Future Use Scenarios

1. WFO in the same discipline possible under recent May 27, 1993, reconfiguration guidance. The facilities in Building 46 could be used to provide welding development, consultation, troubleshooting, and high-tech welding for a variety of government and commercial customers.

2. WFO in a new discipline is unknown under recent May 27, 1993, reconfiguration guidance. Probably none.

3. Commercialization possibilities under a lease agreement: The facilities in Building 46 could be used to provide welding development, consultation, troubleshooting, and high-tech welding for a variety of government and commercial customers.

4. Commercialization under a sale agreement is unlikely in the short term, although there is a long-term possibility.

5. Deactivation effort should be minimal for the building, as it is not contaminated with either radiological or energetic materials. However, it does contain asbestos, which may require abatement.

b) Facility Modifications Required for Likely Use

Probably no major building modification would be required for this use. The basic changes required may involve equipment. 
c) Facility Modifications Required for Other Uses

Unknown.

d) Changes to Safety Envelope

The facility use suggested above should be covered under standard industrial hazard category unless hazardcus materials are involved.

Any new work conducted in Building 46 may require that a safety assessment be performed to identify any new hazards involved in the process.

e) Cleanup Criteria for Each Future Use Scenario

Building 46 is not contaminated with any radioactive or energetic materials, but it does contain asbestos. Abatement may be required before any commercial uses, depending on contract requirements.

f) Disposition of Surplus Equipment

The electron beam welder is large and difficult to move. Any future plans for Building 46 should assume that the electron beam welder will remain in place. 
This page intentionally blank.

$5-32$ 


\section{BUILDING 48 PHYSICAL CHARACTERIZATION}

1) Current Mission Description

a) Facility Capabilities

Building 48 is used for analyzing energetic materials from the stockpile. The first floor of the building is offices; the analytical equipment is located on the second floor. Building 48 also analyzes energetic materials for the Department of Defense. Building 48 is a $7950-\mathrm{ft}^{2}$, reinforced concrete building. It was built in 1970 .

b) Resources Required to Support Operations

Primary Physical Resources:

Electricity

Physical security

Fire protection, sprinklers, fire department

Telecommunication devices

Potable water

Sanitary drains

Humidity control (room 205)

Radio frequency shielded (room 205)

Services:

Human Resources

Finance and Accounting

Environmental, Safety, and Health

Maintenance

Custodial

Payroll

Meal

Supply

c) Current Safety Envelope

Building 48 operations are classified as standard industrial hazard.

d) Current Status

1. No formal CAS review has been done. A quick condition assessment was done in July 1992.

2. No formal CAMP review has been done based on the latest Reconfiguration decision. A CAMP report was submitted on April 1, 1992, which focused on ES\&H needs, infrastructure maintenance, and consolidation projects. 
2) Future Facility Use

a) Alternate Future Use Scenarios

1. Work For Others (WFO) is probable under recent May 27, 1993, reconfiguration guidance. Building 48 is currently doing work for the Department of Defense.

2. WFO in a new discipline is unknown under recent May 27, 1993, reconfiguration guidance. Probably none.

3. Commercialization under a lease agreement is possible under recent May 27, 1993, reconfiguration guidance. Building 48 could be used to analyze other energetic materials required by another industry. One possibility would be companies that manufacture the energetic materials for air bags.

4. Commercialization under a sale agreement is possible under recent May 27, 1993, reconfiguration guidance. Building 48 could be used to analyze other energetic materials required by another industry. One possibility would be companies that manufacture the energetic materials for air bags.

5. Deactivation efforts would require the cleanup of energetic materials. The building is not contaminated with radiological materials. A May 1993 Mound Asbestos survey found asbestos in the thermal insulation of Building 48.

b) Facility Modifications Required for Likely Use

None. Building 48 could be used to analyze energetic materials in the commercial arena or for another government agency.

c) Facility Modifications Required for Other Uses

Unknown.

d) Changes to Safety Envelope

Probably none.

e) Cleanup Criteria for Each Future Use Scenario

The building is contaminated with energetic materials. The building is not contaminated with radiological materials. A May 1993 Mound Asbestos survey found asbestos in the thermal insulation.

f) Disposition of Surplus Equipment

Analytical equipment in Building 48 could be surplused when no longer needed. 


\section{BUILDING 51 PHYSICAL CHARACTERIZATION}

1) Current Mission Description

a) Facility Capabilities

Building 51 houses a laboratory that currently supports the production of thermites and the production of carbon for a lithium battery/capacitor research project funded by Sandia and private industry. The equipment in the laboratory includes two Californiatype fumehoods, a dry atmosphere glovebox, six $1200^{\circ} \mathrm{F}$ tube furnaces, one $3600^{\circ} \mathrm{F}$ tube furnace, and an isostatic press. Building 51 is a $3541-\mathrm{ft}^{2}$, steel frame building built in 1972 .

b) Resources Required to Support Operations

Primary Physical Resources:

Electricity

Physical security

HVAC (includes two California-type fumehoods)

Potable water

Sanitary drains

Fire protection, sprinklers, fire department

Dry nitrogen supply

Services:

Human Resources

Finance and Accounting

Environmental, Safety, and Health

Maintenance

Custodial

Payroll

Meal

Supply

c) Current Safety Envelope

Building 51 operations are classified as standard industrial hazard.

d) Current Status

1. No formal CAS review has been done. A quick condition assessment was done in July 1992.

2. No formal CAMP review has been done based on the latest Reconfiguration decision. A CAMP report was submitted on April 1, 1992, which focused on ES\&H needs, infrastructure maintenance, and consolidation projects. 
a) Alternate Future Use Scenarios

1. Work For Others (WFO) is probable under recent May 27, 1993, reconfiguration guidance. The current lithium battery/capacitor work being done for Sandia is an example of the type of work that Building 51 could continue to pursue.

2. WFO in a new discipline is probable under May 27, 1993, reconfiguration guidance. Building 51 is a laboratory that could be used for other new disciplines with some modifications.

3. Commercialization possibilities under a lease agreement: Probably none.

4. Commercialization possibilities under a sale agreement: Probably none.

5. Deactivation efforts would require the cleanup of the energetic materials in the building. The building is not contaminated with radiological materials. A May 1993 Mound Asbestos Survey determined that Building 51 does not contain asbestos in its thermal insulation systems.

b) Facility Modifications Required for Likely Use

None. Future use of the building would likely be the same.

c) Facility Modifications Required for Other Uses

Unknown.

d) Changes to Safety Envelope

Unknown.

e) Cleanup Criteria for Each Future Use Scenario

Building 51 is contaminated with energetic materials. Building 51 is not contaminated with radiological materials or asbestos contained in the thermal insulation systems.

f) Disposition of Surplus Equipment

None. 


\section{BUILDING 55 PHYSICAL CHARACTERIZATION}

1) Current Mission Description

a) Facility Capabilities

Building 55 is used for storing environmental sampling equipment. Building 55 is a $330-\mathrm{ft}^{2}$, masonry exterior wall building built in 1973.

b) Resources Required to Support Operations

Primary Physical Resources:

Electricity

Physical security

Fire protection, sprinklers, fire department

Potable water

Sanitary drains (one sink)

Services:

Human Resources

Finance and Accounting

Environmental, Safety, and Health

Maintenance

Custodial

Payroll

Meal

Supply

c) Current Safety Envelope

Building 55 operations are classified as standard industrial hazard.

d) Current Status

1. No formal CAS review has been done. A quick condition assessment was done in July 1992.

2. No formal CAMP review has been done based on the latest Reconfiguration decision. A CAMP report was submitted on April 1, 1992, which focused on ES\&H needs, infrastructure maintenance, and consolidation projects.

2) Future Facility Use

a) Alternate Future Use Scenarios

1. WFO in the same discipline is unknown under recent May 27, 1993, reconfiguration guidance. Probably none. 
2. WFO in a new discipline is unknown under recent May 27, 1993, reconfiguration guidance. Probably none.

3. Commercialization possibilities under a lease agreement: Probably none.

4. Commercialization possibilities under a sale agreement: Probably none.

5. Deactivation efforts should be minimal for the building as it is not contaminated with either radiological, asbestos, or energetic materials.

b) Facility Modifications Required for Likely Use

None. Building is currently supporting environmental group. Future use of the building would likely be the same.

c) Facility Modifications Required for Other Uses

Not applicable.

d) Changes to Safety Envelope

Not applicable.

e) Cleanup Criteria for Each Future Use Scenario

Not applicable.

f) Disposition of Surplus Equipment

Not applicable. 


\section{BUTLDING 58 PHYSICAL CHARACTERIZATION}

1) Current Mission Description

a) Facility Capabilities

Building 58 is the alpha filter bank for SW building. Building 58 uses HEPA filtration to filter out any alpha contamination from the exhaust of rooms $2,2 \mathrm{~A}, 4,5,6,6 \mathrm{~A}, 7,8,9,10,10 \mathrm{~A}, 10 \mathrm{~B}, 10 \mathrm{C}, 11,12$, $13,14,15,16,17,18,19,20,20 \mathrm{~A}$ through $20 \mathrm{E}, 21,21 \mathrm{~A}, 142,147$, $147 \mathrm{~A}, 200,203 / 204,205,208,209,210,210 \mathrm{~A}$, and $210 \mathrm{~B}$ in SW building. Building 58 has $6110 \mathrm{ft}^{2}$ and was built in 1977.

b) Resources Required to Support Operations

Primary Physical Resources:

Electricity

Physical security

Fire protection, sprinklers, fire department

Potable water

Sanitary drains

Breathing air

Compressed air

Heat recovery system

Services:

Human Resources

Finance and Accounting

Environmental, Safety, and Health

Maintenance

Custodial

Payroll

Meal

Supply

c) Current Safety Envelope

Building 58 currently operates under SW building's OSR, MD-10298.

The FSAR for 58 and SW buildings is in the approval stages.

d) Current Status

1. No formal CAS review has been done. A quick condition assessment was done in July 1992.

2. No formal CAMP review has been done based on the latest Reconfiguration decision. A CAMP report was submitted on April 1, 1992, which focused on ES\&H needs, infrastructure maintenance, and consolidation projects. 
2) Future Facility Use

a) Alternate Future Use Scenarios

1. WFO in the same discipline is unknown under recent May 27, 1993, reconfiguration guidance. Probably none.

2. WFO in a new discipline is unknown under recent May 27, 1993, reconfiguration guidance. Probably none.

3. Commercialization possibilities under a lease agreement: Probably none.

4. Commercialization possibilities under a sale agreement: Probably none.

5. There are no near future plans to $D \& D$ this building since this building supports SW building.

If the need for HEPA ventilation was eliminated in SW Building, then Building 58 could be deactivated.

The building does contain equipment that is contaminated with radiological and mixed waste materials. A recent survey of Building 58 determined that the building does not contain any asbestos-containing material.

b) Facility Modifications Required for Likely Use

None. This bu: lding is currently supporting SW building. Future use of the building would likely be the same.

c) Facility Modifications Required for Other Uses

Not applicable.

d) Changes to Safety Envelope

Not applicable.

e) Cleanup Criteria for Each Future Use Scenario

Not applicable.

f) Disposition of Surplus Equipment

Not applicable. 


\section{BUILDING 59 PHYSICAL CHARACTERIZATION}

\section{1) Current Mission Description}

a) Facility Capabilities

Building 59 is a $668-\mathrm{ft}^{2}$, californium-252, multiplier, (CFX) neutron radiography facility. The control room for this facility is located in Building 35. The facility has not operated since 1989. The building was built in 1978 .

Californium-252 is used as a neutron source; aluminum-clad enriched uranium-235 acts as the multiplier. The californium and uranium are located in Building 59. Mound plans to return the californium neutron source, which has about 2-3 years of useful service, to Oak Ridge in October 1993, and to return the aluminum-clad uranium to Sandia in approximately one year. The University of Cincinnati has a contract to develop a plan for the removal of the uranium from Building 59.

b) Resources Required to Support Operations

Primary Physical Resources:

Electricity

Physical security

Telecommunication device (phone)

Fire protection, sprinklers, fire department

HVAC

Services:

Human Resources

Finance and Accounting

Environmental, Safety, and Health

Maintenance

Custodial

Payroll

Meal

Supply

c) Current Safety Envelope

Building 59 operations are classified as standard industrial hazard.

d) Current Status

1. No formal CAS review has been done. A quick condition assessment was done in July 1992.

2. No formal CAMP review has been done based on the latest Reconfiguration decision. A CAMP report was submitted on April 1, 1992, which focused on ES\&H needs, infrastructure maintenance, and consolidation projects. 
a) Alternate Future Use Scenarios

1. WFO in the same discipline is possible under recent May 27, 1993 , reconfiguration guidance, but only if the WFO can be identified before the californium source is returned to Oak Ridge. The cost for a new source is $\$ 100-200 \mathrm{~K}$.

2. WFO in a new discipline is unknown under recent May 27, 1993, reconfiguration guidance. Probably none.

3. Commercialization is possible under a lease agreement, but only if the WFO can be identified before the californium source is returned to Oak Ridge. The cost for a new source is $\$ 100$ $200 \mathrm{~K}$.

4. Commercialization is possible under a sale agreement, but only if the WFO can be identified before the californium source is returned to Oak Ridge. The cost for a new source is $\$ 100-200 \mathrm{~K}$.

5. The building's radiological materials are contained. The building would have to be surveyed to determine whether any of the nearby neutron sources have become activated by the bombardment of neutrons.

b) Facility Modifications Required for Likely Use

None. WFO or commercial ventures could use the neutron radiography facility without modifications to the facility.

c) Facility Modifications Required for Other Uses

Unknown.

d) Changes to Safety Envelope

Unknown.

e) Cleanup Criteria for Each Future Use Scenario

The building's radiological materials are contained. The building would have to be surveyed to determine whether any of the nearby neutron sources have become activated by neutron bombardment.

f) Disposition of Surplus Equipment

Unknown. 


\section{BUILDING 87 PHYSICAL CHARACTERIZATION}

1) Current Mission Description

a) Facility Capabilities

Building 87 is a $38,882-\mathrm{ft}^{2}$ building used for destructive testing of explosives and the fabrication of electronic test systems. The building contains office space, rest rooms, a cafeteria, three test cells, the electronic equipment to operate the test cells, and environmental chambers.

b) Resources Required to Support Operations

Primary Physical Resources:

Electricity

Potable water

Sanitary drainage

Physical security

Telecommunication devices

Fire protection, sprinklers, fire department

HVAC

Compressed air

Services:

Human Resources

Finance and Accounting

Environmental, Safety, and Health

Maintenance

Custodial

Payroll

Meal

Supply

c) Current Safety Envelope

Building 87 operations are classified as standard industrial hazard.

d) Current Status

1. No formal CAS review has been done. A quick condition assessment was done in July 1992.

2. No formal CAMP review has been done based on the latest Reconfiguration decision. A CAMP report was submitted on April 1, 1992, which focused on ES\&H needs, infrastructure maintenance, and consolidation projects. 
2) Future Facility Use

a) Alternate Future Use Scenarios

1. WFO in the same discipline is unknown under recent May 27, 1993, reconfiguration guidance. Probably none.

2. WFO in a new discipline is unknown under recent May 27, 1993, reconfiguration guidance. Probably none.

3. Commercialization under a lease agreement possibility: Building 87 would be useful for any application requiring cells for destructive testing.

4. Commercialization under a sale agreement is unlikely in the short term, although there is a long-term possibility.

5. Deactivation effort should be minimal for the building, as it is not contaminated with either radiological or energetic materials.

b) Facility Modifications Required for Likely Use

Probably no major building modification would be required for this use. The basic changes required would involve equipment.

c) Facility Modifications Required for Other Uses

Unknown.

d) Changes to Safety Envelope

The facility use suggested above should be covered under standard industrial hazard category unless hazardous materials are involved.

Any new work conducted in Building 87 may require that a safety assessment be performed to identify any new hazards involved in the process.

e) Cleanup Criteria for Each Future Use Scenario

Building 87 is not contaminated with any radioactive or energetic materials.

f) Disposition of Surplus Equipment

The test cells in Building 87 are large and would be very costly to move. Any future use of the facility should be planned on the assumption that the cells will remain in place. 


\section{BUILDING 94 PHYSICAL CHARACTERIZATION}

1) Current Mission Description

a) Facility Capabilities

Building 94 is a $1240-\mathrm{ft}^{2}$ building that is used for materials compatibility studies in support of defense programs. It is currently in active use for this purpose.

One third of Building 94 is used for laboratories and the remaining two thirds of the building is used for environmental ovens.

b) Resources Required to Support Operations

Primary Physical Resources:

Electricity

Potable water

Sanitary drainage

Physical security

Telecommunication devices

Fire protection, sprinklers, fire department

HVAC

Services:

Human Resources

Finance and Accounting

Environmental, Safety, and Health

Maintenance

Custodial

Payroll

Meal

Supply

c) Current Safety Envelope

Building 94 operations are classified as standard industrial hazard.

d) Current Status

1. No formal CAS review has been done. A quick condition assessment was done in July 1992.

2. No formal CAMP review has been done based on the latest Reconfiguration decision. A CAMP report was submitted on April 1, 1992, which focused on ES\&H needs, infrastructure maintenance, and consolidation projects. 
a) Alternate Future Use Scenarios

1. WFO in the same discipline is unknown under recent May 27, 1993, reconfiguration guidance. Probably none.

2. WFO in a new discipline is unknown under recent May 27, 1993, reconfiguration guidance. Probably none.

3. Commercialization possibilities under a lease agreement: Building 94 would be useful for any application requiring a laboratory or environmental ovens.

4. Commercialization under a sale agreement is unlikely in the short term, although there is a long-term possibility.

5. Deactivation effort should be minimal for the building, as it is not contaminated with either radiological or energetic materials.

b) Facility Modifications Required for Likely Use

Probably no major building modification would be required for this use. The basic changes required would involve equipment.

c) Facility Modifications Required for Other Uses

Unknown.

d) Changes to Safety Envelope

The facility use suggested above should be covered under standard industrial hazard category unless hazardous materials are involved.

Any new work conducted in Building 94 may require that a safety assessment be performed to identify any new hazards involved in the process.

e) Cleanup Criteria for Each Future Use Scenario

Building 94 is not contaminated with any radioactive or energetic materials.

f) Disposition of Surplus Equipment

The ovens and lab equipment in Building 94 could be removed at a moderate cost. 


\section{SECTION 6: UTILITY PLANTS}

A. Planning Basis: The utility plants are a functional unit consisting of the facilities and equipment necessary to provide centralized process and breathing air, steam and condensate, sewage processing systems, chilled water supply and return, and other water systems including potable, process, fire water, and stacks.

1. Present Mission:

Process and Breathing Air:

Provides compressed air both for breathing air and for operation of equipment. Sufficient quality, quantity, and pressure, and redundancy at appropriate pressures, are required.

Steam and Condensate:

Provides dependable and quality steam delivery for process and facility heating to meet the fluctuating demands of the site. These systems must be operated economically and in a manner that supports Mound's energy conservation goals.

Sewage Processing Systems:

Operation of the sewage system is based on the continuing need to comply with even more stringent National Pollutant Discharge Elimination System (NPDES) regulations. This necessitates a need to use advanced technologies to ensure compliance throughout the next 20 years.

\section{Chilled Water Supply:}

The mission of the chilled water systems is to provide reliable and adequate supplies of chilled water (ethylene glycol recirculated system), which is used for the majority of Mound's comfort and process cooling equipment.

\section{Potable, Process, and Fire Protection Water Systems:}

These utilities provide for the ongoing need to ensure dependability and redundancy of these systems while meeting the changing local, state, and federal regulations governing them. 
Stacks:

These items represent a small investment; thus, their need for capital limited and infrequent.

2. Material Condition and Expected Useful Life:

Process and Breathing Air:

Generally the condition of these systems is good because of their relatively new condition. Expected life should be about 15 years.

\section{Steam and Condensate:}

The condition of these systems is fair. However, inadequate redundant boiler capacity exists at present. In the event of failure of one of the two existing boilers during a winter design day, severe damage to heating coils could occur, with resulting interruption of proper environmental conditions. (See Event B.5.)

\section{Sewage and Sewage Processing Systems:}

Adequate conditions prevail. Most of these systems are at the midpoint of their remaining projected useful lives. Changing technologies and regulations are the greater concern. (See Event B.6.)

\section{Chilled Water Supply:}

System components range from new to only fair condition. Distribution to various areas is being addressed. Some chilled water lines are planned for replacement. (See Event B.3.)

\section{Potable, Process, and Fire Water Systems:}

Most of these systems would be rated fair. Projects planned to ensure adequate process and potable water are described in Events B.1. and B.2.

\section{Stacks:}

The condition of the stacks should be considered fair; only minor maintenance is expected to ensure their viability well beyond this planning period. 
3. Key Activities and Upgrades: All activities in Section B are necessary to continue to maintain these utilities in a fair to good condition.

4. ES\&H and S\&S Upgrades Required: No significant ES\&H or S\&S concern exists for this functional unit. Event B.6 does provide for a

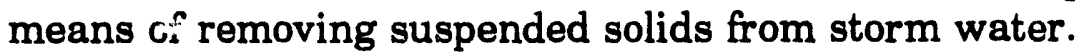

\section{UTILITY PLANTS}

\begin{tabular}{|c|c|c|c|c|c|}
\hline BLDG & DESCRIPTION & ONDITION & $\begin{array}{c}\text { SQUARE } \\
\text { FOOTAGE } \\
(\times 1000)\end{array}$ & AGE (Yrs.) & $\begin{array}{c}\text { REMAINING } \\
\text { PROJECTED } \\
\text { USEFUL LIFE } \\
\end{array}$ \\
\hline EG1 & Emerg. Generator \#1 & & .53 & & \\
\hline EG2 & Emerg. Generator \#2 & & .53 & & \\
\hline EG4 & Emerg. Generator \#4 & & .53 & & \\
\hline EG6 & Emerg. Generator \#6 & & .32 & & \\
\hline EG7 & Emerg. Generator \#7 & & .32 & & \\
\hline $\mathbf{P}$ & Power House Main Hill & Adequate & 15.1 & 45 & 15 \\
\hline SD & $\begin{array}{l}\text { Sanitary Treatment } \\
\text { Not in Service }\end{array}$ & Poor & 1.6 & 45 & 15 \\
\hline WD & Radioactive Waste Treat & Adequate & 16.2 & 45 & 25 \\
\hline WH1 & Well House Good & & .6 & 45 & 15 \\
\hline WH2 & Well House Good & & .6 & 33 & 27 \\
\hline WH3 & Well House Good & & .6 & 33 & 27 \\
\hline 13 & Remote Monitoring & & .05 & & \\
\hline 14 & $\begin{array}{l}\text { Aluminum Melting } \\
\text { Inactive }\end{array}$ & & .05 & & \\
\hline 24 & Potable Water Treatment & Good & .8 & 27 & 33 \\
\hline 56 & Fire Pump Good & & .6 & 20 & 50 \\
\hline 57 & Sanitary Sewer Treatment & t Good & .5 & 18 & 52 \\
\hline 90 & Retort (Explosive Waste) & Good & .7 & 10 & 60 \\
\hline 95 & Utilities Operations-SM & Good & 2.0 & 8 & 62 \\
\hline 112 & $\begin{array}{l}\text { Sanitary Disposal } \\
\text { Sand Filter }\end{array}$ & Excellent & .8 & 9 & 51 \\
\hline 113 & $\begin{array}{l}\text { Sanitary Disposal } \\
\text { Dewatering }\end{array}$ & Excellent & .5 & 4 & 56 \\
\hline
\end{tabular}

B. Description of Events and Projects:

1. The Building 24 water softeners (2), which soften water for the SM/PP area of the plant, will be replaced in FY 1995. The new softener system will be designed to include the latest equipment, materials, controls, and monitoring system to ensure proper water softening. ( $\$ 600 \mathrm{~K}$ - FY 1995 GPP)

2. The deep wells will be upgraded in FY 1995-1996 which includes the 
installation of $a$ fourth well. Currently the use of well \#1 is severely restricted because of the presence of volatile organic compounds. (\$1,000K - FY 1995-1996 GPP)

3. The chilled water line will be replaced in FY 1996 from $R$ Building to the end of the line on the North loop. (\$1,000 -FY 1996 Line Item)

4. Mound's Steam and Condensate Plant will undergo a significant upgrade in the FY 1997-1999 period because of Line Item funding to upgrade the Central Powerhouse Steam Generation System. The program will do the following: replace the existing 70,000 pounds per hour boiler (boiler \#1) with a new 85,000 pounds per hour boiler; install a new 30,000 pounds per hour boiler (boiler \#3); replace the existing deaerator feedwater heater and install another boiler feedwater pump; replace approximately 5,000 linear feet of distribution piping and reinsulate another approximate 5,000 linear feet of distribution piping. ( $\$ 7,000 \mathrm{~K}$ - FY 1997 Line Item)

5. In FY 1998-2000, the site will install a storm water treatment plant to provide a means to remove suspended solids from the storm water before it is released from Mound. The p. ocess to be incorporated is very similar to Mound's current process for treating sanitary sewage using clarifiers, sand filters, and a dewatering belt press process to solidify the solids. (\$5,400K - FY 1998 ES\&H Line Item)

6. Boiler \#2 System Upgrades will be required in the FY 1999-2000 time frame. These upgrades will include: the boiler \#2, economizer replacement; its stack replacement; tubes replacement; and the replacement of the condensate return pump, feedwater pump, and the deionized water make-up pump. (\$580K - FY 1999 GPP)

7. In FY 2005, the existing 790 SCFM air compressor will be replaced with a larger capacity unit. The unit will be nearly thirty years old at the time. Once serving as the site's primary air compressor, the unit currently serves as a backup to the newer 1,270 SCFM air compressor. To ensure $100 \%$ backup capacity, a larger unit will be required. (\$300K - FY 2005 BCE)

8. It is anticipated that in FY 2005-2006, a total steam generation system controls upgrade will be required to increase the system's operational efficiencies. ( $\$ 500 \mathrm{~K}$ - FY 2005 GPP) 
9. The site's masonry stacks will require repainting in FY 2005. These stacks were recently coated with a special paint material using an intermediate layer of fabric reinforcement. This was done in an effort to eliminate the stack's brick spalling problem, which had become a safety concern. The longevity of this "fix" is still uncertain; however, approximately 15 years of service is anticipated. ( $\$ 100 \mathrm{~K}$ - Expense)

10. The economizer unit for boiler \#1 will require replacement in FY 2008 because of its functional fatigue. ( $\$ 300 \mathrm{~K}$ - FY $2008 \mathrm{GPP}$ )

11. In FY 2008-2009, the current aeration tanks will require replacement because of their deterioration over the course of the previous 30 plus years. ( $\$ 1,000 \mathrm{~K}$ - FY 2008 Line Item)

12. The most significant outyear funding requiremant is the expected replacement of boiler \#2 in the FY 2009-2010 time frame. The unit will be 25 years old and will most probably require replacement from both a tachnical and physical condition standpoint. $(\$ 1,300 \mathrm{~K}$ FY 2009 Line Item)

C. Functional Unit Maintenance Activities: An intensive maintenance program has been established on the site's utility plant systems. A coordinated system of in-house and contracted services fulfills the needs of these facilities.

Compressed Air Systems: All of the site's air compressors and dryers are on an annual preventive maintenance inspection program. The valving, air compressors, and dryer units are inspected, overhauled, and repaired on an as-needed basis.

Steam and Condensate: The program includes, but is not limited to, the following items: an annual boiler inspection by Hartford on each boiler analyzing the total functionality of the unit; monthly preventive maintenance of the boiler control systems; yearly boiler valving/gauge calibration; yearly load testing on each boiler to confirm the unit's generating capacities; annual Powerhouse condensate pump preventive maintenance servicing; annual preventive maintenance on the system's three feedwater pumps; daily analysis of the feedwater chemical treatment process; and annual steam trap preventive maintenance inspections.

The Life Cycle Plan assumes that large capital funding requirements to install a new steam generation system are not available on some prescribed schedule. As such, the total system must be upgraded and maintained on an "as required" basis. The functional unit's life extension projects are cost effective when compared to a cycle of total system replacements. Upgrade 
projects are necessary to prevent uneconomically high energy use in steam generation, high levels of maintenance funding, and a risk as to the dependability of the site's steam generation capabilities.

Dewage Treatment Facilities: An intensive maintenance program has been established on the site sewage treatment and disposal facility. Under the guidance of a local sewage treatment specialist, repairs and modifications are made on an "as required" basis based upon p:edictive process data. Periodic inspection is made of the site's sanitary piping using cameras which are run internal to the piping for the purpose of detecting pipe features. The functional unit's annual repair requirements typically center around the need to replace some control components.

The sewage system Life Cycle Plan assumes that capital funding will be required to support the varioua upgrades being driven by environmental regulations. Should this funding not be available, the existing sanitary treatment processes will require administrative management and control, as has been the case in previous years. Unfortunately, administrative and operational control techniques will inevitably lead to NPDES permit violations as the permit levels become more stringent.

Chilled Water System: Mound has a very intensive preventive maintenance program to promote system longevity and dependability. An outside vendor performs routine preventive maintenance service on the Powerhouse chillers and air handling system coils, and strainers are routinely inspected and flushed to guarantee reliable chilled water flow.

Water Systems: Currently, the various pieces of equipment associated with the water pumping, treatment, and distribution system are maintained through routine preventive maintenance inspections, with repairs occurring on an "as needed" basis. The site's deep wells are inspected once every three years by an outside consultant. 


\section{BUILDING EG1 PHYSICAL CHARACTERIZATION}

1) Current Mission Description

a) Facility Capabilities

Building EG1 is a 528- $\mathrm{ft}^{2}$ modular building that is used to house emergency generator \#1. It is currently in active use for this purpose.

b) Resources Required to Support Operations

Primary Physical Resources:

Electricity

Services:

Human Resources

Finance and Accounting

Environmental, Safety, and Health

Maintenance

Custodial

Payroll

Meal

Supply

c) Current Safety Envelope

Building EG1 operations are classified as standard industrial hazard.

d) Current Status

1. No formal CAS review has been done. A quick condition assessment was done in July 1992.

2. No formal CAMP review has been done based on the latest Reconfiguration decision. A CAMP report was submitted on April 1, 1992, which focused on ES\&H needs, infrastructure maintenance, and consolidation projects.

2) Future Facility Use

a) Alternate Future Use Scenarios

1. WFO in the same discipline is unknown under recent May 27, 1993, reconfiguration guidance. Probably none. 
2. WFO in a new discipline is unknown under recent May 27, 1993, reconfiguration guidance. Probably none.

3. Commercialization possibilities under a lease agreement: Building EG1 would be useful for any application requiring emergency generator housing.

4. Commercialization under a sale agreement is unlikely in the short term, although there is a long-term possibility.

5. Deactivation effort should be minimal for the building, as it is not contaminated with either radiological or energetic materials.

b) Facility Modifications Required for Likely Use

Probably no major building modification would be required for this use. The basic changes required would involve equipment.

c) Facility Modifications Required for Other Uses

Unknown.

d) Changes to Safety Envelope

The facility use suggested above should be covered under standard industrial hazard category unless hazardous materials are involved.

Any new work conducted in Building EG1 may require that a safety assessment be performed to identify any new hazards involved in the process.

e) Cleanup Criteria for Each Future Use Scenario

Building EG1 is not contaminated with any radioactive or energetic materials.

f) Disposition of Surplus Equipment

There is no surplus equipment in Building EG1. 


\section{BUILDING EG2 PHYSICAL CHARACTERIZATION}

1) Current Mission Description

a) Facility Capabilities

Building EG2 is a 528- $\mathrm{ft}^{2}$ modular building that is used to house emergency generator \#2. It is currently in active use for this purpose.

b) Resources Required to Support Operations

Primary Physical Resources:

Electricity

Services:

Human Resources

Finance and Accounting

Environmental, Safety, and Health

Maintenance

Custodial

Payroll

Meal

Supply

c) Current Safety Envelope

Building EG2 operations are classified as standard industrial hazard.

d) Current Status

1. No formal CAS review has been done. A quick condition assessment was done in July 1992.

2. No mal CAMP review has been done based on the latest Reconfiguration decision. A CAMP report was submitted on April 1, 1992, which focused on ES\&H needs, infrastructure maintenance, and consolidation projects.

2) Future Facility Use

a) Alternate Future Use Scenarios

1. WFO in the same discipline is unknown under recent May 27, 1993, reconfiguration guidance. Probably none. 
2. WFO in a new discipline is unknown under recent May 27, 1993, reconfiguration guidance. Probably none.

3. Commercialization possibilities under a lease agreement: Building EG2 would be useful for any application requiring emergency generator housing.

4. Commercialization under a sale agreement is unlikely in the short term, although there is a long-term possibility.

5. Deactivation effort should be minimal; the building is not contaminated with radiological or energetic materials.

b) Facility Modifications Required for Likely Use

Probably no major building modification would be required for this use. The basic changes required would involve equipment.

c) Facility Modifications Required for Other Uses

Unknown.

d) Changes to Safety Envelope

The facility use suggested above should be covered under standard industrial hazard category unless hazardous materials are involved. Any new work conducted in building EG2 may require that a safety assessment be performed to identify any new hazards involved in the process.

e) Cleanup Criteria for Each Future Use Scenario

Building EG2 is not contaminated with any radioactive or energetic materials.

f) Disposition of Surplus Equipment

There is no surplus equipment in building EG2. 


\section{BUILDING EG4 PHYSICAL CHARACTERIZATION}

1). Current Mission Description

a) Facility Capabilities

Building EG4 is a $528-\mathrm{ft}^{2}$ modular building that is used to house emergency generator \#4. It is currently in active use for this purpose.

b) Resources Required to Support Operations

Primary Physical Resources:

Electricity

Services:

Human Resources

Finance and Accounting

Environmental, Safety, and Health

Maintenance

Custodial

Payroll

Meal

Supply

c) Current Safety Envelope

Building EG4 operations are classified as standard industrial hazard.

d) Current Status

1. No formal CAS review has been done. A quick condition assessment was done in July 1992.

2. No formal CAMP review has been done based on the latest Reconfiguration decision. A CAMP report was submitted on April 1, 1992, which focused on ES\&H needs, infrastructure maintenance, and consolidation projects.

2) Future Facility Use

a) Alternate Future Use Scenarios

1. WFO in the same discipline is unknown under recent May 27, 1993, reconfiguration guidance. Probably none. 
2. WFO in a new discipline is unknown under recent May 27, 1993, reconfiguration guidance. Probably none.

3. Commercialization possibilities under a lease agreement: Building EG4 would be useful for any application requiring emergency generator housing.

4. Commercialization under a sale agreement is unlikely in the short term, although there is a long-term possibility.

5. Deactivation effort should be minimal for the building, as it is not contaminated with either radiological or energetic materials.

b) Facility Modifications Required for Likely Use

Probably no major building modification would be required for this use. The basic changes required would involve equipment.

c) Facility Modifications Required for Other Uses

Unknown.

d) Changes to Safety Envelope

The facility use suggested above should be covered under standard industrial hazard category unless hazardous materials are involved.

Any new work conducted in Building EG4 may require that a safety assessment be performed to identify any new hazards involved in the process.

e) Cleanup Criteria for Each Future Use Scenario

Building EG4 is not contaminated with any radioactive or energetic materials.

f) Disposition of Surplus Equipment

There is no surplus equipment in Building EG4. 


\section{BUILDING EG6 PHYSICAL CHARACTERIZATION}

1) Current Mission Description

a) Facility Capabilities

Building EG6 is a $320-\mathrm{ft}^{2}$ modular building that is used to house emergency generator \#6. It is currently in active use for this purpose.

b) Resources Required to Support Operations

Primary Physical Resources: Electricity

Services:

Human Resources

Finance and Accounting

Environmental, Safety, and Health

Maintenance

Custodial

Payroll

Meal

Supply

c) Current Safety Envelope

Building EG6 operations are classified as standard industrial hazard.

d) Current Status

1. No formal CAS review has been done. A quick condition assessment was done in July 1992.

2. No formal CAMP review has been done based on the latest Reconfiguration decision. A CAMP report was submitted on April 1, 1992, which focused on ES\&H needs, infrastructure maintenance, and consolidation projects.

2) Future Facility Use

a) Alternate Future Use Scenarios

1. WFO in the same discipline is unknown under recent May 27, 1993, reconfiguration guidance. Probably none. 
2. WFO in a new discipline is unknown under recent May 27, 1993, reconfiguration guidance. Probably none.

3. Commercialization possibilities under a lease agreement: Building EG6 would be useful for any application requiring emergency generatur housing.

4. Commercialization under a sale agreement is unlikely in the short term, although there is a long-term possibility.

5. Deactivation effort should be minimal for the building, as it is not contaminated with either radiological or energetic materials.

\section{b) Facility Modifications Required for Likely Use}

Probably no major building modification would be required for this use. The basic changes required would involve equipment.

c) Facility Modifications Required for Other Uses

Unknown.

d) Changes to Safety Envelope

The facility use suggested above should be covered under standard industrial hazard category unless hazardous materials are involved.

Any new work conducted in Building EG6 may require that a safety assessment be performed to identify any new hazards involved in the process.

e) Cleanup Criteria for Each Future Use Scenario

Building EG6 is not contaminated with any radioactive or energetic materials.

f) Disposition of Surplus Equipment

There is no surplus equipment in Building EG6. 


\section{BUILDING EG7 PHYSICAL CHARACTERIZATION}

1) Current Mission Description

a) Facility Capabilities

Building EG7 is a $320-\mathrm{ft}^{2}$ modular building that is used to house emergency generator \#6. It is currently in active use for this purpose.

b) Resources Required to Support Operations

Primary Physical Resources: Electricity

Services:

Human Resources

Finance and Accounting

Environmental, Safety, and Health

Maintenance

Custodial

Payroll

Meal

Supply

c) Current Safety Envelope

Building EG7 operations are classified as standard industrial hazard.

d) Current Status

1. No formal CAS review has been done. A quick condition assessment was done in July 1992.

2. No formal CAMP review has been done based on the latest Reconfiguration decision. A CAMP report was submitted on April 1, 1992, which focused on ES\&H needs, infrastructure maintenance, and consolidation projects.

2) Future Facility Use

a) Alternate Future Use Scenarios

1. WFO in the same discipline is unknown under recent May 27, 1993, reconfiguration guidance. Probably none. 
2. WFO in a new discipline is unknown under recent May 27, 1993, reconfiguration guidance. Probably none.

3. Commercialization possibilities under a lease agreement: Building EG7 would be useful for any application requiring emergency generator housing.

4. Commercialization under a sale agreement is unlikely in the short term, although there is a long-term possibility.

5. Deactivation effort should be minimal; the building is not contaminated with either radiological or energetic materials.

b) Facility Modifications Required for Likely Use

Probably no major building modification would be required for this use. The basic changes required would involve equipment.

c) Facility Modifications Required for Other Uses

Unknown.

d) Changes to Safety Envelop

The facility use suggested above should be covered under standard industrial hazard category unless hazardous materials are involved. Any new work conducted in Building EG7 may require that a safety assessment be performed to identify any new hazards involved in the process.

e) Cleanup Criteria for Each Future Use Scenario

Building EG7 is not contaminated with any radioactive or energetic materials.

f) Disposition of Surplus Equipment

There is no surplus equipment in Building EG7. 


\section{P BUILDING PHYSICAL CHARACTERIZATION}

\section{1) Current Mission Description}

a) Facility Capabilities

$\mathrm{P}$ Building (the Powerhouse) is a $15,143-\mathrm{ft}^{2}$ building that provides services to the entire Mound plant. These services include plant air, steam, breathing air, chilled water, and softened water. It is currently in active use for this purpose.

b) Resources Required to Support Operations

Primary Physical Resources:

Electricity

Potable water

Sanitary drainage

Physical security

Telecommunication devices

Fire protection, sprinklers, fire department

HVAC

Services:

Human Resources

Finance and Accounting

Environmental, Safety, and Health

Maintenance

Custodial

Payroll

Meal

Supply

Special Resources:

Salt

Water additives (corrosion inhibitors and biocides)

Licensed operators -

3rd class engineer's license

Class 1 operator water license

c) Current Safety Envelope

Powerhouse operations are classified as standard industrial hazard.

d) Current Status

1. No formal CAS review has been done. A quick condition assessment was done in July 1992.

2. No formal CAMP review has been done based on the latest Reconfiguration decision. A CAMP report was submitted on 
April 1, 1992, which focused on ES\&H needs, infrastructure maintenance, and consolidation projects.

2) Future Facility Use

a) Alternate Future Use Scenarios

1. WFO in the same discipline is likely under recent May 27, 1993, reconfiguration guidance. P-Building will probably continue to fulfill its current mission as long as operations continue at Mound.

2. WFO in a new discipline is unknown under recent May 27, 1993, reconfiguration guidance. Probably none.

3. Commercialization possibilities under a lease agreement: P-Building will probably continue to fulfill its current mission as long as operations continue at Mound.

4. Commercialization under a sale agreement is unlikely in the short term, although there is a long-term possibility.

5. Deactivation effort should be minimal for the building, as it is not contaminated with either radiological or energetic materials. However, asbestos has been found in the building, and may require abatement.

b) Facility Modifications Required for Likely Use

No major building modification would be required for this use.

c) Facility Modifications Required for Other Uses

Unknown.

d) Changes to Safety Envelope

The facility use suggested above should be covered under standard industrial hazard category.

e) Cleanup Criteria for Each Future Use Scenario

P-Building is not contaminated with any radioactive or energetic materials. Asbestos abatement may be required before any commercial use of the building, depending on contract requirements.

f) Disposition of Surplus Equipment

None. 


\section{SD BUILDING PHYSICAL CHARACTERIZATION}

1) Current Mission Description

a) Facility Capabilities

The 1593- $\mathrm{ft}^{2} \mathrm{SD}$ Building is currently being decontaminated and decommissioned (D\&D).

SD Building is the old sewage disposal facility built in 1948. SD is contaminated with radiological materials.

b) Resources Required to Support Operations

Not applicable.

c) Current Safety Envelope

SD Building operations are classified as standard industrial hazard.

d) Current Status

1. No formal CAS review has been done. A quick condition assessment was done in July 1992.

2. No formal CAMP review has been done based on the latest Reconfiguration decision. A CAMP report was submitted on April 1, 1992, which focused on ES\&H needs, infrastructure maintenance, and consolidation projects.

2) Future Facility Use

None. 
This page intentionally blank. 


\section{WD BUILDING PHYSICAL CHARACTERIZATION}

\section{1) Current Mission Description}

a) Facility Capabilities

WD Building is a $16,216-\mathrm{ft}^{2}$ building where water that has alpha and beta radiological contamination is processed.

b) Resources Required to Support Operations

Primary Physical Resources:

Electricity

Physical security

Fire protection, sprinklers, fire department

Potable water

Sanitary drains

HVAC

Services:

Human Resources

Finance and Accounting

Environmental, Safety, and Health

Maintenance

Custodial

Payroll

Meal

Supply

c) Current Safety Envelope

An SAR is being written for WD Building.

d) Current Status

1. No formal CAS review has been done. A quick condition assessment was done in July 1992.

2. No formal CAMP review has been done based on the latest Reconfiguration decision. A CAMP report was submitted on April 1, 1992, which focused on ES\&H needs, infrastructure maintenance, and consolidation projects. 
2) Future Facility Use

a) Alternate Future Use Scenarios

1. WFO in the same discipline is unknown under recent May 27, 1993, reconfiguration guidance. Probably none.

2. WFO in a new discipline is unknown under recent May 27, 1993, reconfiguration guidance. Probably none.

3. Commercialization possibilities under a lease agreement: Unknown under recent May 27, 1993, reconfiguration guidance. Probably none.

4. Commercialization possibilities under a sale agreement: Unknown under recent May 27, 1993, reconfiguration guidance. Probably none.

5. Equipment and building are assumed to be contaminated with radiological materials.

WD Building could be deactivated only after deactivating the other radiological buildings.

b) Facility Modifications Required for Likely Use

None. This building is currently supporting the radiological water treatment for the plant. Future use of the building would likely be the same.

c) Facility Modifications Required for Other Uses

Unknown.

d) Changes to Safety Envelope

Unknown.

e) Cleanup Criteria for Each Future Use Scenario

WD Building is contaminated with radiological materials.

f) Disposition of Surplus Equipment

Unknown. 


\section{BUILDING WH1 PHYSICAL CHARACTERIZATION}

1) Current Mission Description

a) Facility Capabilities

Building WH1 is a $374-\mathrm{ft}^{2}$ building that is used for housing the pump for the plant water supply. It is currently in active use for this purpose.

b) Resources Required to Support Operations

Primary Physical Resources:

Electricity

Potable water

Physical security

Services:

Human Resources

Finance and Accounting

Environmental, Safety, and Health

Maintenance

Custodial

Payroll

Meal

Supply

c) Current Safety Envelope

Building WH1 operations are classified as standard industrial hazard.

d) Current Status

1. No formal CAS review has been done. A quick condition assessment was done in July 1992.

2. No formal CAMP review has been done based on the latest Reconfiguration decision. A CAMP report was submitted on April 1, 1992, which focused on ES\&H needs, infrastructure maintenance, and consolidation projects. 
a) Alternate Future Use Scenarios

1. WFO in the same discipline is likely under recent May 27, 1993, reconfiguration guidance.

2. WFO in a new discipline is unknown under recent May 27, 1993, reconfiguration guidance. Probably none.

3. Commercialization possibilities under a lease agreement: Building WH1 would be useful for any application requiring water services from the plant water supply.

4. Commercialization under a sale agreement is unlikely in the short term, although there is a long-term possibility.

5. Deactivation effort should be minimal; the building is not contaminated with either radiological or energetic materials.

b) Facility Modifications Required for Likely Use

Probably no major building modification would be required for this use. The basic changes required would involve equipment.

c) Facility Modifications Required for Other Uses

Unknown.

d) Changes to Safety Envelope

The facility use suggested above should be covered under standard industrial hazard category unless hazardous materials are involved. Any new work conducted in building WH1 may require that a safety assessment be performed to identify any new hazards involved in the process.

e) Cleanup Criteria for Each Future Use Scenario

Building WH1 is not contaminated with any radioactive or energetic materials.

f) Disposition of Surplus Equipment

There is no surplus equipment in WH1. 


\section{BUIILING WH2 PHYSICAL CHARACTERIZATION}

1) Current Mission Description

a) Facility Capabilities

Building WH2 is a $374-\mathrm{ft}^{2}$ building that is used for housing the pump for the plant water supply. It also houses a propane generator for emergency power backup. Building WH2 is currently in active use for this purpose.

b) Resources Required to Support Operations

Primary Physical Resources:

Electricity

Potable water

Physical security

Services:

Human Resources

Finance and Accounting

Environmental, Safety, and Health

Maintenance

Custodial

Payroll

Meal

Supply

c) Current Safety Envelope

Building WH2 operations are classified as standard industrial hazard.

d) Current Status

1. No formal CAS review has been done. A quick condition assessment was done in July 1992.

2. No formal CAMP review has been done based on the latest Reconfiguration decision. A CAMP report was submitted on April 1, 1992, which focused on ES\&H needs, infrastructure maintenance, and consolidation projects. 
2) Future Facility Use

a) Alternate Future Use Scenarios

1. WFO in the same discipline is likely under recent May 27, 1993, reconfiguration guidance.

2. WFO in a new discipline is unknown under recent May 27, 1993, reconfiguration guidance. Probably none.

3. Commercialization possibilities under a lease agreement: Building WH2 would be useful for any application requiring water services from the plant water supply.

4. Commercialization under a sale agreement is unlikely in the short term, although there is a long-term possibility.

5. Deactivation effort should be minimal; the building is not contaminated with either radiological or energetic materials.

b) Facility Modifications Required for Likely Use

Probably no major building modification would be required for this use. The basic changes required would involve equipment.

c) Facility Modifications Required for Other Uses

Unknown.

d) Changes to Safety Envelope

The facility use suggested above should be covered under standard industrial hazard category unless hazardous materials are involved. Any new work conducted in WH2 may require that a safety assessment be performed to identify any new hazards involved in the process.

e) Cleanup Criteria for Each Future Use Scenario

Building WH2 is not contaminated with any radioactive or energetic materials.

f) Disposition of Surplus Equipment

The emergency propane generator could be salvaged if this building were to be torn down. 


\section{BUILDING WH3 PHYSICAL CHARACTERIZATION}

1) Current Mission Description

a) Facility Capabilities

Building WH3 is a $128-\mathrm{ft}^{2}$ building that is used for housing the pump for the plant water supply. It also houses a propane generator for emergency backup. WH3 is currently in active use for this purpose.

b) Resources Required to Support Operations

Primary Physical Resources:

Electricity

Potable water

Physical security

Services:

Human Resources

Finance and Accounting

Environmental, Safety, and Health

Maintenance

Custodial

Payroll

Meal

Supply

c) Current Safety Envelope

Building WH3 operations are classified as standard industrial hazard.

d) Current Status

1. No formal CAS review has been done. A quick condition assessment was done in July 1992.

2. No formal CAMP review has been done based on the latest Reconfiguration decision. A CAMP report was submitted on April 1, 1992, which focused on ES\&H needs, infrastructure maintenance, and consolidation projects. 
2) Future Facility Use

a) Alternate Future Use Scenarios

1. WFO in the same discipline is likely under recent May 27, 1993, reconfiguration guidance.

2. WFO in a new discipline is unknown under recent May 27, 1993, reconfiguration guidance. Probably none.

3. Commercialization possibilities under a lease agreement: Building WH3 would be useful for any application requiring water services from the plant water supply.

4. Commercialization under a sale agreement is unlikely in the short term, although there is a long-term possibility.

5. Deactivation effort should be minimal; the building is not contaminated with either radiological or energetic materials.

b) Facility Modifications Required for Likely Use

Probably no major building modification would be required for this use. The basic changes required would involve equipment.

c) Facility Modifications Required for Other Uses

Unknown.

d) Changes to Safety Envelope

The facility use suggested above should be covered under standard industrial hazard category unless hazardous materials are involved. Any new work conducted in building WH3 may require that a safety assessment be performed to identify any new hazards involved in the process.

e) Cleanup Criteria for Each Future Use Scenario

Building WH3 is not contaminated with any radioactive or energetic materials.

f) Disposition of Surplus Equipment

The propane generator could be salvaged if this building if this building is to be torn down. 


\section{BUILDING 13 PHYSICAL CHARACTERIZATION}

1) Current Mission Description

a) Facility Capabilities

Building 13 is a $47-\mathrm{ft}^{2}$ building that is used for remote monitoring of explosives destruction in the burn area. It is currently in active use for this purpose.

The building contains a video monitor and electrical initiating equipment for firing explosives in the burn area.

b) Resources Required to Support Operations

Primary Physical Resources:

Electricity

Physical security

Telecommunication devices

Services:

Human Resources

Finance and Accounting

Environmental, Safety, and Health

Maintenance

Custodial

Payroll

Meal

Supply

c) Current Safety Envelope

Building 13 operations are classified as standard industrial hazard.

d) Current Status

1. No formal CAS review has been done. A quick condition assessment was done in July 1992.

2. No formal CAMP review has been done based on the latest Reconfiguration decision. A CAMP report was submitted on April 1, 1992, which focused on ES\&H needs, infrastructure maintenance, and consolidation projects. 
2) Future Facility Use

a) Alternate Future Use Scenarios

1. WFO in the same discipline possible under recent May 27, 1993 , reconfiguration guidance. The building could continue as a support facility for the burn area. The burn area would continue to be useful for disposal of a wide range of energetic materials.

2. WFO in a new discipline is unknown under recent May 27, 1993, reconfiguration guidance. Probably none.

3. Commercialization possibilities under a lease agreement: The building could be useful for disposal of a wide range of energetic materials.

4. Commercialization under a sale agreement is unlikely.

5. Deactivation effort should be minimal for the building, as it is not contaminated with either radiological or energetic materials.

b) Facility Modifications Required for Likely Use

No major building modification would be required for this use.

c) Facility Modifications Required for Other Uses

Unknown.

d) Changes to Safety Envelope

The facility use suggested above should be covered under standard industrial hazard category.

e) Cleanup Criteria for Each Future Use Scenario

Building 13 is not contaminated with any radioactive or energetic materials.

f) Disposition of Surplus Equipment

None. 


\section{BUILDING 14 PHYSICAL CHARACTERIZATION}

1) Current Mission Description

a) Facility Capabilities

Building 14 is a $53-\mathrm{ft}^{2}$ building that is used for aluminum melting processes in the burn area. It is currently shut dcwn and inactive for this purpose.

b) Resources Required to Support Operations

Primary Physical Resources:

Electricity

Services:

Human Resources

Finance and Accounting

Environmental, Safety, and Health

Maintenance

Custodial

Payroll

Meal

Supply

c) Current Safety Envelope

Building 14 operations are classified as standard industrial hazard.

d) Current Status

1. No formal CAS review has been done. A quick condition assessment was done in July 1992.

2. No formal CAMP review has been done based on the latest Reconfiguration decision. A CAMP report was submitted on April 1, 1992, which focused on ES\&H needs, infrastructure maintenance, and consolidation projects.

2) Future Facility Use

a) Alternate Future Use Scenarios

1. WFO in the same discipline is unknown under recent May 27, 1993, reconfiguration guidance. Probably none. 
2. WFO in a new discipline is unknown under recent May 27, 1993, reconfiguration guidance. Probably none.

3. Commercialization possibilities under a lease agreement: Building 14 would be useful for any application requiring energetic material storage or general síorage.

4. Commercialization under a sale agreement is unlikely in the short term, although there is a long-term possibility

5. Deactivation effort should be minimal for the building, as it is not contaminated with either radiological or energetic materials.

b) Facility Modifications Required for Likely Use

Probably no major building modification would be required for this use. The basic changes required would involve equipment.

c) Facility Modifications Required for Other Uses

Unknown.

d) Changes to Safety Envelope

The facility use suggested above should be covered under standard industrial hazard category, unless hazardous materials are involved.

Any new work conducted in Building 14 may require that a safety assessment be performed to identify any new hazards involved in the process.

e) Cleanup Criteria for Each Future Use Scenario

Building 14 is not contaminated with any radioactive or energetic materials.

f) Disposition of Surplus Equipment

There is no surplus equipment in Building 14. 


\section{BUILDING 24 PHYSICAL CHARACTERIZATION}

1) Current Mission Description

a) Facility Capabilities

Building 24 is a $840-\mathrm{ft}^{2}$ building that is used for treatment of the potable water system. The building houses two 100,000-gallon tanks and two 55-gallon drums. Water from Building 24 is sent to the SM/PP water tower, which services the SM/PP area.

b) Resources Required to Support Operations

Primary Physical Resources:

Electricity

Potable water (for tanks only)

Sanitary drainage

Physical security

Telecommunication devices

Fire protection, sprinklers, fire department

Services:

Human Resources

Finance and Accounting

Environmental, Safety, and Health

Maintenance

Custodial

Payroll

Meal

Supply

c) Current Safety Envelope

Building 24 operations are classified as standard industrial hazard.

d) Current Status

1. No formal CAS review has been done. A quick condition assessment was done in July 1992.

2. No formal CAMP review has been done based on the latest Reconfiguration decision. A CAMP report was submitted on April 1, 1992, which focused on ES\&H needs, infrastructure maintenance, and consolidation projects. 
2) Future Facility Use

a) Alternate Future Use Scenarios

1. WFO in the same discipline is unknown under recent May 27, 1993, reconfiguration guidance. Probably none.

2. WFO in a new discipline is unknown under recent May 27, 1993, reconfiguration guidance. Probably none.

3. Commercialization possibility under a lease agreement: Building 24 would be useful for treating the potable water system for the SM/PP area. The system is capable of servicing the entire plant.

4. Commercialization under a sale agreement is unlikely in the short term, although there is a long-term possibility.

5. Deactivation effort should be minimal; the building is not contaminated with either radiological or energetic materials.

b) Facility Modifications Required for Likely Use

No major building modification would be required for this use.

c) Facility Modifications Rs ruired for Other Uses

Unknown.

d) Changes to Safety Envelope

The facility use suggested above should be covered under standard industrial hazard category, unless hazardous materials are involved.

Any new work conducted in Building 24 may require that a safety assessment be performed to identify any new hazards involved in the process.

e) Cleanup Criteria for Each Future Use Scenario

Building 24 is not contaminated with any radioactive or energetic materials.

f) Disposition of Surplus Equipment

The water tanks in Building 24 are large and would be costly to move. Any future use of the facility should be planned on the assumption that the water tanks will remain in place. 


\section{BUILDING 56 PHYSICAL CHARACTERIZATION}

1) Current Mission Description

a) Facility Capabilities

Building 56 is a $613-\mathrm{ft}^{2}$ building that houses a pumping station.

Adjacent to this facility is a 350,000-gallon groundwater storage tank. This system provides an emergency supply of fire protection water at an adequate pressure to supplement the regular plant fire water system. A diesel generator provides emergency power if the plant power fails.

b) Resources Required to Support Operations

Primary Physical Resources:

Electricity

Potable water

Physical security

Telecommunication devices

Fire protection and sprinklers

Heating

Services:

Maintenance

This facility does not house any personnel but is serviced by personnel from Building 98 .

c) Current Safety Envelope

Building 56 operations are classified as standard industrial hazard.

d) Current Status

1. No formal CAS revierv has been done. A quick condition assessment was done in July 1992.

2. No formal CAMP review has been done based on the latest Reconfiguration decision. A CAMP report was submitted on April 1, 1992, which focused on ES\&H needs, infrastructure maintenance, and consolidation projects. 
2) Future Facility Use

\section{a) Alternative Future Use Scenarios}

1. WFO in the same discipline will occur under recent May 27, 1993, reconfiguration guidance. This facility is needed to provide emergency fire protection water.

2. WFO in a new discipline is unlikely because no different discipline will be allowed.

3. Commercialization under a lease agreement is likely.

4. Commercialization under a sale agreement is very unlikely.

5. Deactivation effort should not be great for Building 56 because it is not contaminated with radioactive or energetic materials. However, the building has thermal insulation containing asbestos.

b) Facility Modifications Required for Likely Use

Probably none, except to remove asbestos and replace with thermal insulation containing no asbestos.

c) Facility Modifications Required for Other Uses

Unknown.

d) Changes to Safety Envelope

The facility uses expected now would be covered under standard industrial hazard category.

e) Cleanup Criteria for Each Future Use Scenario

Building 56 is not contaminated with any radioactive or energetic material. It will require removal of asbestos-containing thermal insulation and replacement with acceptable insulation.

f) Disposition of Surplus Equipment

Equipment in Building 56 probably will not be surplused. 


\section{BUILDING 57 PHYSICAL CHARACTERIZATION}

1) Current Mission Description

a) Facility Capabilities

Building 57 is a $510-\mathrm{ft}^{2}$ building used for analysis of sewage before its disposal. It is currently in active use for this purpose. The laboratory in Building 57 contains equipment such as ovens, a scale, and dissolved oxygen monitors needed to perform testing required by Mound's Ohio EPA permits.

b) Resources Required to Support Operations

Primary Physical Resources:

Electricity

Potable water

Sanitary drainage

Physical security

Telecommunication devices

Fire protection, sprinklers, fire department HVAC

Services:

Human Resources

Finance and Accounting

Environmental, Safety, and Health

Maintenance

Custodial

Payroll

Meal

Supply

Special Resources:

Chemicals

c) Current Safety Envelope

Building 57 operations are classified as standard industrial hazard.

d) Current Status

1. No formal CAS review has been done. A quick condition assessment was done in July 1992.

2. No formal CAMP review has been done based on the latest Reconfiguration decision. A CAMP report was submitted on April 1, 1992, which focused on ES\&H needs, infrastructure maintenance, and consolidation projects. 
a) Alternate Future Use Scenarios

1. WFO in the same discipline likely under recent May 27, 1993, reconfiguration guidance. As long as any work is performed at Mound, there will probably be a need for the services provided by Building 57.

2. WFO in a new discipline is unknown under recent May 27, 1993, reconfiguration guidance. Probably none.

3. Commercialization possibilities under a lease agreement: Unlikely.

4. Commercialization under a sale agreement is unlikely.

5. Deactivation effort should be minimal; the building is not contaminated with radiological or energetic materials. It does contain asbestos, which may require abatement.

b) Facility Modifications Required for Likely Use

No major building modification would be required for this use.

c) Facility Modifications Required for Other Uses

Unknown.

d) Changes to Safety Envelope

The facility use suggested above should be covered under standard industrial hazard category. Any new work conducted in Building 57 may require that a safety assessment be performed to identify any new hazards involved in the process.

e) Cleanup Criteria for Each Future Use Scenario

Building 57 is not contaminated with any radioactive or energetic materials. Commercial use of the building may require asbestos abatement, depending on contractual requirements.

f) Disposition of Surplus Equipment

None. 


\section{BUILDING 90 PHYSICAL CHARACTERIZATION}

\section{1) Current Mission Description}

a) Facility Capabilities

Building 90 houses the thermal treatment equipment that is used to burn and dispose of energetic materials. The Ammunition Peculiar Equipment (APE) uses propane gas to burn the energetic materials. This APE is unique to the DOE complex. Building 90 is a $656-\mathrm{ft}^{2}$, steel frame building. It was built in 1983.

b) Resources Required to Support Operations

Primary Physical Resources:

Electricity

Physical security

Propane

Services:

Human Resources

Finance and Accounting

Environmenial, Safety, and Health

Maintenance

Custodial

Payroll

Meal

Supply

c) Current Safety Envelope

Building 90 operations are classified as a medium industrial hazard.

d) Current Status

1. No formal CAS review has been done. A quick condition assessment was done in July 1992.

2. No formal CAMP review has been done based on the latest Reconfiguration decision. A CAMP report was submitted on April 1, 1992, which focused on ES\&H needs, infrastructure maintenance, and consolidation projects. 
a) Alternate Future Use Scenarios

1. WFO in the same discipline is probable under recent May 27, 1993, reconfiguration guidance. Local, state, or federal departments could use this facility to dispose of their ordnance and other energetic material.

2. WFO in a new discipline is unknown under recent May 27, 1993, reconfiguration guidance. Probably none.

3. Commercialization possibilities under a lease agreement: Probably none, because of the training that is needed to operate this facility.

4. Commercialization possibilities under a sale agreement: While unlikely in the short term, there is a long-term possibility.

5. Deactivation efforts would require the cleanup of the energetic materials in the building. The building is not contaminated with radiological materials.

b) Facility Modifications Required for Likely Use

None. This building is currently used to burn energetic materials.

Future use of the building would likely be the same.

c) Facility Modifications Required for Other Uses

Not applicable.

d) Changes to Safety Envelope

Not applicable.

e) Cleanup Criteria for Each Future Use Scenario

Not applicable.

f) Disposition of Surplus Equipment

The APE could be surplused if there was no longer a need for Building 90. 


\section{BUILDING 95 PHYSICAL CHARACTERIZATION}

1) Current Mission Description

a) Facility Capabilities

Building 95 is a $2000-\mathrm{ft}^{2}$ building that is used as a chilled water plant for the SM/PP Hill and Test Fire areas of Mound. It is currently in active use for this purpose. Building 95 contains two large glycol chiller systems.

b) Resources Required to Support Operations

Primary Physical Resources:

Electricity

Potable water

Sanitary drainage

Physical security

Telecommunication devices

Fire protection, sprinklers, fire department

HVAC

Services:

Human Resources

Finance and Accounting

Environmental, Safety, and Health

Maintenance

Custodial

Payroll

Meal

Supply

Special Resources:

Water treatment chemicals

c) Current Safety Envelope

Building 95 operations are classified as standard industrial hazard.

d) Current Status

1. No formal CAS review has been done. A quick condition assessment was done in July 1992.

2. No formal CAMP review has been done based on the latest Reconfiguration decision. A CAMP report was submitted on April 1, 1992, which focused on ES\&H needs, infrastructure maintenance, and consolidation projects. 
2) Future Facility Use

a) Alternate Future Use Scenarios

1. WFO in the same discipline is possible under recent May 27, 1993, reconfiguration guidance. There are many operations that may rely on a source of chilled water.

2. WFO in a new discipline is unknown under recent May 27, 1993, reconfiguration guidance. Probably none.

3. Commercialization possibilities under a lease agreement: Unlikely.

4. Commercialization under a sale agreement is unlikely.

5. Deactivation effort should be minimal for the building, as it is not contaminated with either radiological or energetic materials.

b) Facility Modifications Required for Likely Use

Probably no major building modification would be required for this use.

c) Facility Modifications Required for Other Uses

Unknown.

d) Changes to Safety Envelope

The facility use suggested above should be covered under standard industrial hazard category.

Any new work conducted in Building 95 may require that a safety assessment be performed to identify any new hazards involved in the process.

e) Cleanup Criteria for Each Future Use Scenario

Building 95 is not contaminated with any radioactive or energetic materials.

f) Disposition of Surplus Equipment

None. 


\section{BUILDING 112 PHYSICAL CHARACTERIZATION}

1) Current Mission Description

a) Facility Capabilities

Building 112 is a $785-\mathrm{ft}^{2}$ Butler building housing tertiary sand filters for sanitary waste treatment.

b) Resources Required to Support Operations

Primary Physical Resources:

Electricity

Potable water

Sanitary drainage

Physical security

Fire protection and sprinklers

Heating

Services:

Maintenance

This facility does not house any personnel.

c) Current Safety Envelope

This facility is considered to be covered under the standard industrial hazard classification. However, the equipment is probably slightly contaminated with radioactive material.

d) Current Status

1. No formal CAS review has been done. A quick condition assessment was done in July 1992.

2. No formal CAMP review has been done based on the latest Reconfiguration decision. A CAMP report was submitted on April 1, 1992, which focused on ES\&H needs, infrastructure maintenance, and consolidation projects. 
2) Future Facility Use

a) Alternative Future Use Scenarios

1. WFO in the same discipline will occur under recent May 27, 1993, reconfiguration guidance. This facility is needed for continued waste treatment of sanitary waste.

2. Probably no different discipline will be allowed for WFO.

3. Commercialization under a lease agreement may be possible, but radioactive contamination of the sand filters may cause legal problems.

4. Commercialization under a sale agreement is very unlikely.

5. Deactivation of the facility might require removal of radioactive contamination.

b) Facility Modifications Required for Likely Use

Probably none.

c) Facility Modifications Required for Other Uses

Unknown.

d) Changes to Safety Envelope

Probably no changes will be required.

e) Cleanup Criteria for Each Future Use Scenario

Unknown.

f) Disposition of Surplus Equipment

Equipment in Building 112 is contaminated and is not likely to be surplused. 


\section{BUILDING 113 PHYSICAL CHARACTERIZATION}

1) Current Mission Description

a) Facility Capabilities

Building 113 is a $547-\mathrm{ft}^{2}$ Butler building housing a sludge dewatering press for sanitary waste disposal.

b) Resources Required to Support Operations

Primary Physical Resources:

Electricity

Potable water

Physical security

Sanitary drainage

Fire protection and sprinklers

Heating

Services:

Maintenance

This facility does not house any personnel.

c) Current Safety Envelope

Building 113 operations are classified as standard industrial hazard.

d) Current Status

1. No formal CAS review has been done. A quick condition assessment was done in July 1992.

2. No formal CAMP review has been done based on the latest Reconfiguration decision. A CAMP report was submitted on April 1, 1992, which focused on ES\&H needs, infrastructure maintenance, and consolidation projects.

2) Future Facility Use

a) Alternative Future Use Scenarios

1. WFO in the same discipline will occur under recent May 27, 1993 , reconfiguration guidance. This facility is needed for continued waste treatment of sanitary waste. 
2. Probably no different discipline will be allowed for WFO.

3. Commercialization under a lease agreement may be possible, but radioactive contamination of the sludge dewatering press may cause legal problems.

4. Commercialization under a sale agreement is very unlikely.

5. Deactivation effort of the facility might require removal of radioactive contamination.

b) Facility Modifications Required for Likely Use

Probably none.

c) Facility Modifications Required for Other Uses

Unknown.

d) Changes to Safety Envelope

Probably no changes will be required.

e) Cleanup Criteria for Each Future Use Scenario

Unknown.

f) Disposition of Surplus Equipment

Equipment in Building 113 is contaminated and not likely to be surplused. 


\section{SECTION 7: SOUTH PROPERTY}

\section{1) Current Mission Description}

\section{a) Facility Capabilities}

The South Property consists of 124 acres of undeveloped land acquired by Mound in 1981. It includes areas of rolling woodlands, grasslands, scrub, and shrubs. Several areas on the South Property may qualify as federally-protected wetlands, but this has not been fully determined to date.

The southeast corner of this property has access from Benner Road, leading to a gravel parking lot, approximately $200 \mathrm{ft} \times 500 \mathrm{ft}$, that is used for parking by outside contractors. A gravel road, approximately $2100 \mathrm{ft}$ long, runs along the eastern edge of the property, connecting the parking lot with the main Mound site. There are no. paved roads on the South Property.

Three production wells on the western edge of the South Property supply potable water to the entire Mound site. As of January, 1993, there were eight CERCLA monitoring wells on the property, with 15 more proposed. In addition, there were seven other monitoring wells and piezometers. There is one abandoned well on the property that was there when Mound purchased the site.

There are no structures on the South Property. Several existing structures were demolished after Mound purchased the property. With the exception of water lines running from the production wells to the main Mound site, there are no pipelines or underground storage tanks on the South Property. There is one $12.47 \mathrm{kV}$ electric power line running overhead through the middle of the property, from Benner Road in the south to Building 21. A separate outside power feed from Dayton Power and Light runs directly to the production wells to provide pump power.

The northwest corner of the South Property, an area $300 \mathrm{ft} \times 300 \mathrm{ft}$ and $10 \mathrm{ft}$ deep, has been used as a "Spoils Area" in support of Mound construction activities. Excavated soil and construction materials have been deposited there. 
b) Resources Required to Support Operations

Primary Physical Resources:

Minimal.

Services:

Custodial

c) Current Safety Envelope

South Property operations are classified as standard industrial hazard.

d) Current Status

1. No formal CAS review or condition assessment has been done.

2. No formal CAMP review has been done based on the latest Reconfiguration decision.

\section{2) Future Facility Use}

a) Alternate Future Use Scenarios

1. WFO in the same discipline is unknown under recent May 27, 1993 reconfiguration guidance. Probably none.

2. WFO in a new discipline is possible under recent May 27, 1993 reconfiguration guidance. The Mound Environmental Restoration Group was planning to use the contractor parking lot as a staging area for clean soil to be used as backfill in support of CERCLA cleanup activities. CERCLA sampling requirements will continue regardless of the future uses of the property.

3. Commercialization possibilities under a lease agreement: Many.

4. Commercialization under a sale agreement is unlikely in the short term, although there is a long-term possibility. 
5. The South Property is known to be contaminated with radioactive thorium and plutonium isotopes. There may also be hazardous chemicals present. Deactivation of the site may require characterization and cleanup of this contamination.

b) Facility Modifications Required for Likely Use

Unknown

c) Facility Modifications Required for Other Uses

Unknown.

d) Changes to Safety Envelope

Any new work conducted on the South Property may require that a safety assessment be performed to identify any new hazards involved in the process.

e) Cleanup Criteria for Each Future Use Scenario

The South Property is known to be contaminated by a plume of radioactive thorium-232 (up to $54.3 \mathrm{pCi} / \mathrm{g}$ ) and plutonium-238 (up to $34,000 \mathrm{pCi} / \mathrm{g}$ ), starting in the vicinity of Building 21 , and continuing approximately $300 \mathrm{ft}$ to the south. In addition, low levels of radioactivity can be found in the Spoils Area (plutonium-238 less than $25 \mathrm{pCi} / \mathrm{g}$ and thorium-232 less than $5 \mathrm{pCi} / \mathrm{g}$ ), along with gasoline contamination. This contamination may require cleanup prior to unrestricted use of the site, depending on contract requirements.

f) Disposition of Surplus Equipment

None. 


\section{Distribution}

EXTERNAL

OSTI, UC-700 (58)

R. Church, City of Miamisburg (2)

L. D. Kirkman, DOE/DAO (10)

INTERNAL

B. M. Alexander

S. G. Abrahamson

K. J. Bole

V. L. Clark

C. L. Fellers

C. S. Friedman

J. M. Fullencamp

D. A. Galvin

R. C. Herman

T. W. Hughes

D. R. Lammlein

D. F. Luthy

P. J. Marx (2)

D. L. Michaels

C. K. Ohler

W. D. Pardieck (4)

V. M. Pizzuto

W. R. Tonne

J. H. Walton

M. G. Wilson

J. J. Zahora

Publications

Library

(2) 
